\title{
USE OF PRODUCT-COUNTRY IMAGE CUES IN MAGAZINE ADVERTISING: A CONTENT ANALYSIS
}

MBA Thesis

Submitted by: Marek E. Dziedzic

In Partial Fulfillment of the

Degree of

Master of Business Administration

Supervised by: Dr. Nicolas Papadopoulos

Copyright $\odot$ 2007, Marek E. Dziedzic 


$\begin{array}{ll}\begin{array}{l}\text { Library and } \\ \text { Archives Canada }\end{array} & \begin{array}{l}\text { Bibliothèque et } \\ \text { Archives Canada }\end{array} \\ \begin{array}{l}\text { Published Heritage } \\ \text { Branch }\end{array} & \begin{array}{l}\text { Direction du } \\ \text { Patrimoine de l'édition }\end{array} \\ \begin{array}{l}\text { 395 Wellington Street } \\ \text { Ottawa ON K1A ON4 }\end{array} & \begin{array}{l}\text { 395, rue Wellington } \\ \text { Ottawa ON K1A ON4 } \\ \text { Canada }\end{array}\end{array}$

Your file Votre référence ISBN: 978-0-494-23354-2 Our file Notre référence ISBN: 978-0-494-23354-2

NOTICE:

The author has granted a nonexclusive license allowing Library and Archives Canada to reproduce, publish, archive, preserve, conserve, communicate to the public by telecommunication or on the Internet, loan, distribute and sell theses worldwide, for commercial or noncommercial purposes, in microform, paper, electronic and/or any other formats.

The author retains copyright ownership and moral rights in this thesis. Neither the thesis nor substantial extracts from it may be printed or otherwise reproduced without the author's permission.
AVIS:

L'auteur a accordé une licence non exclusive permettant à la Bibliothèque et Archives Canada de reproduire, publier, archiver, sauvegarder, conserver, transmettre au public par télécommunication ou par l'Internet, prêter, distribuer et vendre des thèses partout dans le monde, à des fins commerciales ou autres, sur support microforme, papier, électronique et/ou autres formats.

L'auteur conserve la propriété du droit d'auteur et des droits moraux qui protège cette thèse. $\mathrm{Ni}$ la thèse ni des extraits substantiels de celle-ci ne doivent être imprimés ou autrement reproduits sans son autorisation.
In compliance with the Canadian

Privacy Act some supporting forms may have been removed from this thesis.

While these forms may be included in the document page count, their removal does not represent any loss of content from the thesis.
Conformément à la loi canadienne sur la protection de la vie privée, quelques formulaires secondaires ont été enlevés de cette thèse.

Bien que ces formulaires aient inclus dans la pagination, il n'y aura aucun contenu manquant.

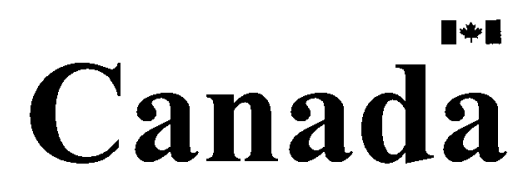




\section{ABSTRACT}

While an extensive body of past research among consumers indicates that product country image (PCI) influences their behaviour, there have been virtually no studies of whether and how practitioners use $\mathrm{PCl}$ cues in marketing strategy. This thesis is part of a larger research project on $\mathrm{PCl}$ from the marketing management perspective and focuses specifically on the use of $\mathrm{PCl}$ in advertising. Drawing on a large-scale content analysis of advertisements in Canadian and American business, news, fashion, and lifestyle magazines, the frequency, intensity, and strength of $\mathrm{PCl}$ usage was measured and found to be significant. Limitations in existing classification schemes for products, appeals, and execution styles that are necessary for this type of analysis were identified and new classifications were developed and presented. The thesis concludes by outlining the benefits and limitations of the study and suggests directions for future research. 


\section{ACKNOWLEDGEMENT}

I would like to thank my supervising professor, Dr. Nicolas Papadopoulos, for all the guidance, support, and help that he has offered throughout this research project. Additionally, I would like to extend my gratitude to my colleagues and fellow students of Dr. Papadopoulos, Mr. Irfan Butt and Mr. Shavin Malhotra, and Mrs. Irinela Papadopoulos, for their help in this research. This acknowledgement would not be complete without thanking my friends who have had to put up with my stress over the past several months - I am glad that you are still my friends after all of this. Finally, and most importantly, I would like to thank my mother and father, without who's support - emotionally, psychologically, and most prominently financially - this would never have happened. Thank you. 


\section{TABLE OF CONTENTS}

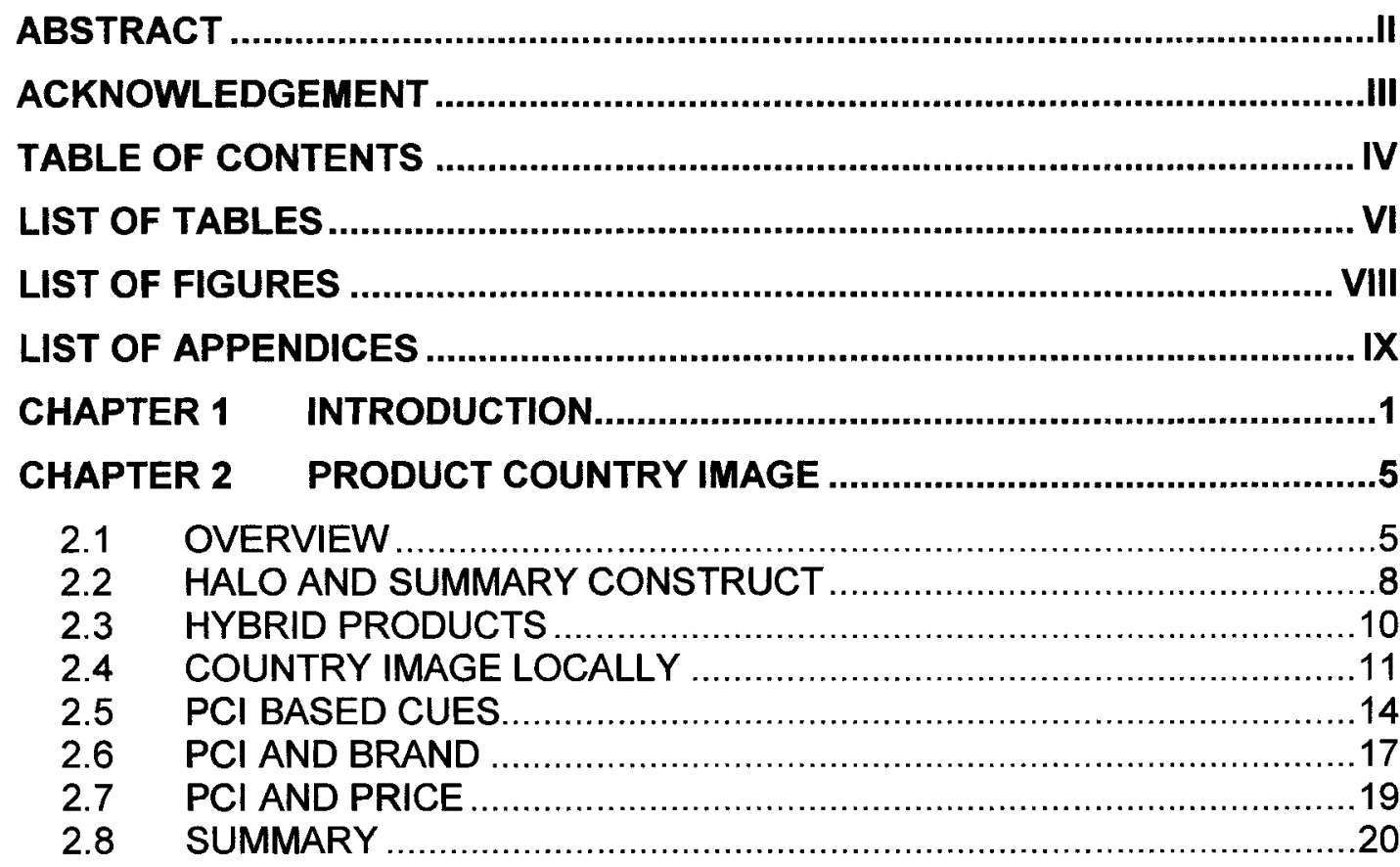

CHAPTER 3 ADVERTISING ...............................................................22

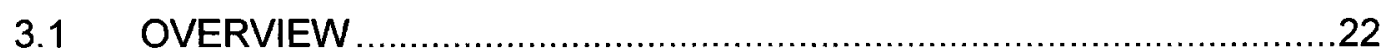

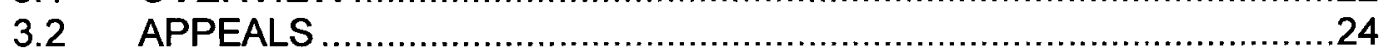

EXECUTION STYLES

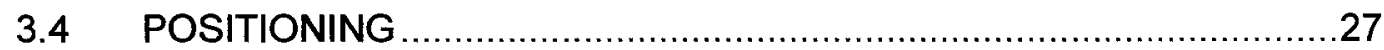

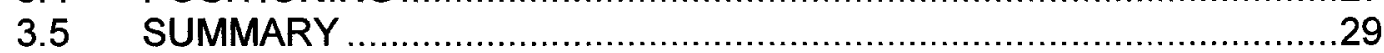

CHAPTER 4 INTERNATIONAL ADVERTISING..........................................31

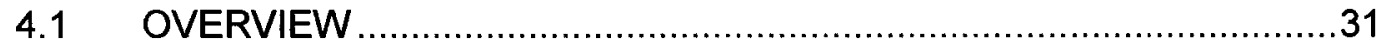

4.2 STANDARDIZATION VS. GLOBALIZATION ............................... 33

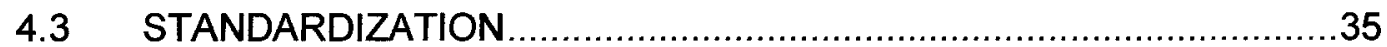

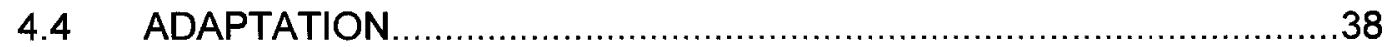

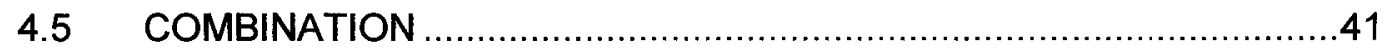

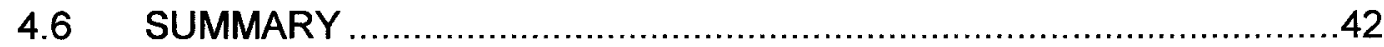

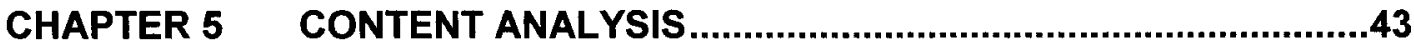

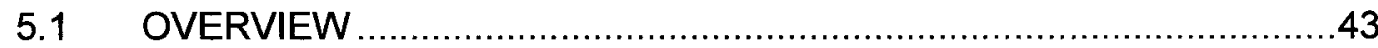

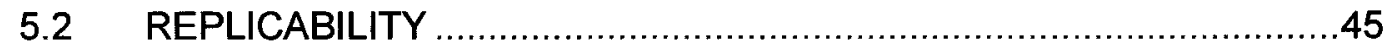

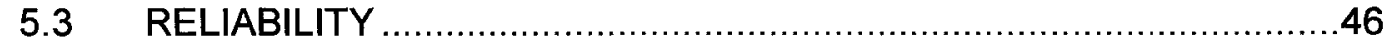

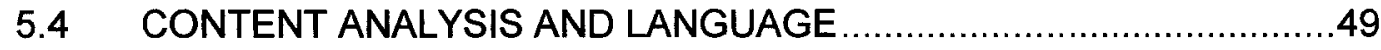

5.5 CONTENT ANALYSIS AND INTERNATIONAL ADVERTISING ...........51

5.6 CONTENT ANALYSIS CONCERNS WITH PCI IN PRINT MEDIA .........53

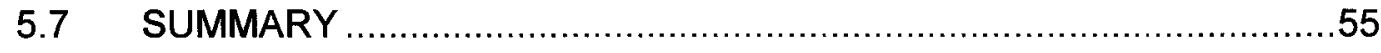

CHAPTER 6 RESEARCH QUESTIONS ..................................................57

CHAPTER 7 METHODOLOGY..............................................................60 


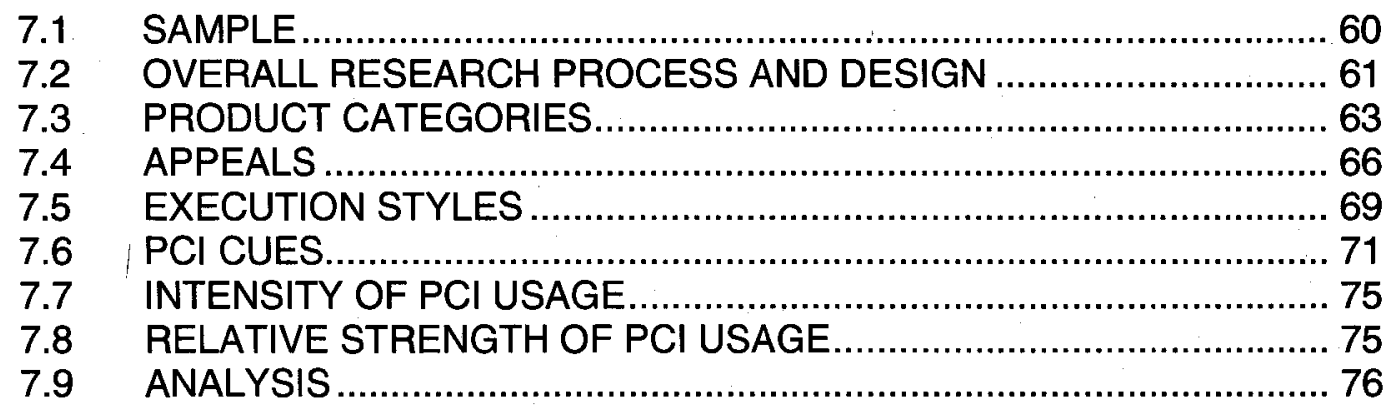

CHAPTER 8 DATA ANALYSIS AND RESULTS ........................................ 78

8.1 DEMOGRAPHIC INFORMATION ON THE SAMPLE ....................... 78

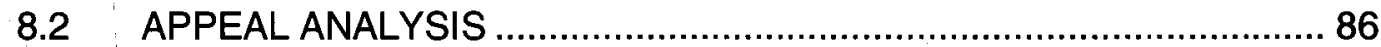

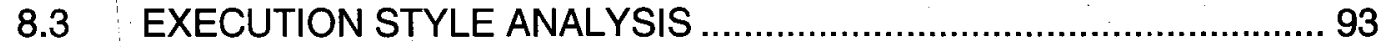

8.4 EXECUTION STYLE VS. APPEAL ANALYSIS ...............................101

$8.5 \quad$ PCI CUE ANALYSIS ...............................................................103

$8.6 \quad$ PCI INTENSITY ANALYSIS .................................................119

$8.7 \quad$ PCI STRENGTH ANALYSIS ...............................................128

CHAPTER 9 DISCUSSION AND CONCLUSION .......................................138

CHAPTER 10 BENEFITS, LIMITATIONS \& FURTHER RESEARCH..............141

REFERENCES ...................................................................................145

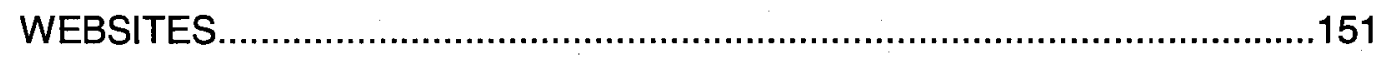

APPENDICES..........................................................................................153 


\section{LIST OF TABLES}

Table 1: Kleppner-Rochschild Execution Styles ............................................... 26

Table 2: Frequency of Different Methodologies Used ....................................... 52

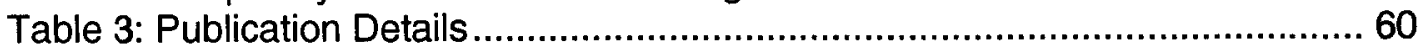

Table 4: Northwestern University Product Classification ................................... 64

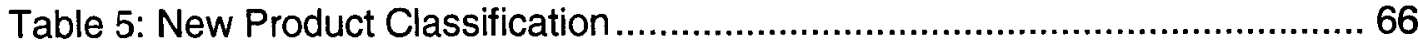

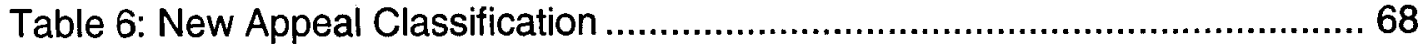

Table 7: New Execution Style Classification ..................................................... 70

Table 8: Brand and Non-Brand PCl Cues ..................................................... 73

Table 9: Fine Print PCl Cues..................................................................... 74

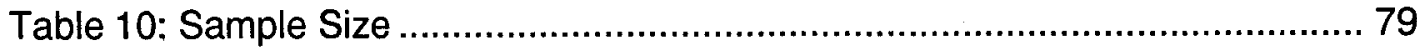

Table 11: Average Advertisements per Magazine ........................................... 79

Table 12: Percentage of Single vs. Multiple Page Advertisements ....................... 80

Table 13: Frequency of Advertiser's Home Countries ..................................... 82

Table 14: Distribution of Business and Consumer Advertisements....................... 83

Table 15: Distribution of Advertising Organization Type .................................... 84

Table 16: Frequency Distribution of Products Advertised .................................. 85

Table 17: Frequency Distribution of Appeals .................................................. 87

Table 18: Use of Emotional/Rational Appeals ............................................... 88

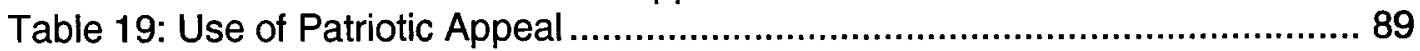

Table 20: Use of Patriotic Appeal by Product Classification ................................. 89

Table 21: Use of Patriotic Appeal by Advertiser's Home Country ......................... 90

Table 22: Top Organizations to use Patriotic Appeal......................................... 91

Table 23: Use of Appeals across Magazine Types........................................... 92

Table 24: Use of Appeals within Magazine Types ............................................ 92

Table 25: Frequency Distribution of Execution Style ..................................... 94

Table 26: Use of PCl Execution Style............................................................. 95

Table 27: Use of PCI Execution Style by Product Classification .......................... 97

Table 28: Use of PCI Execution Style by Advertiser's Home Country................... 98

Table 29: Top Organizations to use PCl Execution Style .................................... 99

Table 30: Use of PCI Execution Style across Magazine Types .........................100

Table 31: Use of PCI Execution Style within Magazine Types...........................101

Table 32: $\mathrm{PCl}$ Execution and Patriotic Appeal across Product Classes ...............103

Table 33: Frequency Distribution of Advertisements with PCI Cues ....................104

Table 34: Frequency Distribution of PCl Cues.................................................105

Table 35: Frequency Distribution of Fine Print PCI Cues...................................105

Table 36: Frequency Distribution of Prominent PCI Cues..................................107

Table 37: Use of Prominent PCI Cues by Product Class ..................................109

Table 38: Use of Prominent PCl Cues by Appeal .............................................111

Table 39: Use of Prominent PCI Cues by Execution Style.................................113

Table 40: Use of Prominent $\mathrm{PCl}$ Cues across Magazine Type .........................115

Table 41: Use of Prominent PCl Cues by Advertisement Type.........................115

Table 42: Use of Prominent PCl Cues by Organization Type ...........................117

Table 43: Country Association of Prominent Non-Brand PCl Cues ....................118

Table 44: Frequency Distribution of PCI Intensity.........................................120

Table 45: Average PCI Strength by Product Class ..........................................131

Table 46: Average PCl Strength by Execution Style......................................132

Table 47: Average PCl Strength by Appeal ................................................133 
Table 48: Average PCI Strength by Advertiser's Home Country........................134

Table 49: Average PCI Strength by Magazine Type ..........................................135

Table 50: Average PCI Strength by Advertisement Type...................................136

Table 51: Average PCl Strength by Product Type ............................................136 


\section{LIST OF FIGURES}

Figure 1: Normalized PCI Intensity by Product Class ......................................122

Figure 2: Normalized PCI Intensity by Appeal ...............................................123

Figure 3: Normalized PCI Intensity by Execution Style.....................................125

Figure 4: Normalized PCI Intensity by Advertiser's Home Country ......................126

Figure 5: Normalized PCI Intensity by Magazine Type .....................................127

Figure 6: Frequency Distribution of PCI Strength .......................................129 


\section{LIST OF APPENDICES}

Appendix A: Pollay's 42 Advertising Appeals ...............................................153

Appendix B: Development of Final Product Classification Used .........................156

Appendix C: Developed Nations................................................................159

Appendix D: Frequency of Appeals by Product Class ....................................160

Appendix E: Appeals by Magazine Tables ...................................................161

Appendix F: Frequency of Execution Style by Product Class ............................165

Appendix G: Execution Style by Magazine Tables ..........................................166

Appendix H: Execution Style versus Appeal..............................................170

Appendix I: Normalized PCI Intensity by Product Class...................................171

Appendix J: Normalized PCI Intensity by Execution Style ..................................172

Appendix K: Normalized PCl Intensity by Appeal ...........................................173

Appendix L: Normalized PCI Intensity by Advertiser's Home Country ..................174

Appendix M: Normalized PCl Intensity by Magazine Type ................................175

Appendix N: L'Oréal Paris Advertisement ........................................................176

Appendix O: Maybelline New York Advertisement.........................................178 


\section{CHAPTER 1 INTRODUCTION}

The primary focus of this research was to determine how and to what degree product country image $(\mathrm{PCl})$ is used in advertising. Additionally, international advertising strategies focusing on $\mathrm{PCl}$ were also analysed with specific reference to differences between advertisers from various countries.

When bombarded by too much information, consumers tend to develop summary constructs, which they use as criteria for product comparison. Research has indicated that $\mathrm{PCl}$ can significantly affect consumers' behaviour and influence the decision making process. The literature indicates that consumers associate different countries with different degrees of quality, reliability and performance and this has significant implications for product acceptance. As such, $\mathrm{PCl}$ has been suggested as a potential summary information cue. However, research to date on the $\mathrm{PCl}$ phenomenon, while substantial, has focused exclusively on the consumer's perspective. Instead, this study focuses on the producer's perspective, which has not been researched so far.

Using summary criteria effectively within advertising is vital in maintaining competitive advantage in the world of marketing. In order for marketers to maximize the effectiveness of their advertising strategies, they must use effective execution approaches to appeal to consumers' wants and needs.

As the barriers for cross border trade continue to decrease, a global perspective on marketing and advertising is imperative for successful commerce. With the globalization of the marketplace, additional considerations are necessary when developing international advertising strategies. As local markets become saturated and competition increases, understanding how to effectively implement 
advertising strategies to successfully expand into foreign regions becomes increasingly important.

In light of the above, this study drew from knowledge in the areas of $\mathrm{PCl}$, advertising, and international advertising. In conducting this research, a content analysis of magazine advertisements was employed. It was therefore essential that concerns regarding objectivity, reliability and specific $\mathrm{PCl}$ considerations were understood as a prerequisite to the analysis.

This project was a continuation of a broader research program conducted by Dr. Nicolas Papadopoulos, which focuses on $\mathrm{PCl}$ and country branding. More specifically, the broader research aims to determine the use of $\mathrm{PCl}$ cues in advertising and the strategies used by marketers. The initial phase of this research was conducted by Sandeep Lidder (2005) as part of her MBA research project and detailed the problems and issues pertaining to the content analysis of advertising media with specific reference to $\mathrm{PCl}$ considerations. An exploration of international marketing strategies and $\mathrm{PCl}$ represented the second phase of this project and was conducted by Manuela Teodorescu (2005) as part of her MBA project research. The present project represented the third phase of the research, which undertook the analysis of data gathered during the previous two phases. The results of this work will allow future researchers to conclude the broader research project in order to help advance knowledge on the use of $\mathrm{PCl}$ cues in advertising.

This document is divided into 10 chapters, which introduce the project; explore the various areas of literature pertaining to this research; detail the research questions being posed; describe the methodology that was employed; detail the pre-analysis performed on the data; provide details of the analysis performed; summarize and discuss the findings; and highlight the benefits and 
limitations of the research project as well as suggest considerations for future research. A more detailed review of the chapters follows.

The literature review begins in chapter 2 with an overview of past $\mathrm{PCl}$ studies. While many theories exist on how $\mathrm{PCl}$ influences consumer buying behaviour and product comparison, this paper focused on the halo and summary construct theory. Hybrid products (products which are associated with multiple countries) are discussed as well as domestic country branding, brand name, and price considerations with respect to $\mathrm{PCl}$.

Chapter 3 provides general background on advertising methods. It discusses the difference between execution styles and appeals and presents categories from the literature for classifying advertisements.

Many areas have been studied under the umbrella of international advertising; however, standardization and adaptation are at the forefront of this area of research. Chapter 4 discuses the differences between global marketing strategies and standardized ones, as well as detailing standardization, adaptation, and combination approaches to advertising. Due to the international nature of this research, international advertising considerations were included in the analysis of the data.

The literature review concludes with chapter 5, which discusses various considerations that must be addressed when undertaking content analysis research. Objectivity and reliability are discussed as well as specific considerations with respect to language, international advertising, and $\mathrm{PCl}$ in print media.

Chapter 6 provides a framework for the primary research question being asked and then explains the various correlations which will be tested. 
The methodology for this research is discussed in chapter 7 . The chapter details the processes involved in the content analysis and associates the work with constructs presented in the literature review. It also provides details on the preanalysis of the results. Several issues were recognized with the methodology that had been proposed originally and the changes made are explained in this chapter.

The analysis of the data is provided in chapter 8 , which addresses the frequency, intensity, and strength of use of $\mathrm{PCl}$ cues within magazine advertisements. This chapter also offers data and analysis on potential correlations and observations.

General discussion and conclusions based upon the data and analysis are summarized in chapter 9.

Chapter 10 concludes this paper by offering the research benefits, limitations, and potential general directions for future research as part of the broader project. 


\section{CHAPTER 2 PRODUCT COUNTRY IMAGE}

$\mathrm{PCl}$ and its effect on consumers' behaviour during the purchasing process has been an area of intense study for the last 40 years. Since the mid 1960's over 1000 major works have been published on the subject, including more than 400 in a variety of prominent academic journals (Papadopoulos, 2004).

The expansion of global business, increased competition, and the growing complexity of marketing have caused an increase in the use of PCl-based marketing techniques. With a growing number of products available to consumers, marketers can utilise country cues to "add value to their products and differentiate them" from their competition (Baker and Ballington, 2002, p 160).

This chapter begins with a brief overview of the research conducted on $\mathrm{PCl}$. The constructs of $\mathrm{PCl}$ as a halo and summary effect are explained, followed by a discussion on hybrid products and local country-product image. The final sections detail the relationships between $\mathrm{PCl}$, branding, and price.

\subsection{OVERVIEW}

Consumers use two categories of information cues to evaluate products: intrinsic and extrinsic (Han and Terpstra, 1988). Intrinsic cues such as taste, design, and performance usually cannot be evaluated before the use of a product. Extrinsic information cues, such as price, brand name, and warranty, however, can be evaluated without any prior knowledge of the particular product. Furthermore, they can be evaluated before the completion of the purchasing process. Customers use these cues to infer product quality and purchase value during their purchasing decision. $\mathrm{PCl}$ is one of these extrinsic cues. 
$\mathrm{PCl}$ is the view consumers hold about the quality of products developed in a particular country. It has often been referred to as the 'made-in' tag on products. This "'made in' image is the picture, the reputation [and,] the stereotype that businessmen [sic] and consumers attach to products of a specific country" (Nagashima, 1970, p68). It influences the perceived levels of quality, reliability, and performance of various commodities through that country's image. Research conducted on PCl has spanned various subject groups and products, and has utilized various methodological approaches (Laroche et al., 2003). The majority of this research has demonstrated a strong positive relationship between product views and country views.

The literature on $\mathrm{PCl}$ has demonstrated that there is a considerable connection between the views of existing products and new products from a particular country. The association that consumers make to a country with respect to quality, reliability, and performance can have significant implication for product acceptance. Papadopoulos (2000) wrote that 'made in' Germany or Japan can greatly enhance brand equity, especially for products that do not also have highprofile names like Mercedes or Toyota" (p30). Research conducted by Sanjeev and Sammer (1996) found that when the similarities between a well recognized existing product and a new product were high, the transference of beliefs to the new product was also high. This allows for similar products from the same country to benefit from the positive view of existing products. This can be leveraged by marketers to form connections between accepted, proven commodities and new, unknown ones.

However, this relationship is highly attribute-specific. For instance, technology may be evaluated differently than fashion for a specific country, and 
subsequently each of these dimensions may be evaluated differently across different criteria such as quality, performance, design, or value (Han and Terpstra, 1988; Laroche et al., 2003). Throughout PCl research, many different dimensions have been used as evaluation criteria. However, innovativeness, design, prestige, and workmanship have been predominant (Mohomad et al., 2005). Innovativeness has been defined in the literature as "the inclusion of new technology and engineering advances in a product" (Mohomad, 2005, p70). The physical and visual characteristics with respect to overall appearance, variety, and style are encapsulated by the design dimension. Prestige refers to the exclusive nature of the product including brand name and status. Finally, workmanship refers to the products quality, reliability, durability, and craftsmanship.

Although consumers' views about a particular product and country may not be equal, these views are nevertheless connected. This implies that while consumers' views about a specific product may be lower than their views of the country as a whole, as their opinion of the country grows, so will their view of the product (Papadopoulos, 2000).

Research conducted by Laroche et al. (2003) indicated that members of subcultures are more likely to evaluate products from similar subcultures more favourably. Similar traditions, lifestyles, customs, and language may cause underlying connections, which translate into positive evaluation of goods. This supports the notion that in the absence of accurate knowledge of a country's image, consumers may rely on weak, "inappropriate, or irrelevant associations, often carried from childhood onwards," (Papadopoulos and Heslop, 2002, p21) to form views about a country. Country image is a combination of variables such as representative products, national characteristics, economic and political 
background, history, and tradition (Nagashima, 1970). This construct is generated through "mass communication, personal experience, and views of national opinion leaders" (Nagashima, 1970, p68). As consumers become more familiar with the products and countries, their potentially inaccurate images will be replaced with more accurate ones.

Extensive research has been conducted on $\mathrm{PCl}$ with respect to domestic and foreign consumer products; however, studies of service products are more limited. Phau and Prendergast (2000) indicated that the majority of research conducted on the effect of $\mathrm{PCl}$ on service products was limited to ethnocentricity. They indicated that cultural resistance, patriotism, conservatism, collectivism, and older age cause many consumers to choose domestic services over foreign ones.

The connection with country image and product is significant and influential. The more positive the country image, the higher the value associated with the country's products. However the opposite may be true as well, that as a country's products are viewed more positively, so will the country and the people (Papadopoulos, Heslop, and Beracs, 1990). This has been witnessed in Japan, for instance, which was seen as the producer of cheap imitation electronics in the 1970s but since then has developed into a world accepted designer and manufacturer of leading edge high-tech electronics and other products.

\subsection{HALO AND SUMMARY CONSTRUCT}

Several theories have been developed (Han, 1989) and evaluated which connect the cognitive process with PCl cues (Knight and Calantone, 2000). Of these theories, two are of significant relevance when consumers evaluate products: the halo and summary effects (Han, 1989). The halo effect suggests that 
consumers use country image in product evaluation when other criteria are unavailable or unknown. Conversely the summary construct proposes that in the existence of too much information, product imagery is used as a summarizing criterion to distinguish products.

Country image as a halo maintains that consumers use country cues when a product's true quality is unavailable prior to purchase, for instance choosing a restaurant in an unfamiliar city based on the nationality of the food (Italian, Chinese, or Greek). This is particularly apparent in image products such as perfume, clothing, etc. It has been argued that, if country image acts as a halo for product quality, then as consumers become more familiar with products from a particular country, the country image will have a decreasing significance (Johansson et al., 1985). The halo theory implies a two-step relationship: consumers infer product quality from country correlations and subsequently country image influences customer evaluation of products. This implies that country image leads to beliefs, which lead to brand attitude (Han, 1989).

The summary construct is based on the concept of information chunking, which implies that individual information or attributes are grouped together into higher order units and stored in memory. This concept stems from the notion that instead of memorizing the individual attributes of any particular products, these are all stored under an umbrella construct such as country or brand. This allows for consumers to infer certain characteristics based on brands with the same country of origin having very similar product attributes (Han, 1989). This can be viewed by the general acceptance of such notions as "German cars are all of high quality and performance" or "Japanese electronics are all of high workmanship". The summary theory implies that consumers create product constructs using country image as an 
index, and subsequently that country image, more so than product attributes, affects a customer's view of a brand from that country. Thus the summary construct entails product beliefs, which leads to country image, which leads to brand attitude (Han, 1989).

It has been suggested that these two theories act in combination. When sufficient or excessive information is available, consumers use country as a summary to make a decision. Conversely, when insufficient or no attributable information is available, the consumer uses the halo effect to impose current beliefs about a country or other products from the same country onto the product in question (Han, 1989; Teodorescu, 2005).

\subsection{HYBRID PRODUCTS}

An increasing number of products can no longer be associated with only one country. International manufacturing operations of many large multinational companies have continued to grow in order to reduce cost and increase ease of distribution. It has therefore been suggested that "as a result [of this international expansion], much of the 'image' of country of origin has become lost" (Roostal, $1963, \mathrm{p} 16)$. Due to the lower cost of labour in developing countries, more products are becoming hybrid products. In such cases, consumers can distinguish between country of design, country of manufacture, country of assembly, and the producer's home country (Papadopoulos and Heslop, 2002).

$\mathrm{PCl}$ effects vis-à-vis developing countries are particularly influential and significant for product evaluation. Research has indicated that developed countries are evaluated more positively as countries of design than developing countries. However, the opposite occurs for countries of assembly and manufacture where 
developing countries are evaluated higher. Furthermore, the same research has implied that the more complex a product (computers, technology, etc.) the more important the country of design becomes (Ahmed, d'Astous, and El Adraoui, 1994). In order to utilize the best image of the varying $\mathrm{PCl}$ effects, "global manufacturers should focus production on developed countries or adopt countervailing strategies" (Nebenzahl and Jaffe, 1996, p18), for instance emphasizing the 'German engineering' of a car manufactured in Mexico.

The work conducted by Phau and Prendergast (2000) indicates that in the $21^{\text {st }}$ century, consumers are aware that the 'made-in' country and country of brand are rarely the same. They offer the example of Nike, which is considered to be an American product but which has generally been acknowledged as being made all over the world. Many brands use this dual identity to associate superior product quality and brand image to render the physical manufacturing location extraneous.

The use of country of brand rather than country of origin or manufacture has been suggested as a better focal point for advertising. Consumers tend to associate themselves with a particular brand due to their self-concepts and as such the embedded brand characteristics are unlikely to change if the location of manufacture changes. Similarly, the association with country of brand for luxurious products can outweigh negative views towards less favorable manufacturing countries (Phau and Prendergast, 2002).

\subsection{COUNTRY IMAGE LOCALLY}

Considerable research has been conducted on the effect of $\mathrm{PCl}$ in foreign markets, but the implications that country cues have on local markets are just as important. The literature indicates that consumers tend to evaluate domestic 
products more positively (Mohamed et al., 2005). Many consumers favour domestic products even when they are more expensive because of nationalism, the belief of domestic superiority, or concerns with international servicing of products (Han and Terpstra, 1988).

The consumer's preference for domestic goods can be explained partly by the concept of consumer ethnocentrism as originally explained by Shimp and Sharma (1987). They define consumer ethnocentrism as the belief that purchasing imported products is simply wrong because "it hurts the domestic economy, causes loss of jobs, and is plainly unpatriotic" (Bawa, 2004).

Despite this sort of evidence, domestic marketers are resistant to push local goods for fear that they may harm exports (Baker and Ballington, 2002). Practitioners are cautious in promoting domestically produced commodities in local markets for fear that this will disrupt importing and exporting relations. "Psychologically, selling harder in a country's home market somehow comes to be seen as equivalent to imposing restrictions on imports", according to Baker and Ballington (2002, p166).

Some recent studies have indicated that consumer ethnocentrism may be diminishing (Vida and Fairhurst, 1999). Younger and more educated consumers are acting in a more rational and calculated manner when comparing products and focus on attributes such as price, quality, and performance. If this is the case, then consumers search for the highest degree of quality or lowest price point when differentiating products and country cues can be an influential attribute. Therefore, country attributes associated with quality, performance, and reliability can be used in the promotion of products both locally and internationally. Advertising superior products domestically based on quality and performance can actually increase 
import and export relations and promotes competition across borders. As long as practitioners advertise on attributes beyond leveraging domestic country of origin, then the concerns raised by Baker and Ballington (2002) appear to be unwarranted.

It is critical to distinguish the subtle but important difference between a $\mathrm{PCl}$ advertising campaign run domestically and a patriotic advertising campaign. While the first uses country cues from the country within which the advertisement is being run, the latter only attempts to promote the product from a 'buy domestically' perspective and focuses on consumer ethnocentrism. For example, 'German engineering' is often associated with a high degree of precision and quality. This view is (theoretically) independent of the geographic location of consumers. However, if Volkswagen advertises its vehicles in Germany as having 'German engineering' there is a distinction to be made whether they are advertising their cars as crafted with a high degree of precision and quality or whether the focus of the advertisement is a patriotic appeal.

This suggests that country associations of expertise in a particular industry or product can affect both local and international consumers, albeit in different ways. While consumer ethnocentrism promotes the purchase of domestic products, the literature has indicated that this factor is less apparent in the growing, younger, and more educated population (Al-Sulaiti and Baker, 1998; Vida and Fairhurst, 1999). As such, it is possible that only when price and quality are considered equal, might national pride of its own merit exert significant influence on consumers to purchase locally over imported competition. 


\subsection{PCI BASED CUES}

A multitude of cues can be used to associate a product or service with a particular geographical location. The research conducted by Lidder (2005) was used as the foundation for these categories. Small alterations and additions were incorporated in the present study in an attempt to cover all possible $\mathrm{PCl}$ cues.

\section{Brand Names with Location}

Several brand names include a geographical location within the name of the brand itself, which causes a geographical association as a default. This includes brands such as L'Oréal Paris, Holland America tours, etc.

\section{Foreign Language Content}

Advertisements that contain foreign language text of any kind fall into this classification. For instance the use of Asian characters within print advertisements has increased, providing an ethnic, oriental association. Similarly, many advertisements in Asia contain English words even though a very small portion of the population can read English (Mueller, 1992). Advertisements that include photographs of landscape, which contain text within the photograph itself, are excluded from this category.

\section{Cultural Indication}

Any personalities, attire, etc. that can be associated with a particular geographic or cultural region are covered in this category. This includes celebrities, traditional attire, food, and events. 


\section{Slogans}

Slogans within advertisements that contain country cues are encompassed by this category and include such things as 'made with German engineering' or 'the pride of the Southwest'.

\section{International Scenery}

This category encompasses all forms of imagery within an advertisement that is closely associated with a particular geographic region. This includes background of identifiable cities such as Paris, New York, or Hong Kong amongst others. Monuments, landscape, and other recognisable structures, which are also associable with a particular region, fall into this category.

\section{International Symbols}

Flags and various other symbols are commonly associated with various geographic areas or to represent specific regions. For instance the maple leaf, beaver, and igloo are often associated with Canada, while the fleur-de-lys is often associated with Quebec. This category is used for such indicators.

\section{Product Photos That Include 'Made-in'}

Many advertisements contain photographs of the product being promoted. Occasionally this may also display the product's 'made-in' mark. This category simply addresses these direct country associations in the form of visible cues on the product and not separate content in the advertisement. This includes 'made-in', flag, brand, or other geographic depictions that are a physical part of the product being advertised, for instance the 'made-in' mark on the face of a watch, the British flag on the roof of a Mini Cooper, or the L'Oréal brand name on product packaging. 


\section{Copyright Information}

Certain advertisements may include fine print legal information that includes a country cue. This category encompasses all such documentation. There is a question whether this form of information is included as a country cue or due to imposed legislation. This will be discussed further in section 5.6, which details concerns regarding content analysis with specific reference to $\mathrm{PCl}$ and print media. Regardless of the purpose, it can still be used as a country association by consumers and therefore is a $\mathrm{PCl}$ cue that is included in this study.

URLS

Although URLs are free to be constructed in any form and some are not limited to having a particular suffix dependent on the country (such as Canadian websites ending in '.ca'), these suffixes can still be an indication of country association. Furthermore, certain web address may contain country cues within the name itself, for instance BakingAssocCanada.com. As such, they are included among $\mathrm{PCl}$ cues.

\section{Contact Information}

This represents contact information of the company headquarters or other operating locations in the form of a traditional mailing address, international phone number, or email addresses containing a country specific suffix (as described in the URLs section). This category also encompasses statements, which indicate where particular items are available. For instance many fashion advertisements include a 'New York, Milan, Tokyo' statement indicating where the product is sold through major retailers. 


\section{Popular Brand Names}

Many international brands have an existing country association and as such no longer need additional cues. Toyota, for instance, has become highly associated with Japan (Seixas, 2003; Papadopoulos, 2006) and therefore does not require additional, separate $\mathrm{PCl}$ cues to connect it to its country of origin.

\section{$2.6 \mathrm{PCl}$ AND BRAND}

Brand has been used as a major differentiating factor during product evaluation by consumers since product features and qualities can be easily copied. Kotler and Gertner (2002) suggest that "even when differentiation based on product characteristics is possible; often consumers do not feel motivated or able to analyze them in adequate depth" (p249). As such, the literature pertaining to advertising suggests that brand is among the most influential cues that consumers use to determine quality when direct information is unavailable. However, a study by Han and Terpstra (1988) comparing the views held by consumers towards binational products indicates that country association is a very influential cue, potentially more important than brand. Their study, which compared various binational product models (local-brand/local-made, local-brand/foreign-made, foreign-brand/local-made, and foreign-brand/foreign-made), found that "sourcing country stimuli [...] have more powerful effects than brand name on consumer evaluations" (p251). This can be demonstrated by such brands as Toyota, which is recognized as being Japanese but several of their models are built in the United States, and General Electric which is an American brand but many of their products are manufactured in Japan. 
Han (1990) suggested that the use of brand or country imagery as the most influential umbrella attribute to describe the quality of products is dependent on consumer familiarity with a specific country's products. When consumers are not familiar with the products of a particular country, they may remove that particular brand from a small set of alternatives during the purchasing decision. For instance, when deciding to purchase a car, a consumer may exclude South Korean brands if he or she is unfamiliar with the country's products, and limit the brand selection to Japanese, European and American automobile manufacturers.

When specific information about product attributes is unavailable, consumers may depend on country image stereotypes to fulfill these attributes. However, as consumers become more familiar with a country's products, they will be able to formulate a more detailed and accurate account of the attributes of the country's products since they are more likely to accept the overall country image as a summary framework when evaluating individual brands (Han, 1989). As consumers' images of a specific country become more detailed and favourable, they are less likely to exclude a particular brand when generating subsets of brands for purchasing decisions (Han, 1990).

However, Erickson, Johansson, and Chao (1984) argue to the contrary that "there is little significant impact on consumer attitudes towards brands [by country image]" (p694) and subsequently that the country of origin affects only beliefs but not attitude towards products. They propose that as consumers become more familiar with specific brands, they rely less on country image as an aid during the buying process. This seems to be contrary to the majority of research, which describes a deep correlation between brand and country image. This implied connection makes Honda's reliability and ingenuity and Japan's precision and 
sophistication essentially indistinguishable. On the whole, the majority of the literature confirms that the attributes of the brand transfer over to the country image and vice versa.

Research conducted by Nebenzahl and Jaffe (1996) concluded that "the perceived value of a product is a weighted average of its perceived brand and made in country values" (p20). What is significant is that this combined value was shown to be potentially higher or lower when compared to the brand value on its own without country cues. When no country cues were given, consumers tended to assume that the 'made-in' country and the country associated with the brand are the same. For instance, many consumers believed that a Mexican built Volkswagen Golf was 'made in' Germany based solely on the knowledge that the Volkswagen brand is German.

In many cases, the country of origin is used in close association with brand name or on occasion instead of a brand name. Using a country branding strategy over a traditional branding strategy can have significant benefits according to Kleppe, Iversen, and Stensaker (2002). The additional dimension of country image associates consumer opinions about different countries to the product. Country image can thus influence an entire category of products, such as French wines or perfumes, or provide the brand for a specific product like Café de Colombia (Kotler and Gertner, 2002). This provides further considerations to the marketing strategy of hybrid products as mentioned earlier.

\section{$2.7 \mathrm{PCI}$ AND PRICE}

While research has demonstrated the impact that $\mathrm{PCl}$ has on the perception of quality and in the overall purchasing decision process, Johansson, Douglas, and 
Nonaka (1985) suggest that several other cues are just as influential when offered individually. The literature indicates that in the absence of other information cues, consumers may rely on country cues or brand to aid in differentiating products. However, price is often used as an indicator of quality wherein more expensive products are assumed to be of higher quality or value.

Products that are associated with countries, which imply a lower degree of quality, refinement, or reliability must offer high financial incentives in order to compete against similar products. To counter this negative view, it has been suggested that focus should be shifted away from the manufacturing or assembling country and towards the country of design to impart a higher level of quality. In some instances companies attempt to distance their brand from their country of origin. For instance, Daewoo associates itself with Italian style, British handling, and German engineering but never mentions its South Korean origins (Papadopoulos, 2000).

\subsection{SUMMARY}

The literature has indicated several potential summarizing cues that consumers use when evaluating products including price, brand, and country image. Research conducted on $\mathrm{PCl}$ as a halo or summary effect has demonstrated that there exists a significant correlation between perceived quality of products and country cues from the customer's point of view. This effect can be seen in both foreign and domestic markets where product superiority can be based on little more than a product-country relationship.

$\mathrm{PCl}$ as an influential factor on the buying behaviour of consumers has led the literature to suggest its increased use in advertising campaigns. However, the way 
in which practitioners implement $\mathrm{PCl}$ based techniques in advertising is not known based on the available $\mathrm{PCl}$ research.

Due to the expansion of multinational enterprises, the concept of a single country association is quickly disappearing in favour of hybrid products which amalgamate different countries of brand, manufacture, and design. $\mathrm{PCl}$ in product marketing strategies has become an increasingly potent and viable solution in the international advertising arena, according to the literature. 


\section{CHAPTER 3 ADVERTISING}

Advertising is the art of attracting attention to a product or business with the goal of trying to persuade or influence (Richards and Curran, 2002; Faber, 2002). It provides the arguments over which consumers reflect during the mental buying process. For the purposes of this research it is necessary to provide a general overview of advertising. This includes its role in positioning strategy, and in particular, the difference between an advertising appeal and an execution style. Respectively, these answer the advertiser's questions of why should consumers buy our product? (Kleppner, 1984), and how do we tell them (Rothschild, 1987)?

This chapter begins by providing an overview of the concept of advertising and describes some of the difficulties involved in the classification of specific advertisements. It then continues by elaborating on the concepts of appeals and execution styles and concludes with a summary relating the concept of positioning, the backbone of marketing strategy, with country image.

\subsection{OVERVIEW}

The effectiveness of advertising is difficult to measure. Traditionally volume of sales has been used to determine the effectiveness of advertisements, but there are problems associated with this approach. As Onkvisit and Shaw (1999) write, volume of sales has a great deal of 'noise' associated with it since this criterion is affected by more than just advertising effectiveness. "Economic conditions, advertising budget, campaign execution, pricing strategy (of the advertiser and of the competitors), competitors' promotional campaigns, resellers support, product 
quality, etc." (p21) are all factors which affect volume of sales but do not affect "advertising appeal and message" (p21).

Weilbacher (1984) writes that advertising techniques fall into two general categories: appeals and executions. He defines an appeal as "the device by which specific consumer response is solicited in [an] advertisement" (p197) while the execution is the manner in which the specific appeal is communicated in an advertisement. While appeals are completely independent of specific advertising media, execution styles can be more limited by the communication medium.

The structure of any advertisement is described by Kleppner (1984) as beginning with the promise of a benefit supported by proof, which leads to product purchase. The appeal portion of the advertisement is covered by the promise of a benefit while the proof is conveyed through the execution style. However, advertisements are not limited to putting forth a single appeal and may use multiple executions as well.

The classification of advertisements by appeal or execution style in advertising research is therefore very difficult. The literature agrees that defining a complete listing of appeals or executions styles is problematic or potentially impossible due to the complexity of existing techniques and continuing availability of new ones. While some "advertisements can fit equally well into more than one of the classifications... [others] have a certain ambiguity about them that makes classification difficult" (Weilbacher, 1984, 198).

Furthermore, due to the possibility of multiple execution devices being included in a single advertisement, the dominant style may be interpreted inconsistently among different observers. While this may be considered ineffective if the primary appeal or execution is diluted by secondary ones, Weilbacher (1984) 
argues to the contrary stating that this can produce "genuinely creative and particularly effective advertisement[s]" (p198).

\subsection{APPEALS}

An appeal is the 'reason why' a particular product should be bought. It is important to distinguish an appeal as the selling proposition versus the manner in which this proposition is communicated to the consumer.

The appeal of an advertisement is the rational or emotional attraction or benefit that the product or service can offer. Research conducted by Pollay (1983) and adapted by Albers-Miller and Gleb (1996) examined various advertising studies over the last quarter-century to produce a listing of advertising appeals. By concatenating the work of other academics and filtering for duplication, these researchers presented 42 distinct appeals used in advertising (please see Appendix A for the complete list of Pollay's (1983) appeals). These appeals consist of various emotional and rational cues which relate to a consumer's "interests, wants, goals, or problems" (Kleppner, 1984, p345).

In constructing advertisements, it is important to understand that while some appeals may be universal, others may not be accepted or understood by consumers in particular countries. Research conducted by Albers-Miller and Gleb (1996) suggests that consumers in different countries may respond differently to a particular appeal due to cultural and other country specific factors. Therefore, advertisers must be aware of what is appropriate when developing international advertisements. 


\subsection{EXECUTION STYLES}

Rothschild (1987) describes an execution style as the manner by which a particular appeal is presented to consumers, which affects their purchasing behaviour. As stated earlier, the classification of execution styles is a problematic endeavour. Researchers of the area are quick to point out that any categories provided are designed to encompass most execution styles, and caution that attempting to capture all possible executions is impractical due to the nature of the continuing creative growth of advertising and the introduction of new execution styles or variants.

Upon consulting various printed texts on the subject of execution styles, Kleppner's visual techniques (1984) and Rothschild's execution styles (1987) were initially determined as being the most appropriate for this study. Both classifications, however, were developed to include television advertisements and as such some categories were determined as unsuitable for print media research.

The individual categories within the two classifications were compared to eliminate any duplicate listings and then combined to form a single classification. Categories which were specific to broadcast media were then removed (e.g.: computer animation, stop motion, etc). Finally, $\mathrm{PCl}$ as its own category was added to the list to produce a new execution style classification as shown in Table 1. This list of execution styles was tested on a sample magazine issue and was determined, at the time of the proposal for this thesis, to be sufficient to categorize print advertisements. 


\section{Table 1: Kleppner-Rochschild Execution Styles}

\begin{tabular}{|l|l|}
\hline Animation & The use of animated people, places, or things as \\
& $\begin{array}{l}\text { Thesed to 'real-life' equivalent depictions. Often used to } \\
\text { opposed } \\
\text { target younger audiences. }\end{array}$ \\
\hline Celebrity spokesperson & $\begin{array}{l}\text { Offers the endorsement of a specific product by a } \\
\text { celebrity. }\end{array}$ \\
\hline Expert spokesperson & $\begin{array}{l}\text { Offers the endorsement of a credible individual who can } \\
\text { provide expertise on the product or service category. }\end{array}$ \\
\hline Unknown consumer & Offers the testimony of true customers and users. \\
\hline Close-up & Still photography and artwork depicting the product. \\
\hline Demonstration & $\begin{array}{l}\text { Demonstrates the advantages of a product without } \\
\text { specific reference to any competitors. This includes the } \\
\text { use or results of products in everyday situations. }\end{array}$ \\
\hline Factual & $\begin{array}{l}\text { Provides information about a product including figures, } \\
\text { attributes, characteristics, news, information, etc. }\end{array}$ \\
\hline Humour & $\begin{array}{l}\text { Creates an association between a memorable humorous } \\
\text { depiction and the product. }\end{array}$ \\
\hline Product comparison & $\begin{array}{l}\text { A direct comparison between two or more products of } \\
\text { various brands. }\end{array}$ \\
\hline Sex & $\begin{array}{l}\text { Uses sexual cues to attract the attention of the consumer } \\
\text { and provides implicit or explicit benefit of gaining sensual } \\
\text { or sexual attractiveness through the use of the product. }\end{array}$ \\
\hline Situations & $\begin{array}{l}\text { Depiction of people enjoying the product which is often } \\
\text { coupled with excitement and motivation. }\end{array}$ \\
\hline Slice of life & $\begin{array}{l}\text { Depicts a true life predicament and offers a solution to } \\
\text { provide happiness. Relies on the consumer being able to } \\
\text { relate to the situation. }\end{array}$ \\
\hline $\begin{array}{l}\text { Uses country cues and associations to depict or } \\
\text { demonstrate product attributes, characterises, or } \\
\text { superiority }\end{array}$ \\
\hline
\end{tabular}

Weilbacher (1984) cautioned that developing a complete listing of execution styles may be impossible and furthermore that specific advertisements may fall under multiple executions. In categorizing any advertisement, it is important to distinguish the main execution style from additional information included. For instance, an advertisement for a hair product that consists primarily of a picture of a model with attractive hair, followed by some text indicating how the product contains a new formula, should be classified as sex rather than factual even though there is information also present. The categories created are meant to represent the main method by which the appeal is transmitted, and since a single 
advertisement may use several styles, it is vital for this research to distinguish the primary execution style from any secondary ones. This is particularly difficult in situations where the advertisement may have an ambiguous execution, which could fall into multiple styles.

\subsection{POSITIONING}

Positioning is the principal tool that marketers use to influence a potential buyer's perception of a brand. It can be defined as "the act of designing the company's offerings and image so that they occupy a meaningful and distinct competitive position in the target customer's minds" (Kotler 1997). It is the foundation on which all marketing and advertising decisions are based for a particular brand or product. "Optimal positioning is the cornerstone on which persuasive messaging is developed ... [and is fundamental to the]... entire communications strategy" (Robertson, 2005).

Hodock (1980) indicated that positioning is composed of three components: target environment, buying incentive, and supporting evidence. These components are interconnected and must work in unison in order to achieve the advertiser's promise of generating sales.

The first goal of the positioning strategy is to define the target market segment. This is achieved by determining the "demographics, usage patterns, end benefits, life style, or self-concept" (Hodock, 1980, p33) of the target consumers. Globalization has made this more difficult by expanding the availability of market segments and generating new, international ones. "Language, aesthetic styles, and story themes" (Alden, Steenkamp, and Batra, 1999, p77) determine potential 
cultural symbols which can be used to generate potential target segments for positioning.

The use of culture to position products is further complicated by the availability of global, local, and foreign consumer culture positioning techniques. Global consumer culture, as introduced by Alden, Steenkamp, and Batra (1999), targets global segments on the premise that certain consumers worldwide share specific appeals or can draw benefits from a particular product globally. For instance, busy people worldwide may value time saving products. According to the same researchers, local consumer culture positioning aligns a product with "local cultural meanings, reflects the local culture's norms and identities, [portrays it] as consumed by local people in the national culture, and/or [depicts it] as locally produced for local people" (p77). Finally, foreign consumer culture positioning focuses on the brand personality, prestige, exclusivity, and foreign origins.

The second component of positioning is the buying incentive or end benefit of a product. This is what it offers to "motivate target prospects to buy it over other products" (Hodock, 1980, p33). As detailed earlier, Kleppner (1984) describes this as the appeal of the advertisement's strategy, the 'reason why' the product should be bought. This may be in the form of a rational or emotional plea to the consumer, but it is vital that it successfully addresses the wants and needs of the particular target market segment.

The final element of positioning is offering supporting evidence of the benefit claim to the prospective consumer. The evidence provided "lends credibility to the benefit promised" (Hodock, 1980, p33). In the advertising process this is the execution style. Different combinations of appeal and execution style may be used 
and, as noted in the previous section, in many cases multiple appeals and execution styles may be used in a particular advertisement.

It is imperative that a link be maintained from one component to the next in the development of a positioning strategy. For instance, advertising a cough syrup that tastes better will not yield increased sales if the target market is looking for a cough syrup that lasts longer.

Several specific positioning strategies have been developed and researched. Of these, comparative positioning has been the focus of extensive research and is of specific interest to $\mathrm{PCl}$ research. This is the technique of associating a new, lesser known brand with a dominant, accepted brand in an effort to achieve faster product acceptance for the former. The advertiser's objective in such cases is to formulate a connection between the two products that the consumer can quickly understand and willingly accept. This has particular implications for $\mathrm{PCl}$ advertising since the connecting attribute may be country of origin, of brand, of design, or of manufacture. The concept of comparative position superimposes the appealing attributes of an accepted product on a new one where there may not be any true connection.

Hodock (1980) describes positioning as being the 'spine' of any advertising strategy from which stems the decisions on target market, appeal, and execution. These three components must be correlated in order to produce successful advertising.

\subsection{SUMMARY}

For the purposes of this research it is important to understand the difference between appeals and execution styles. The primary focus of this work was to 
classify appeals and execution styles in print advertisements in order to determine the frequency of $\mathrm{PCl}$ usage as an appeal or execution in relation to other styles. The literature is in agreement that this form of classification can be problematic due

to the possibility of multiple execution styles being used in a particular advertisement, and this research attempted to address this potential problem. 


\section{CHAPTER 4 INTERNATIONAL ADVERTISING}

The global expansion of organizations into foreign markets has made international advertising increasingly more important. Whether to standardize or customize marketing strategies has been argued for nearly half a century.

This chapter begins with an overview of international advertising and introduces the debate pertaining to whether to standardize or customize advertising strategies. The chapter continues by addressing the differences between standardization and globalization, provides arguments for and against standardization and adaptation, and concludes with an analysis of the combination approach.

\subsection{OVERVIEW}

International trade has been an appealing and lucrative endeavour for firms, particularly since the end of the Second World War, due to the emergence of the world economy. As a result, the area of international advertising has been extensively studied since the early 1950s. While several issues have been researched under the umbrella of international advertising, the question of standardization has been at the forefront. Almost a third of all papers written on international advertising after 1990 have focused on the debate of whether to standardize or customize (Zou, 2005). Understanding whether people are truly the same all over the world, and more importantly whether they are affected by advertising in the same manner is a necessity of successful international advertising. 
Levitt (1983) declared that due to the growing homogenization of needs across borders the concept of standardization must prevail. He stated that technology was the driving force that was bringing commonality to the global arena. Since his initial publication, he has arguably become the most cited author on standardization.

The counterpoint to this concept was provided by Wind (1986), a strong advocate of adaptation. He cautioned that the differences between different markets should not be ignored since this can cause cultural insensitivity. By ignoring the values and attitudes of a particular market, a campaign that is incredibly successful in one country could be disastrous in another. While he did note the obvious advantages of standardization, he believed that it was not executable and recommended that advertisers "think globally [and] act locally" (Wind, 1986, p26).

As noted by Moriarty and Duncan (1991; cited in Taylor 2005), the debate between standardization and adaptation has produced a lot of grey area. They further suggested that researchers should "[conceptualize] global advertising versus local advertising as a continuum rather than as a dichotomy" (Moriarty and Duncan, 1991, in Taylor, 2005, p8).

Three options appear to exist for international advertisers. Practitioners can standardize their advertising strategies for a global market, customize their approach for specific markets, or exist somewhere in between, utilising a mixture of both standardized and customized approaches. 


\subsection{STANDARDIZATION VS. GLOBALIZATION}

One of the major debates that researchers of international advertising have with respect to whether to pursue a standardized, an adaptive, or a combined approach is the question of what is a standardized advertisement. Many researchers have discussed which elements must be homogeneous in order for an advertisement to be considered standardized.

Backhaus, Muhlfeld, and Van Doorn (2001) summarize several views that have been presented to answer the debate of what constitutes a standardized advertisement. The first view dictates that there should be minimal, if any, divergence with respect to theme, imagery, or illustration in international advertisements, with only translation into local language being taken into consideration (Onkvisit and Shaw, 1987; Reiter and Santana, 1992). The second view defines a standardized advertisement as one where one or more of the three main aspects of an advertising campaign are standardized. This refers to the "creative selling proposition, the actual elements of an advertisement, and the language" (Backhaus, Muhlfeld, and Van Doorn, 2001, p54). The third view is an advertisement that maintains the same theme internationally regardless of specific copy or illustration differences (Duncan and Ramaprasad, 1995). This final viewpoint offers a differentiation between a standardized and a globalized strategy.

The concepts of standardization and globalization are similar but very distinct in nature. Pitcher (1985) wrote that much of the advertising that we call 'international' in reality is not. In many cases it is designed, created, and executed by local advertising agencies and, while the product and the company may be international, "its advertising often remains specific to the local country or region" 
(Stewart and McAuliffe, 1988, p22). The concept of a standardized approach is an advertisement that focuses on a specific, domestic target during its inception and is then released globally maintaining the same specific focus. A global advertisement is one where the focus is global straight from the onset, taking into consideration international market similarities and differences.

In an effort to determine whether true staridardization or globalization was occurring in international advertising, Rosen, Boddewyn, and Louis (1998) conducted research to determine whether multinational companies use a single or different advertising agency domestically and abroad. It was believed that international brands (brands that are marketed in different markets under the same name) would be more likely to maintain a single agency and implement a globally standardized advertisement strategy; a strategy based domestically but taking into consideration the global marketplace. The results contradicted these speculations and demonstrated that the majority of companies utilized a different advertising agency at home and internationally. The findings took into consideration different scenarios including standardized versus non-standardized brands and products across many different categories.

The only notable observation with respect to companies choosing a single advertising agency was that companies who possessed a very large advertising budget (larger than $\$ 20$ million) tended to be more likely to use the same advertising agency domestically as internationally. However this trend was only apparent in slightly over half of the large companies (Rosen, Boddewyn, and Louis, 1998). Perhaps this indicates that larger, more powerful companies may feel that they do not need to customize their message and can 'buy' their way into international markets. 
The development of technology and communication has theoretically caused the globalization of the world and the unification of people. However, it has been argued that "no single country is a single unified market, but is composed of marketing segments, each with its own characteristics" (Fatt, 1967, p60). The concept of adaptation dictates that a marketing strategy should be customized to adhere to the social and cultural distinctiveness of its particular international market. It has been questioned whether advertisers can successfully capture a more significant portion of these segmented nations using a tailored approach as opposed to appealing to universal basic human appeals.

\subsection{STANDARDIZATION}

Through the use of standardization, organizations are capable of creating a "more homogeneous image of the firm and its brand in multiple markets" (Taylor and Okazaki, 2005, p98). Glubal companies which operate in a unified way across a majority of the entire world can do so at a comparatively lower cost. This makes the sale of the same product in the same way everywhere financially appealing (Levitt, 1983). A. C. Fatt, the Chairman of the Board and CEO of Grey Advertising, stated that, "even different people are basically the same and an international advertising campaign with a universal appeal can be effective in any market" $(1967$, p60). This argument suggests that people possess the same (or very similar) raw natural wants and needs which can be leveraged by global companies to standardize their practices in the global arena.

Through global economies of scale, organizations can offer high-quality products at low cost. It has been suggested that if the cost is low enough, people worldwide will buy a product, even if it is not exactly what they want, simply 
because it is almost exactly what they want and such a good deal (Levitt, 1983). This stems from the concept of mass marketing, which has not been generally accepted as a successful approach. Telling people what they should buy has been replaced by for consumer-focused marketing where consumers tell the producers what they want to buy.

Technology attempts to provide an "alleviation of life's burdens and the expansion of discretionary time and spending power" (Levitt, 1983, p99). If customers used these as criteria to purchase products, then global standardization could be an effective strategy for worldwide distribution. The reality though is that many of the products that people buy do not simply make their lives easier, save them money or offer them more time (Hallaq and Pettit, 1983). Subjective factors such as status, style, and performance are often used as the primary criteria for making purchasing decisions (Jamal and Goode, 2001). This, however, can still support the notion of standardization.

"A corporation with a well-known and accepted brand name is more likely to be successful using greater levels of standardization than a firm without such acceptance and name recognition" (Hite and Fraser, 1988, p8). Expensive and luxurious products such as "Cartier watches, Louis Vuitton handbags, or Canon cameras" (Wind, 1986, p23) are more likely to successfully adopt a globally standardized marketing approach. Although research indicates that the majority of multinational organizations currently use a combination approach in their international advertising (Yin, 1999), it has been suggested that as these companies acquire more brand recognition within foreign markets, they will be able to slide along the standardization/adaptation continuum towards the standardized endpoint, accepting more globally unified strategies. 
While it cannot be denied that technology is bringing the world closer together through newer, quicker, and richer communication and transportation methods, the notion that this technology is causing the world to become a single global entity is questionable. Nevertheless, the increase of 'worldly people' does offer a unique opportunity for standardization. The ease of travel has, in some sense, unified the global market. As more and more people travel the world, the ability to offer similar products in different areas becomes appealing. Even 40 years ago, Roostal (1963) noted that "nearly every third Western European travels abroad [within Western Europe]". Thus, similar products across Europe can more easily be homogeneously marketed for international product recognition. Similarly, Americans travelling all over the world can find comfort in the standardization of McDonald's and Coca-Cola. Although beer is offered in French McDonald's and the water used for Coca-Cola in Japan may be different, the high level of brand recognition has allowed these companies to utilize a standardized approach and subsequently allowed the wary traveller an opportunity to identify with a 'domestic' product internationally.

Financial benefits related to advertising cost savings and coordinated strategies are benefits associated with standardization. Additionally, the ability to appeal to cross-market segments is considered another strength of standardization (Taylor and Okazaki, 2005). However, other concerns are often overlooked, such as egos which can come into play when standardization is concerned. Local offices may feel that they know their local markets better then the global headquarters and thus feel they could provide a better campaign than what is offered by head office. Similarly, local consumers may object to being told what they should buy from a foreign multinational organization. The question thus becomes: can a great, 
localized strategy outperform a good (but not great) standardized one (Duncan and Ramaprasad, 1995)?

In various comparative studies done on the effectiveness of standardized advertisements, the subject countries have been very different in terms of language, culture, demographics, and economy. This extreme approach has often been due to the availability and accessibility of data. These studies have demonstrated that when very divergent countries have been selected and compared, the data indicated "numerous and significant" differences between the selected countries, according to Onkvisit $(1999, \mathrm{p} 23)$. This seems to indicate that global standardization is not possible. Therefore, the option to utilize a customized approach is still very appealing in international advertising.

\subsection{ADAPTATION}

"Despite increasing globalization tendencies, variations between countries" (Theodosiou and Leonidou, 2003, p142) indicate a lack of homogeneity within countries and imply that standardization may not be an effective method of advertising. "Levitt's strongest support for standardization is technology and the trend towards modernization", writes Yin (1999). Using the example of China, which has in recent years become a huge consumer of the technology market, this researcher therefore deduced that China should be a ripe target for a standardized advertising strategy. However, the results of his research favour a combination approach and thus suggests, "that technology and the trend toward modernization do not necessarily warrant standardization in foreign markets" (p29).

While language issues in intercultural communication are apparent and obvious, "understanding non-verbal signals that are generally coded so 
automatically within a culture that we are unconscious of them" is just as great an issue, write Hornik and Rubinow (1981, p10). "The international advertiser must constantly be on the alert to cultural variations. Advertising planning, research, segmentation, media selection, creative considerations, and campaign strategies all become more complex when the additional variables of international operations are introduced" (p10).

As noted earlier, Pollay (1983) created a list of 42 categories of rational and emotional appeals commonly used in advertising. He compiled the list from research conducted in other advertising studies and deduced from value judgements across several disciplines that a finite list of appeals may exist. However, Albers-Miller and Gleb (1996) suggested that different countries react differently to different cultural appeals. Built on the assumption that advertising and culture are related in even the smallest aspect, their research suggests that certain countries will view the same specific appeals in a different light. This limits the effectiveness of globalization, which attempts to focus on a small subset of universal appeals, since such a subset may be very small indeed or in fact may not exist altogether.

Communication theory states that an observer's culture highly dictates the manner in which she or he perceives information (Kanso, 1992). Subsequently it can be derived from this theory that if a message sender wishes to successfully impart information to an individual in a culture other than the sender's own, then the sender must be familiar with the receiver's culture. If the above argument is valid, then it can be applied to international advertising, where advertisers must be familiar with their targets' culture in order to communicate effectively. 
When developing international advertisements, it has been suggested that the buying proposition and creative presentation are two distinct aspects of advertising that must be considered individually under the concept of utilizing standardization or customization. Research has indicated that the buying proposition or the selling platform could be maintained roughly half the time when implementing an advertisement into a new international market, while the creative presentation was successfully standardized less than a third of the time (Killough 1978).

Further research conducted on this concept indicated that the more competitive a market is, the less standardization is used by the competing players. At the same time, organizations entering less developed markets tend to use standardized strategies. It has been suggested that in less sophisticated markets, multinational advertisers have been less concerned with being highly competitive. Due to the perceived superiority of Western products and limited competition, standardization can be sufficiently effective in these particular markets. Alternately, in highly competitive markets where consumer discrimination of products is more apparent and widespread, customization is more abundant (James and Hill, 1991).

The differences in advertising content, creative approach and consumer opinion are diverging in international markets, which promotes the concept that hard standardization is no longer a viable consideration when considering international advertising. In the United States, for instance, a hard-sell approach has been observed in television advertisements where advertisers attempt to inform and educate consumers (Nevett, 1992). This can be viewed by the ' 4 out of 5 dentists recommend', 'as compared to the other leading brand', and 'according to so-and-so' product superiority claims that are visible daily on American television. 
This is quite different from British television advertisements, which attempt to entertain their viewers and consumers; this is more conducive to a soft-sell technique (Nevett, 1992).

\subsection{COMBINATION}

Instead of looking at standardization and adaptation as polar opposites, choosing a strategy somewhere in the middle has become the focus for many advertisers since the 1990s (Yin, 1999). As mentioned, the view is that standardization and adaptation are opposite ends of a continuum and the combination strategy allows for marketers to exist somewhere in between, leveraging the advantages of both standardization and adaptation techniques (Theodosiou and Leonidou, 2003). While strategies in international marketing endeavours are often standardized, the creative themes, implementation, and executions are sometimes standardized, and language and nationality of models are almost never standardized (Duncan and Ramaprasad, 1995). "The trick for advertisers is to recognize the commonalities [in various international markets] and seize them. At the same time, [advertisers must] be sensitive to even small differences that are meaningful to various societal groups, even within a single country" (Cook, 1992, p8). As such, a combination approach has been suggested.

The combination approach is appealing to international advertisers since it allows them to maintain certain aspects of their international identity, such as trademarks, which are the most important aspect when transferring a product from a local market to a foreign one (Yin, 1999) while at the same time customizing their approach for individual differences in different countries. 


\subsection{SUMMARY}

International advertising is increasingly important due to the expansion and availability of foreign marketplaces. For standardization to be most effective, globalization must amalgamate international wants and needs to provide a unified global marketplace. Conversely, hard adaptation requires considerable allocation of resources, which is unappealing to the business world. Due to the increasingly mixed culture of the world, practitioners seem to have abandoned the polar strategies of pure standardization or adaptation in favour of a mixed combination strategy. In order to successfully advertise in these markets, marketing techniques need to be adapted for specific cultures and regions to maximize the effectiveness of advertising initiatives while at the same time maximizing the financial and temporal development advantages of standardization. 


\section{CHAPTER 5 CONTENT ANALYSIS}

Along with the various observational research methods, content analysis specifically allows for a systematic evaluation of communication content from various qualitative sources. It focuses on the analysis of the messages rather than the interpretation of the message by the sender or the receiver (Kassarjian, 1977).

This chapter begins with a brief overview of content analysis in academic research and addresses concerns with its use. Replicability and reliability are two areas at the "heart of content analysis research and directly affect research quality" (Kolbe and Burnett, 1991, p249) and as such will be discussed, along with concerns related to bilingual studies, international advertising and $\mathrm{PCl}$ considerations.

\subsection{OVERVIEW}

Content analysis is a quantitative approach that allows 'open-ended' data to be categorized, explored, and evaluated (Harwood and Garry, 2003; Sonpar and Golden-Biddle, 2005) from a variety of sources such as "media advertising, print materials, and sundry verbal and nonverbal messages" (Kolbe and Burnett, 1991, p243). It is fundamental to research pertaining to mass communication since it specifically caters to the study of messages (Kolbe and Burnett, 1991). As such, content analysis focuses on "the study of the message itself, and not the communicator or the audience" (Kassarjian, 1977, p8).

Since content analysis concentrates on the message and not the interpretation, it has been suggested that it limits the potential contribution to "both theory building and marketing practices" (Lerman and Callow, 2004, p508). For 
instance, it is able to analyse advertisement content, but not its effect on consumers and society (Lerman and Callow, 2004). However, the literature suggests that it can still substantially contribute to consumer behaviour research (Kolbe and Burnett, 1991).

Although the flexibility of content analysis is considered one of its major strengths, its subjectivity produces continual criticisms. Data collection, analysis, and interpretation are all susceptible to research bias (Harwood and Garry, 2003). This is a critical concern for advocates and practitioners of this methodology since the existence of bias can limit the ability for researchers to contribute to knowledge through inferred conclusions (Kolbe and Burnett, 1991). As such, objectivity is paramount in content analysis. Objectivity within content analysis is defined as the replicability and reliability of specific research. This essentially breaks objectivity down into two categories: documentation and judges.

Objectivity is vital to the quality and subsequent acceptance of content analysis findings. Coupled with its systematic and quantitative characteristics, these traits distinguish it from other forms of observational research methodologies (Kassarjian, 1977).

Ensuring a systematic process during the analysis of content has been suggested as an aid to help support the findings of content analysis work. This requires that the development of categories and evaluation of content be done in a consistent manner. In so doing, partial or biased analysis is minimized (Kassarjian, 1977). 


\subsection{REPLICABILITY}

As in the natural sciences, detailed and sufficient documentation of the processes and procedures involved in content analysis research helps promote impartiality. The inclusion of rules and procedures allows the validation of research findings and future replications. The replicability factor of content analysis simply dictates that "the categories of analysis be defined so precisely that different analysts may apply them to the same body of content and secure the same results" (Kassarjian, 1977, p9).

The involvement of judges or coders in content analysis is complicated and crucial. Kolbe and Burnett (1991) indicate that training, pretesting, and the interdependence and number of judges are all critical in maintaining objectivity.

The independence of judges refers to their ability to make decisions about content autonomously without influence from the researchers or other judges. If sufficient training has been conducted, then this should ensure the freedom of the judges to make non-influenced decisions about the data.

While multiple judges can be used in coding data for content analysis, it is vital that the way in which the judges are distributed across the sample is documented in the findings. Judges, who test subsets of the total data findings, while offering some degree of objectivity, limit the total validity of the data as compared with cases where the judges judge the entire available data for consistent judgement. Lerman and Callow (2004) further add to this point by indicating that if independent judges from say the United States and United Kingdom analyse unique subsets of the total data, even though they share a 
common language, inter-judge reliability does not exist due to potential cultural differences and as such objectivity can be lost.

Krippendorff (2004) suggests that the more judges and the more 'common' they are, the more the replicability of data can be ensured. He further states that as long as sufficient overlap for duplicate evaluation of data exists, judges may focus on specific subsets of the complete data. The pretesting of categories "checks the reliability of the coding process" (Kolbe and Burnett, 1991, p245). In order to improve inter and intra-judge coding reliability, training is vital to ensure that all judges are familiar with the coding scheme and operational definitions.

\subsection{RELIABILITY}

The reliability in content analysis is primarily achieved through the use of multiple independent judges. The degree to which these judges or coders agree on the analysis of data is often used as an indicator of the degree of objectivity. This intercoder reliability or intercoder agreement is a "measure of the extent to which independent judges make the same coding decisions in evaluating the characteristics of messages, and is at the heart of [content analysis]" (Lombard, Snyder-Duch, and Bracken, 2002, p587).

Several different measures have been suggested for determining the agreeability of judges. The primary difficulty with offering a measure of the level of agreement between judges is taking into consideration random chance. For instance, if we assign two judges and offer them no instruction other than to evaluate 100 advertisements to determine whether they exhibit a particular appeal or not, on random chance, they should agree about half the time. 
The literature does not describe any completely satisfactory index for measuring the level of agreement between judges. Measurements that do not account for chance agreement tend to be too liberal while those that do account for chance agreement are too conservative. As such, it is recommended that multiple indices be used and listed in content analysis findings (Lombard, Snyder-Duch, and Bracken, 2002).

The main measures that have been suggested are summarized below (Lombard, Snyder-Duch, and Bracken, 2002):

\section{Percent Agreement}

The most common metric used for assessing the agreement of judges is percent agreement. It is also called simple agreement, percentage of agreement, raw percent agreement, or crude agreement. It provides an index between 0.0 (no agreement) and 1.0 (perfect agreement) which represents the percentage of all evaluated decisions that judges agree upon.

Percent agreement is commonly used since it is simple, intuitive, and easy to calculate, and can effortlessly accommodate multiple judges. The downfalls of this method are that it completely fails to account for chance agreement, especially when few categories exist in the analysis schema, and only measures agreements and disagreements. It does not allow for 'close' judgements and thus is usually limited for nominal variables.

\section{Holsti's Method}

A variation on percent agreement is used for Holsti's Method which allows for reliability tests when the judges evaluate different units. This is achieved by calculating metrics across a set of variables. Unfortunately this can hide variables 
with "unacceptably low levels of reliability" (Lombard Snyder-Duch and Bracken, 2002, p591).

\section{Scott's Pi}

Scott's $\mathrm{Pi}$ is a method that accounts for chance agreements by taking into account both the number of categories as well as the distribution of values amongst them. Its flaw is that it assumes that the proportion observed is the true proportion instead of the result of agreement amongst the judges. In other words, it assumes that the judges have distributed their judgments the same across the various categories. As such, it is often viewed as being too conservative.

\section{Cohen's Kappa}

Cohen's Kappa uses the same formula as Scott's pi to account for chance agreement. Since it only accounts for distribution beyond the values in the marginals, it is also considered a conservative index. Specifically, even with perfect agreement the index has a maximum value less than 1.00. Similar to some of the other measures, it is primarily used for measuring the agreement in research with nominal level variables.

\section{Krippendorff's Alpha}

This measure is specifically designed for instances where variables utilise

different measurements (nominal, ratio, etc.) and allows for multiple judges. Using the same assumptions as Scott's pi, Krippendorff's Alpha also accounts for chance agreements. Its largest failing is its complexity and difficulty to calculate, especially for interval and ratio level variables.

Academics have difficulty agreeing on what values each of these measures should produce in order for the reliability of content analysis research to be 
acceptable. It has been suggested that "coefficients of .90 or greater would be acceptable [by] all, 0.80 or greater would be acceptable in most situations, and below that, there exists great disagreement" (Neuendork as quoted by Lombard, Snyder-Duch, and Bracken, 2002, p593). Lombard, Snyder-Duch, and Bracken (2002) have argued that a score of 0.70 is sufficient for exploratory research and have further maintained that for the more conservative measures (Cohen's Kappa and Scott's Pi) more liberal criteria can be used.

\subsection{CONTENT ANALYSIS AND LANGUAGE}

Conducting content analysis where several languages are involved in the material being evaluated introduces a unique set of concerns. For instance, evaluating documentation written in the vernacular can potentially produce different findings than evaluating the same documentation in a translated form. Translations of various media by the communication distributor, third party translators, or researchers themselves can potentially produce differing content.

Research conducted by Campbell, Cornelia, and Shrives (2005) suggests that the content disclosed by some organizations may vary in different linguistic editions. That is to say that "different translations of what are nominally the same documents are used to convey different emphases to different national audiences" (p342). In order to account for such discrepancies within bilingual analyses of content, they suggest that bilingual judges must be employed.

The use of bilingual judges allows researchers to determine whether a "consistent standard has been used to classify material from across [multiple] countries" (Lerman and Callow, 2004, p511). Accuracy in translated documents is achieved if the same issues are covered in the text. When the use of bilingual 
judges is appropriate, Campbell, Cornelia, and Shrives (2005) further caution that true bilingualism must be ensured in both the cultural and linguistic sense. This ensures that the cultural significance of the message in its context is also appropriately translated.

Volumetric considerations are another major concern when conducting content analysis across multiple languages. A large number of content analysis studies involving documents capture data as a proportion of some count (words, sentences, pages, etc.) assuming that volume signifies importance (Campbell, Cornelia, and Shrives, 2005). For instance, if content is measured by page proportion this could cause problems if translated versions of documents are longer or shorter than the native language versions. In cases like this proportional significance may be skewed due to the writing constraints of particular languages. For instance, the German language contains many complicated, multi-syllabic words that require several English words to relay the same message thus making English versions of the same texts longer.

The linguistic limitations of researchers therefore are potentially a factor in country selection when designing content analysis frameworks. Overall this is not a deturent to using content analysis, but should be taken into consideration during the design phase of research, especially if particular countries are used as representations of regions. The use of the United Kingdom as a representation of Europe based solely on the convergence of the country's and the researcher's native languages is an example of poor country selection and may produce biased results. 


\subsection{CONTENT ANALYSIS AND INTERNATIONAL}

\section{ADVERTISING}

Content analysis offers a quantitative look at how often specific techniques are used in international advertising across multiple countries. Unfortunately it does not offer any answers to the question of why certain techniques are used more frequently than others.

When selecting countries for comparative content analysis, often very diverse countries are used. Commonly due to limitation of access and for convenience reasons, countries with differing cultural, social, and language traits have been compared. This often results in severe differences in the comparative data (Onkvisit and Shaw, 1999).

Onkvisit and Shaw (1999) suggest that comparative research should be conducted on homogeneous regions. For instance, the United States should be compared with Canada or the United Kingdom, but not Mexico or France. By limiting the linguistic differences and attempting to maintain a similar cultural and economic demographic, they suggest that further insight can be achieved in determining the potential effectiveness of advertising on a smaller, non-global yet international scale. To this effect, research conducted by Nevett (1992) which compared the United Kingdom and United States, which possess various social and cultural similarities, revealed that there are significant differences in the appeal of advertisement content and creative approach.

Taylor (2002) argues that content analysis is not an effective method to conduct research on international advertising. While many studies have been conducted in this manner and furthermore these studies have suggested particular 
practical guidelines that should be followed for successful advertising, Taylor (2002) disputes the research findings. He states that, "[The researchers presume] that professionally produced advertisements in a country correctly reflect general advertising principles and that 'what is practiced is what is effective' in the country being studied" (p49).

However, this researcher's views appear to be in a small minority and are not supported by either other researchers or logical analysis. First, out of 32 papers on international advertising published in the Journal of Advertising between 1994 and 2004 (please see Table 2 for details), 11 (34\%) have used content analysis as their methodological approach. This significant portion of the major works indicates that it is a favoured method of conducting research on international advertising. Second, Taylor (2002) is correct in saying that for content analysis to be effective, the assumption must be made that what advertisers are doing is successful, but he is likely incorrect in questioning this assumption. If advertisements are accepted by consumers and translate into sales, then it is safe to assume that the efforts that advertisers are employing are effective for the consumers. In order to allow for a margin of error, it can be conceded that what practitioners do may not be always the most effective, but is nevertheless effective to a significant degree.

\section{Table 2: Frequency of Different Methodologies Used}

\begin{tabular}{|l|c|c|}
\hline & Frequenes & Percentage \\
\hline Content Analysis & 11 & 34 \\
\hline Experiment & 8 & 25 \\
\hline Survey & 7 & 22 \\
\hline Conceptual & 3 & 9 \\
\hline Secondary Data Analysis & 2 & 6 \\
\hline Qualitative & 1 & 3 \\
\hline Total & 32 & $99^{*}$ \\
\hline${ }^{*}$ Numbers do not add up to $100 \%$ due to rounding. \\
\hline \multicolumn{2}{|l}{ Source: Taylor (2002) } \\
\hline
\end{tabular}




\subsection{CONTENT ANALYSIS CONCERNS WITH PCI IN PRINT MEDIA}

Conducting content analysis research is a difficult process that contains a great deal of individual interpretation. Print media are particularly difficult to compare since they can contain a great deal of information and utilise both written and visual cues. The different categories of $\mathrm{PCl}$ based cues have been discussed earlier (see section 2.5); however, several concerns have been offered in conducting content analysis of print advertisements with specific reference to $\mathrm{PCl}$. These considerations include but are not limited to website address, brand names, copyright and trademark information, language, people, and integrated 'made-in' statements (Lidder, 2005).

The inclusion of a URL address in an advertisement has been suggested as a potential indication of country association. The use of '.ca' or '.co.uk' can offer an image of Canada or the United Kingdom respectively. This association has an intrinsic flaw due to the nature of URL address assignment. A URL can be anything and many can be assigned to anyone. While some suffixes are limited to particular countries, others do not have this limitation. For example, '.ca' is limited to Canadian websites while suffixes such as '.tv' (Tuvalu), '.com' (commercial), '.net' (network), etc. are available to anyone. This makes the interpretation of website addresses as a PCl indicator difficult.

Several brands around the world either have embedded a $\mathrm{PCl}$ cue in the brand name itself or have a strong association to a specific country. Unlike other $\mathrm{PCl}$ cues, which may or may not be used by an advertiser, those that are part of a brand name are likely to appear in all advertisements for the brand. This may lead 
to the thought that, since brand decisions are part of the 'product' element of the marketing mix, $\mathrm{PCl}$ cues within them should not be considered in 'advertising'oriented content analysis. However, since the brand name is the key communication element for the brand itself, it is commonly, and correctly, used in content analysis and was also used in this study.

L'Oréal Paris, Canadian Magazine Publishers Association, and Singapore Airlines, all contain obvious associations to countries based on their use of location within their brand name. The mere inclusion of the brand name in an advertisement can therefore imply some degree of the conscious use of a $\mathrm{PCl}$ appeal. However, Holland Alaska tours sends a mixed message since it associates with both the Netherlands and the United States. In this case is the advertiser using a PCl appeal for both countries? Certain brands such as BMW or Hitachi are associated with Germany and Japan respectively based on their huge brand recognition, but this should not necessarily be confused with using a PCl appeal to advertise.

Many print advertisements include fine print copyright, trademark, and other information. This information can contain country specific cues, such as a Honda advertisement, known as a Japanese company, specifying the copyright holder as American Honda Motors Inc. This presents the concern as to whether the legal information is included for legal reasons or as a $\mathrm{PCl}$ cue to associate the company locally (Lidder, 2005). As with the reasoning for the brand name, in this study it was assumed that regardless of why the company name may be included in "fine print" information, the choice of a company name in the first place was a matter of the firm's communication strategy. Therefore, $\mathrm{PCl}$ related fine print information was included in the analysis. 
The use of a foreign language, whether in advertising text or, for example, as part of a photograph of the product or its package, can be an indication of $\mathrm{PCl}$. For example, the use of Asian characters and writing is increasing in North American advertisements according to Muller (1992), who also indicated that many advertisements in Japan use English words in their messages even though a dominant majority of Japanese people do not speak any English.

Celebrities, people wearing local attire, place-specific scenery, and other such elements can also potentially be used as $\mathrm{PCl}$ cues. In such cases, the advertiser assumes that the cues are significant, that they can differentiate the product based on its country of association, and that the target audience will be able to associate them with the intended country. The potential problem of whether, in a content analysis study, the judges will be able to correctly identify such cues can be addressed by using judges from the same culture as the advertisers' intended target audience.

Considerations like these must be taken into account when formulating the criteria for conducting content analysis on print media advertisements. Particular concerns exist with respect to what can be considered an active $\mathrm{PCl}$ cue by the advertiser and what is included due to legal or other technical reasons.

\subsection{SUMMARY}

Content analysis has been used in a significant amount of international advertising research in the last 15 years since this technique focuses on the analysis of communication media. In order to make this methodology a viable and valuable tool for academic research, objectivity, and reliability must be maintained 
through the use of extensive and detailed documentation, judge training, and an acceptable level of agreement between judges. 


\section{CHAPTER 6 RESEARCH QUESTIONS}

The literature on $\mathrm{PCl}$ has indicated that consumers are very susceptible to country cues during the purchase decision making process, and that a significant correlation exists between country imagery and product acceptance. Due to this relationship it has been suggested that practitioners employ $\mathrm{PCI}$ techniques in their marketing strategies. However, $\mathrm{PCl}$ research to date has been conducted on consumer attitudes and the actual degree of usage of country cues by practitioners is unknown. The usage of $\mathrm{PCl}$ cues can have particularly significant implications in international advertising since cultural overtones can skew perceptions of specific countries.

The primary focus of this research was to determine the frequency, type, and intensity of $\mathrm{PCl}$ usage within a sample of magazine advertisements. The frequency of use of $\mathrm{PCl}$ was analysed across the execution style and various cues within each advertisement to determine the following:

- What proportion of advertisements use $\mathrm{PCl}$ as an execution style?

- What proportion of advertisements use $\mathrm{PCl}$ cues (independent of execution style used)?

The intensity and strength of $\mathrm{PCl}$ usage was also addressed by cataloguing the number of cues used and analysing their relative prominence in advertising to answer the following two questions:

- How intensely are $\mathrm{PCl}$ cues used within magazine advertising?

- What is the relative strength of $\mathrm{PCl}$ cue usage within magazine advertising? 
The two proportion variables, and the intensity and strength observations, were cross-tabulated against several advertisement demographics to determine if any patterns or correlations existed:

o Product category (e.g.: apparel, furniture, travel, etc.).

- Target country (e.g.: do advertisements targeted at Canadians use more country cues than advertisements targeted at Americans?).

- Advertiser's home country (e.g.: do brands from France use more PCI based advertising than brands from the United States?).

- Brand (e.g.: does Tommy Hilfiger use more country cues than Honda?).

- Magazine type (e.g.: do business magazines contain more advertisements with $\mathrm{PCl}$ cues than fashion magazines?).

General appeal patterns will also be catalogued to determine if $\mathrm{PCl}$ advertising tends to use rational or emotional appeals more predominately.

Additionally, with regard to international advertising, a general overview of the advertisements was performed to determine the use of standardization and adaptation. Canadian and American publications were compared to determine if the frequency, intensity, and strength of $\mathrm{PCl}$ advertising was significantly different. Subsequently, specific advertisements were compared to consider explicit differences between Canadian and American versions.

In conclusion, since the literature indicates that $\mathrm{PCl}$ is capable of substantially influencing consumers in product selection and acceptance, this study was guided by the two main expectations. First, that this research would indicate considerable usage of $\mathrm{PCl}$ cues in advertising while the usage of $\mathrm{PCl}$ as an appeal or execution style may be low in relation to other appeals and executions styles 
used overall. Second, that the various advertisement classifications (product class, magazine type, etc.) would be significant in the distribution of $\mathrm{PCl}$ use and that a significant difference would be observed in the use of PCl between Canadian and American publications. 


\section{CHAPTER 7 METHODOLOGY}

As described earlier, this research was a continuation of a broader research project initiated by my supervisor, which was undertaken originally by Lidder (2005) and was continued by Teodorescu (2005). As such, the methodological approach was limited in some respects to what was already accomplished by the other researchers.

\subsection{SAMPLE}

To analyze the use of $\mathrm{PCl}$ in advertising content analysis was conducted using a sample of Canadian and American magazine advertisements. The sample is composed of 3008 advertisements selected from the eight magazines shown in Table 3. Six issues were selected from each publication covering alternating months between November 2003 and December 2004. In a few cases where a particular back issue was not available, the next closest issue was used.

\section{Table 3: Publication Details}

\begin{tabular}{|l|l|l|l|l|}
\hline & & & & \\
\hline
\end{tabular}


The publications were selected across the two markets to represent a wide and varying target audience: business, news, fashion, and lifestyle. Furthermore, the gathering of alternating months of a year's worth of data was done to provide an assortment of advertisements not limited by seasonal patterns. While the sample is limited to Canadian and American publications, as mentioned in section 5.5 the literature indicates that countries with similar culture and language can produce more pertinent information than drastically differing countries which possess inherent differences.

Only advertisements of one full page or more in size were used. Multiple page spreads were considered as one advertisement unless the same producer advertised a different brand on each page. The content analysis literature does not address the issue of how to handle multiple page advertisements (which may refer to one or more brands by the same producer), or, specifically for $\mathrm{PCl}$, multiple appearances of the same country cue (e.g. foreign brand name) in the same ad. The database was designed so as to account for such issues.

\subsection{OVERALL RESEARCH PROCESS AND DESIGN}

The advertisements were removed from the publications and catalogued numerically. The initial database that was made available for this research contained only the base information for each advertisement, specifically: the date, country of publication, total number of pages, proportion of full page advertisements to overall content, and other quantitative metrics of the issue in which an advertisement appeared, plus the brand being advertised and the company placing the advertisement. 
For this research several additional variables were catalogued for each full page advertisement in the sample. Specifically, the product category, primary appeal, primary execution style, usage of various country cues, intensity, and overall strength of $\mathrm{PCl}$ usage, were determined and catalogued, as well as additional brand and advertisement demographic information.

Preliminary analysis of the data made apparent several serious concerns about the various classification schemes that had been selected at the proposal stage of this thesis. In addition to difficulties in developing a classification for $\mathrm{PCl}$ cues, which was expected since this is the first ever study on this topic, the schemes developed from earlier research for the product, appeal, and execution style classifications were found to be inadequate and in some instances wrong when applied. This led to low inter-judge agreeability and skewed results (e.g.: one category accounting for over $50 \%$ of all observations). In turn, this led to the rethinking and redevelopment of the classifications used. The following subsections show the original classification schemes and how these were modified.

Once the concerns with the classifications schemes were addressed, in order to minimize reliability concerns associated with content analysis research two judges were used in cataloguing all qualitative information within the database. Three additional judges were used to increase agreeability levels for some of the quantitative data. An iterative process was used throughout the research, in which the data was checked and rechecked by the various judges to ensure that technical mistakes in the form of human error were minimized. Final agreement of the few remaining differences within each classification was achieved by discussion among the judges. 
Basic calculations for level of agreeability and Scott's Pi calculations (detailed in Equation 1) were used to support reliability. The variables of interest in this research were all represented using classifications with large varying and nonrelated classes and so, concerns about random agreeability were minimized. The smallest of these classifications contained 25 classes, whereby random agreement would yield only $4 \%$ agreeability; however, as detailed in the following subsections, the levels of agreeability found were much higher.

\section{Equation 1: Scott's Pi}

$\mathrm{A}=\frac{\mathrm{P}_{0}-\mathrm{P}_{c}(\mathrm{~A})}{1-\mathrm{P}_{c}(\mathrm{~A})}$

$\mathrm{P}_{0}$ : calculated level of agreeability

$P_{c}$ : probability of chance agreement $(1 / n)$

\subsection{PRODUCT CATEGORIES}

The analysis of the data required that each advertisement be categorized by the product type which it was advertising. A review of the existing literature failed to yield a complete product category classification. Although content analysis has been used throughout various marketing and advertising studies, most have limited their focus to a particular sector. Upon further investigation several potential product categories were found from alternative sources (e.g.: World Advertising Research Center (WARC); Wiles, Wiles, and Tjernlund (1995); Teodorescu (2005); NAICS and Reader's Institute (2005)). These individual categories were compared in order to determine the most viable classification for this research.

Using completeness, clarity, and conciseness as criteria for the product categories, it was felt, at the proposal stage, that the Northwestern University Reader's Institute (2005) product classification could be a good candidate for this 
research. The Reader's Institute's product classification was specifically designed for content analysis of advertisements including both print and broadcast media. The classification, shown in Table 4, is composed of 24 categories which appeared to be sufficiently broad to allow for relevant product correlations while being concise enough to limit misinterpretation during judging.

\section{Table 4: Northwestern University Product Classification}

\begin{tabular}{|l|}
\hline Apparel (including shoes) \\
\hline Appliances (washing machines, toasters) \\
\hline Auto (cars, car parts, shops) \\
\hline Computer (hardware, software, services, etc.) \\
\hline Department Stores (for multiple categories, Marshall Field's, Macy's) \\
\hline Discount Stores (for multiple categories, Target, Wal-Mart, K-Mart) \\
\hline Education (schools, classes, courses) \\
\hline Electronics (TV, radio, DVD players) \\
\hline Entertainment (movies, theatre, night clubs) \\
\hline Financial (insurance, banks, loans) \\
\hline Food / Groceries (supermarkets, grocery stores, alcohol/ tobacco) \\
\hline Furniture \\
\hline Home Improvement (building materials, supplies, accessories) \\
\hline Issues (political, social, economic) \\
\hline Medicine \& Health (pharmaceuticals, hospitals, procedures, health insurance, diet) \\
\hline Restaurants \\
\hline Music (events, concerts, live performances, CDs) \\
\hline Non-profit (religious institutions/ services, volunteer, donate) \\
\hline Personal accessories (cosmetic products, jewellery, watches) \\
\hline Real Estate (rent/ sale) \\
\hline Social (relationships, dating) \\
\hline Sports (sports events, sporting goods, fitness clubs, country clubs) \\
\hline Telecommunications (phone, wireless) \\
\hline Travel (airlines, hotels, places, conferences, etc.) \\
\hline Other \\
\hline *This category was surprisingly absent from the original list and was added to the list shown \\
in the proposal for this thesis \\
\hline Source: Reader Institute - Northwestern University \\
\hline
\end{tabular}

Since this classification was specifically designed to analyse advertising media, it had been assumed that it would be sufficient for this study and it was used initially to classify the sample. However, initial results produced one highly saturated class, "personal accessories", which in the Northwestern University 
Product Classification included cosmetics products, jewellery, and watches. This category accounted for nearly a third $(28.9 \%)$ of the sample and the top four classes accounted for over half $(54.5 \%)$ of the sample. Furthermore, several product types that were encountered would not fit in any of the existing categories.

In order to solve this issue, a new product classification was devised based on a bottom up instead of a top down approach. Each of two judges provided a specific description of the product or service being advertised in each case. The specific products were then combined to produce product groups by each judge. These efforts yielded a new product classification, which produced a more even distribution and eliminated the initial skew of the data. The manner in which the products were grouped is detailed in Appendix B, and the final product classification used is shown in Table 5. 
Table 5: New Product Classification

\begin{tabular}{|l|}
\hline Apparel \& Accessories \\
\hline Appliances \& Furniture \\
\hline Business Service \\
\hline Cars \& Related \\
\hline Computer Hardware/Software \\
\hline Consumer Electronics \\
\hline Corporate \\
\hline Cosmetics \\
\hline Education \& Training \\
\hline Entertainment \\
\hline Financial Service \\
\hline Food \\
\hline Household Cleaners \\
\hline Home Décor \& Improvement \\
\hline Issues, Charities, NGO's \\
\hline Liquor \& Tobacco \\
\hline Media \\
\hline Medicines/Medical \\
\hline Personal Health \& Care \\
\hline Retail \\
\hline Telecomm \\
\hline Toiletries \\
\hline Travel \\
\hline Watches \& Jewellery \\
\hline Other Products \& Service \\
\hline
\end{tabular}

A $92.3 \%$ level of agreeability between the judges was observed, which is very high considering random chance agreement in this case is only $4 \%$. A Scott's $\mathrm{Pi}$ calculation yielded $91.8 \%$ reliability.

\subsection{APPEALS}

As described in section 3.2, the appeal refers to the selling proposition within an advertisement. It addresses the wants and needs of the consumer. An extensive list of appeals used in advertising exists as presented by Pollay (1983) and adapted by Albers-Miller and Gleb (1996) (Appendix A). The literature commonly classifies appeals more generally as being rational or emotional. The proposed work attempted to classify rational appeals as anything which was 
sourced or derived primarily from the intellect and emotional appeals as anything that derived mainly from emotions rather than reason.

Cataloguing each advertisement based on the general "rational" versus "emotional" appeal categories led to very low levels of agreeability between the judges. This led to a re-evaluation of the initial concepts and development of a new classification.

The same approach used to develop the new product classification was used to produce new categories for the appeals. A new bottom up specific appeal classification was developed as part of the thesis supervisor's broader research project, by returning to the literature on the area. The works of Kleppner (1984), Rothschild (1987), Kotler and Turner (1989), Armstrong et. al (2004), Belch, Belch, and Guolla (2005), Moriarty (2005), and Lamb et. al (2006) were consulted and a list of specific appeals was developed. The specific appeals were developed to closely relate to various rational and emotional states outlined in the literature. These states, which can be invoked in a consumer, were used as the foundation of the new categories. The nomenclature from past reșearch was retained to maintain the reasonable association of the specific appeals the broader categories of "emotional" and "rational" mental constructs.

Once developed, these classes were double-checked by this researcher and then used by two judges. From the specific appeals, emotional or rational associations were derived. The result was an $82.9 \%$ level of agreeability between the judges and a Scott's Pi of $82.2 \%$. Table 6 details the new appeal classification. 
Table 6: New Appeal Classification

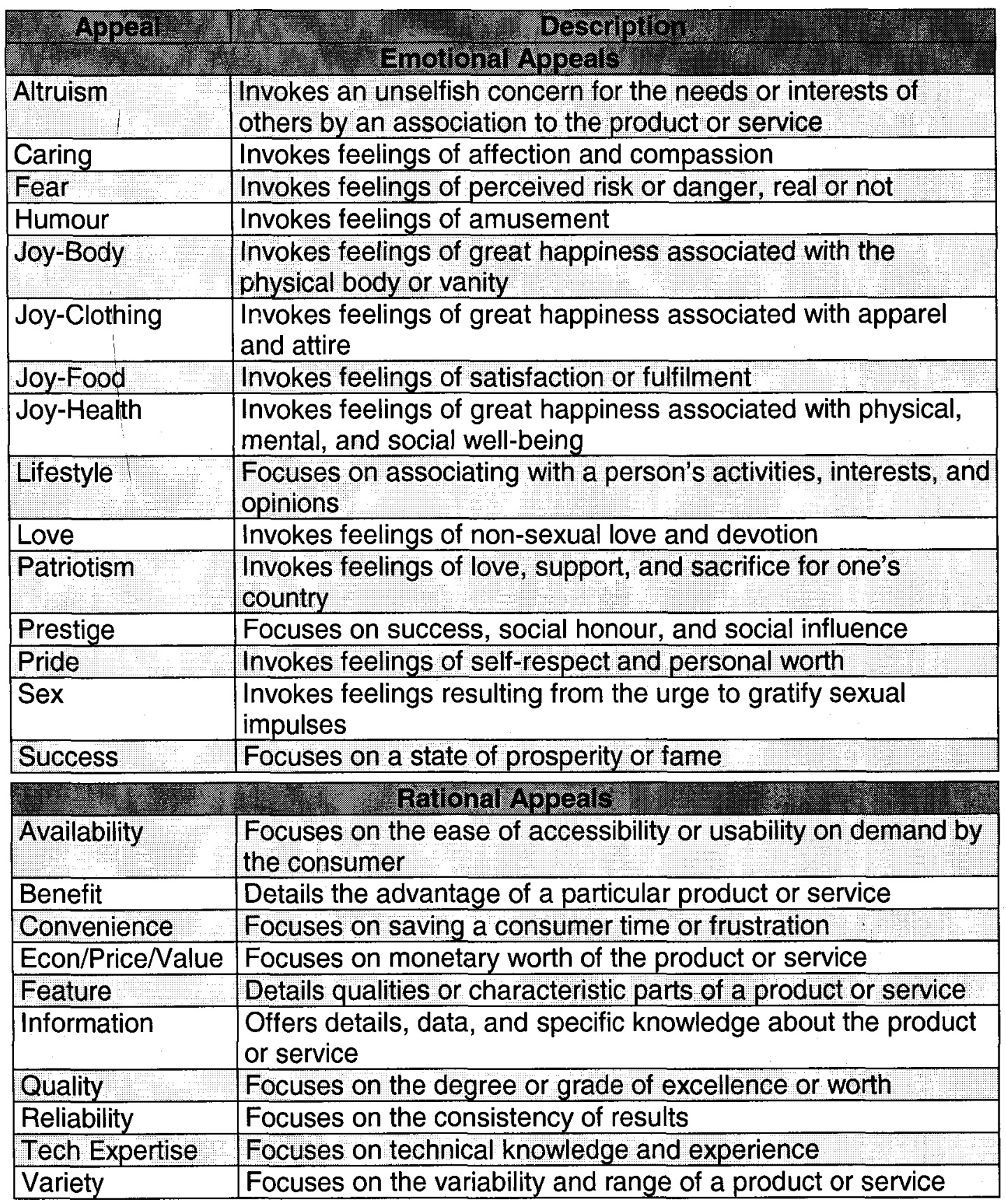

One benefit arising from the process used to develop the appeal classification was the identification of the patriotism category, which is not included in any of the general schemes in the literature, but is central in $\mathrm{PCl}$ research. 


\subsection{EXECUTION STYLES}

A key focus of this research was to determine the frequency of use of $\mathrm{PCl}$ in advertising. By cataloguing the execution style utilized in each advertisement the proportion of $\mathrm{PCl}$ used as a primary execution style as compared with other methods was determined.

The combined Kleppner-Rochschild listing of execution styles as detailed in section 3.3 was used for this content analysis: animation, celebrity spokesperson, expert spokesperson, unknown consumer, close-up, demonstration, factual, humour, product comparison, sex, situations, slice of life, and $\mathrm{PCl}$.

As with the product and appeal classifications, the implementation of the Kleppner-Rochschild listing resulted in low levels of agreement between the judges. A new execution style classification was developed. By revisiting the literature (the works identified in the above section on appeals), merging several suggestions from past research, and then working from the ground up (i.e.: from detailed description of each advertisement's execution style) to create the final categories that are shown in Table 7. 
Table 7: New Execution Style Classification

\begin{tabular}{|c|c|}
\hline Celebrity-Endorse & $\begin{array}{l}\text { Formal and explicit approval or support by a widely } \\
\text { known person }\end{array}$ \\
\hline Celebrity-General & $\begin{array}{l}\text { The inclusion of a widely known person in a non- } \\
\text { endorsement or testimonial manner }\end{array}$ \\
\hline Celebrity-Testimonial & $\begin{array}{l}\text { A statement affirming the value of a product or service } \\
\text { by a widely known person }\end{array}$ \\
\hline Consumer-Fantasy/Mood & $\begin{array}{l}\text { Association to a fictional, imaginative, or idealistic } \\
\text { prevailing psychological state }\end{array}$ \\
\hline Consumer-Image & $\begin{array}{l}\text { Associates the product or service with an iconic } \\
\text { mental representation }\end{array}$ \\
\hline Consumer-Storyline & $\begin{array}{l}\text { A plot or story associating with a product or service } \\
\text { directly involving a consumer }\end{array}$ \\
\hline Consumer-Testimonial & $\begin{array}{l}\text { A statement affirming the value of a product or service } \\
\text { by a user of that product or service }\end{array}$ \\
\hline Consumer-Vignette & $\begin{array}{l}\text { A situational depiction involving a consumer enjoying } \\
\text { the product }\end{array}$ \\
\hline Endorse-Complementary & $\begin{array}{l}\text { Approval or support of a product or service, which } \\
\text { enhances or augments the advertised product or } \\
\text { service }\end{array}$ \\
\hline Endorse-Customer & $\begin{array}{l}\text { Formal and explicit approval or support by a user of } \\
\text { that product or service }\end{array}$ \\
\hline Endorse-Employee & $\begin{array}{l}\text { Formal and explicit approval or support by an } \\
\text { employee of the company being advertised }\end{array}$ \\
\hline Endorse-Expert & $\begin{array}{l}\text { Formal and explicit approval or support by an expert } \\
\text { pertaining to the subject matter associated with the } \\
\text { product or service }\end{array}$ \\
\hline $\mathrm{PCl}$ & $\begin{array}{l}\text { Close country association to the product or service in } \\
\text { an effort to elevate its value, quality, etc. }\end{array}$ \\
\hline Product-Association & $\begin{array}{l}\text { The real or fictional correlation of a product or service } \\
\text { with another state, action, or event }\end{array}$ \\
\hline Product-Comparative & $\begin{array}{l}\text { The direct comparison of a product or service with } \\
\text { one of its competitors }\end{array}$ \\
\hline Product-Demonstration & $\begin{array}{l}\text { The demonstration of the advantages of a product or } \\
\text { service without specific reference to any competitors }\end{array}$ \\
\hline Product-Dramatization & $\begin{array}{l}\text { A plot or story associating with a product or service, } \\
\text { which focuses on the product or service without } \\
\text { directly involving a consumer }\end{array}$ \\
\hline Product-Hero & $\begin{array}{l}\text { The depiction of a product possessing abilities or } \\
\text { character far greater than typically associated with } \\
\text { such products }\end{array}$ \\
\hline Product-Illustration & $\begin{array}{l}\text { The presentation of information through dialogue or } \\
\text { depiction }\end{array}$ \\
\hline Product-Problem/Solution & $\begin{array}{l}\text { The depiction of a specific problem and its solution by } \\
\text { the product or service }\end{array}$ \\
\hline
\end{tabular}




\begin{tabular}{|l|l|}
\hline Product-Technology & $\begin{array}{l}\text { Focus on a product's superior technology or } \\
\text { technique }\end{array}$ \\
\hline Product-Torture & $\begin{array}{l}\text { The demonstration of the usage of a product or } \\
\text { service in unrealistic or extreme conditions }\end{array}$ \\
\hline Special Effects & Any and all unusual or special visual images \\
\hline Spokesperson-Employee & $\begin{array}{l}\text { A company employee serving as a regular advocate } \\
\text { of a specific product, service, or cause }\end{array}$ \\
\hline Spokesperson-Fictitious & $\begin{array}{l}\text { A fictitious or fantasy character serving as a regular } \\
\text { advocate of a specific product, service, or cause }\end{array}$ \\
\hline Straight-News/Info & $\begin{array}{l}\text { The presentation of general information about a new } \\
\text { product or service }\end{array}$ \\
\hline Straight-Sell & $\begin{array}{l}\text { A straight forward directive to purchase a product or } \\
\text { service }\end{array}$ \\
\hline
\end{tabular}

Using the revised execution style classification, an $82.5 \%$ level of agreeability was obtained between the two judges. A Scott's Pi calculation resulted in $81.8 \%$ agreeability.

\subsection{PCI CUES}

Regardless of the primary execution style used to communicate the message, or of the primary appeal as the selling proposition in each advertisement, all $\mathrm{PCl}$ cues were tabulated. In other words, the 11 different $\mathrm{PCl}$ cues that were detailed in section 2.5 were catalogued for each advertisement: brand name with location, foreign language content, cultural indication, slogans, international scenery, international symbols, product photos that include 'made-in', copyright information, URLs, contact information, and popular brand name.

An effort was made to include any cue in this research which could potentially associate a product or service with a particular geographic location. Initial analysis of the $\mathrm{PCl}$ cues within the advertisements resulted in two obvious splits, which had not been taken into account during the initial considerations for this research. The first of these was the distinction between brand and non-brand PCl cues. The 
second refers to the "prominence" of the cues, depending on whether they appeared in the main or fine print part of each advertisement.

\section{Brand and Non-Brand PCI Cues}

The initial list of potential PCI cues included brand name with location. It was discovered that a large proportion of the cues found within the advertisements belonged to this category. Therefore, country cues which were directly associated with the brand name were separated from the remainder of the main cues.

Any country indicators within the firm, brand, or otherwise directly included in the name of the product or service were classified as brand cues. This category of $\mathrm{PCl}$ cues was further separated into country reference, culture, and language cues. Brand cues also included "popular" brands. Many international brands no longer need or use additional country cues as they have an existing, strong, and recognizable association to a country. As stated earlier in section 2.5 , Toyota is an example of such a Japanese firm.

The remaining main cues, or non-brand cues, simply refer to all other forms of imagery that are independent of the firm or brand name. Table 8 provides details of the specific brand and non-brand subcategories. 
Table 8: Brand and Non-Brand PCI Cues

\begin{tabular}{|c|c|}
\hline rand Cues (Finm: Bri & End, Sub Brand) - \\
\hline Country Reference & $\begin{array}{l}\text { Inclusion of a geographic location within the brand name } \\
\text { as well as well known or popular brands (e.g.: Maybelline } \\
\text { New York, Toyota) }\end{array}$ \\
\hline Culture & $\begin{array}{l}\text { Indirect, non-linguistic, suggestive association to a country } \\
\text { (e.g.: Rising Sun Cruises) }\end{array}$ \\
\hline Language & $\begin{array}{l}\text { Linguistic country indication or use of foreign language } \\
\text { within the brand name (e.g.: Vichy Laboratoires) }\end{array}$ \\
\hline & \\
\hline Best Claims & $\begin{array}{l}\text { Direct claims of superior performance or service with } \\
\text { reference to a geographic area (e.g.: \#1 in Canada, } \\
\text { Canada's best, etc.) }\end{array}$ \\
\hline Country Reference & $\begin{array}{l}\text { Textual reference to a geographical region in the heading, } \\
\text { body text, etc. }\end{array}$ \\
\hline Culture & $\begin{array}{l}\text { Suggestive cultural depiction, which could indicate a } \\
\text { country association }\end{array}$ \\
\hline Flag & Direct depiction of a country significant symbolic flag \\
\hline Language & Linguistic country indication or the use of foreign language \\
\hline Made In & Direct or indirect inclusion of made in information \\
\hline Model & Obvious depiction of foreign people or attire \\
\hline Operations & $\begin{array}{l}\text { Indications of multinational operations (e.g.: a listing of } \\
\text { location of hotels) }\end{array}$ \\
\hline Other Brand & $\begin{array}{l}\text { Inclusion of any non-related brand, which contains a } \\
\text { geographic location within it }\end{array}$ \\
\hline Scenery (Man Made) & $\begin{array}{l}\text { Imagery associated with a geographic region, which is man } \\
\text { made (e.g.: Eiffel Tower, Statue of Liberty, etc.) }\end{array}$ \\
\hline Scenery (Nature) & $\begin{array}{l}\text { Imagery associated with a geographic region, which is not } \\
\text { man made (e.g.: Grand Canyon, Niagara Falls, etc.) }\end{array}$ \\
\hline Service & $\begin{array}{l}\text { Indication of local operations with service to multiple } \\
\text { geographic locations (e.g.: serving all of North America) }\end{array}$ \\
\hline & \\
\hline
\end{tabular}

\section{Prominent and Fine Print PCI Cues}

Country cues that appeared in the heading, slogan, body text, and main advertisement visuals were classified as "prominent". On the other hand, those that appeared as fine print in the form of legal explanations or other technical details (usually at the bottom of the page and in small font) were considered "fine print" cues. 
The distinction between prominent and fine print cues was made in order to prevent inflated data resulting from cues which may have been included for technical and legal reasons as opposed to for direct country association purposes.

Brand cues may be both prominent and fine print; however, many of the nonbrand cues cannot be fine print (e.g.: flag, model, scenery, etc.). Therefore, separate fine print subcategories for the non-brand cues were developed and are described in Table 9.

Table 9: Fine Print PCI Cues

\begin{tabular}{|l|l|}
\hline \multicolumn{1}{|c|}{ PCl Cue } & \multicolumn{1}{c|}{ Description } \\
\hline URL (body) & $\begin{array}{l}\text { Geographic reference in the body of the URL (e.g.: } \\
\text { www.canada.org) }\end{array}$ \\
\hline URL (suffix \& email) & $\begin{array}{l}\text { Geographic reference in the suffix of the URL (e.g.: .ca, } \\
\text {.co.uk, etc.) }\end{array}$ \\
\hline Address & Direct geographic contact information in the fine print \\
\hline Other Brand & $\begin{array}{l}\text { Inclusion of any non-related brand, which contains a } \\
\text { geographic location within it }\end{array}$ \\
\hline Country Reference & Textual reference to a geographical region in the fine print \\
\hline
\end{tabular}

An iterative process was utilised for the cataloguing of the $\mathrm{PCl}$ cues. The counting of country cues was an objective exercise and as such it was not necessary to calculate levels of agreement. The judges checked and doublechecked the counts in order to minimize the possibility of technical errors and human error. All judges were of higher education; it is reasonable to assume that their individual counts are as accurate as is possible.

To summarize, $\mathrm{PCl}$ cues are separated into brand and non-brand cues. Each of these can be further separated into prominent and fine print versions. Brand cues refer to $\mathrm{PCl}$ cues which are a direct part of the name of the firm, brand, product, or service. The remaining main cues are classified as non-brand cues and include flags, scenery, linguistic references with the advertisement, etc. 


\subsection{INTENSITY OF PCI USAGE}

This research evaluated the existence of 11 different $\mathrm{PCl}$ cues as detailed in the previous section. A three step process was used to evaluate the intensity of $\mathrm{PCl}$ usage.

First, all country cues within an advertisement were added. In the event of a particular cue being used many times within a single advertisement, each cue was counted separately (e.g.: an advertisement that had two pictures of a product box with the words L'Oréal Paris on it was counted as two PCl cues).

Second, in order to normalize this data to allow for effective analysis, a simple equation was utilized. Using the raw intensity scores, the range was determined by subtracting the lowest score from the highest and dividing the result by ten (i.e.: $\left[X_{\max }-X_{\min }\right] / 10$, where $X$ represents the raw data values) to achieve ten equal sized categories.

Lastly, each advertisement was assigned a score between 0 and 10 based on the category corresponding to its number of cues.

\subsection{RELATIVE STRENGTH OF PCI USAGE}

The overall strength of $\mathrm{PCl}$ usage in each advertisement was determined by a 7-point scale. This was a subjective analysis by the judges on the advertiser's use of $\mathrm{PCl}$ within each specific advertisement. The scale ranged from 1-very weak to 7-very strong. Advertisements which did not include any $\mathrm{PCl}$ cues were left blank (0). In assigning a value to each advertisement in the research, the concerns mentioned in section 5.6 were taken into consideration. Specifically this referred to the use of URLs, photos of products containing 'made-in' information, and 
copyright information, which, although they may be signals of particular country associations, are not examples of strong country cues since their inclusion in an advertisement may be the result of legal or other considerations.

\subsection{ANALYSIS}

The country with which each cue was associated was a point of interest in this research. In order to simplify the data results, countries were grouped and classification was limited to Canada, the USA, worldwide associations (international, global, etc.), other developed countries, and transitional countries. This distinction was determined using the listings provided by the World Bank and International Monetary Fund (please see Appendix $C$ for details).

The question of primary interest, which was addressed in this research, was to examine the overall usage of country image in magazine advertisements whether as an appeal, execution style, or an independent cue. These questions were addressed through the use of frequency tables and cross-tabulations of the sample (please see chapter Chapter 6 for research question details). Pearson chisquared statistics were used, where applicable, on the cross-tabulations to highlight any significant correlations, which existed between the use of $\mathrm{PCl}$ and product, publication, country of advertising, country of origin, specific country cues, etc.

In current marketing research, chi-square tests for significance are readily accepted as being sufficient to prove significance. Research conducted by Decady and Thomas (2000) has proposed that these findings may be too liberal, however, and have offered alternative statistics which should be employed on multiplecategory response samples. The sample used in this research can be considered a 
multiple-category response sample since each advertisement may yield multiple cues and thus the sampling will not yield a random sample of the population. By treating the sample as random and using Pearson's chi-square, the statistical testing was liberal in accepting significance in differences among variables. This was considered acceptable since the majority of this research was interested in cases where the statistical significance was not present in which case the chisquare test is conservative.

The final stage of analysis was a qualitative discussion and overview of patterns and relationships, which were observed during the judging process, which may not have been captured by the quantitative measurement of the sample. This included specific examples of differences and similarities of advertisements within American and Canadian publications, overall usage of cues, etc.

It is important to note that in this research, it is irrelevant whether any $\mathrm{PCl}-$ related cues were perceived, acted upon, or even correctly associated by a consumer. The focus of this research is what the advertiser has done in an effort to associate a product or service to a country both passively (through the unconscious inclusion of $\mathrm{PCl}$ cues) and actively (through the conscious and premeditated inclusion of $\mathrm{PCl}$ cues). 


\section{CHAPTER 8 DATA ANALYSIS AND RESULTS}

This chapter will begin by providing general demographic information about the sample, followed by an analysis of the various components as detailed by the research question chapter. Execution style, appeals used, and their correlation will be discussed as they relate to $\mathrm{PCl}$. This will be followed by an examination of the individual country cues used within magazine advertising, and the chapter will conclude by examining the intensity and strength of $\mathrm{PCl}$ cues within the sample.

It is critical to note that although the sample offers detailed information on other aspects of magazine advertising, the focus of this research is limited to country association with respect to execution style, appeals, and overall advertising strategies. While summary data will be offered on the sample in its entirety for both execution styles and appeals, reference to non- $\mathrm{PCl}$ issues should only be considered exploratory and incidental to the main objective of this study.

\subsection{DEMOGRAPHIC INFORMATION ON THE SAMPLE}

This section details the design of the sample in terms of magazines used, distribution of advertisements, advertisers within the sample, and finally products advertised. Throughout, a comparison is maintained between Canadian and American publications where similarities and differences of interest are highlighted and discussed.

The total sample contained 3008 advertisements from four Canadian and four American publications. These publications were matched by genre: business, fashion, lifestyle, and news. The specific magazine totals by magazine type and country are listed in Table 10. As the table indicates, the American publications are 
larger in all but the lifestyle case where Canadian Living produced more advertisements than Family Circle. In total, the consumer-oriented magazines (fashion and lifestyle) accounted for $65 \%$ of the sample, while those oriented more to a business audience (business and news) accounted for $35 \%$.

Table 10: Sample Size

\begin{tabular}{|l|l|r|l|l|r|}
\hline Magazine & \multicolumn{3}{|c|}{ Canada } & \multicolumn{3}{c|}{ USA } & Tolar \\
\hline Business & Canadian Business & 231 & Fortune & 501 & 732 \\
\hline News & Maclean's & 105 & Time & 225 & 330 \\
\hline Fashion & Glow & 441 & Glamour & 522 & 963 \\
\hline Lifestyle & Canadian Living & 577 & Family Circle & 406 & 983 \\
\hline Total & & 1354 & & 1654 & $\mathbf{3 0 0 8}$ \\
\hline
\end{tabular}

The distribution of advertisements as a percentage of the content of each magazine type as a whole has been included in Table 11. While the overall average advertisement percentage of the total is similar in both Canadian and American publications, it should be noted that Canadian-published Glow has a much higher advertisement to content ratio than American-published Glamour (61.3\% versus $42.3 \%)$. By contrast, Canadian published Maclean's has a much lower ratio than American published Time (28.9\% versus $51.2 \%$ ).

\section{Table 11: Average Advertisements per Magazine}

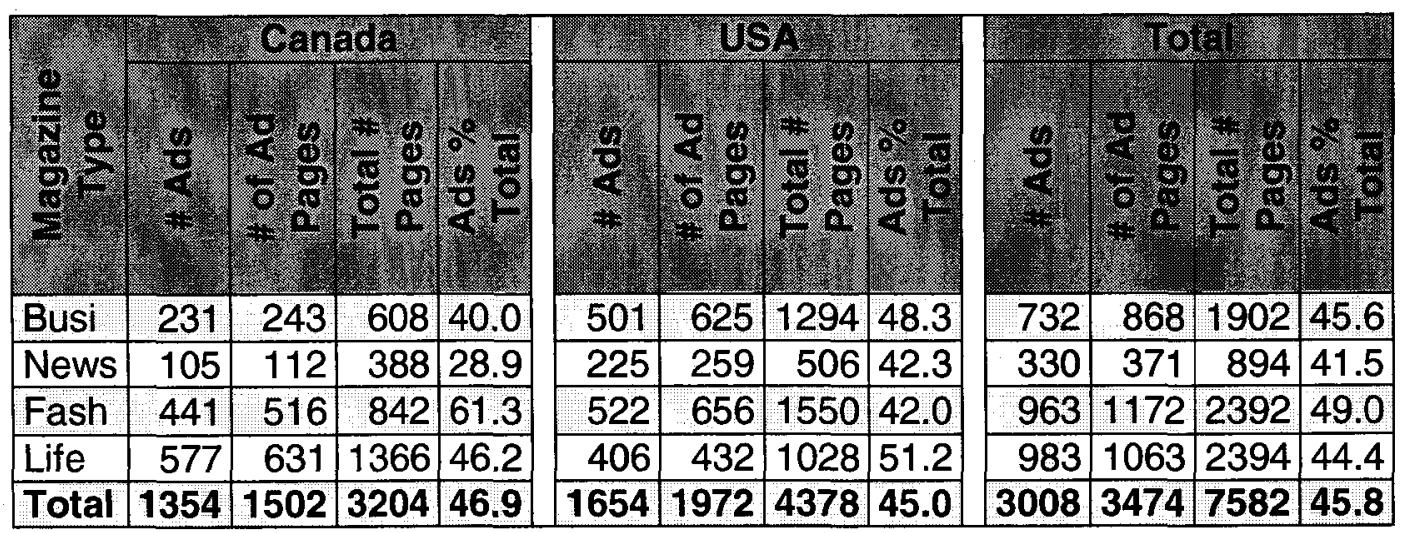

The differences observed between the numbers of advertisements and number of advertisement pages in Table 11 are due to the inclusion of 
advertisements which span more than one page. The content analysis literature to date does not offer any suggestions of how to deal with multiple paged advertisements; thus, to address this, different advertisement page counts were recorded and are summarized in Table 12.

Table 12: Percentage of Single vs. Multiple Page Advertisements

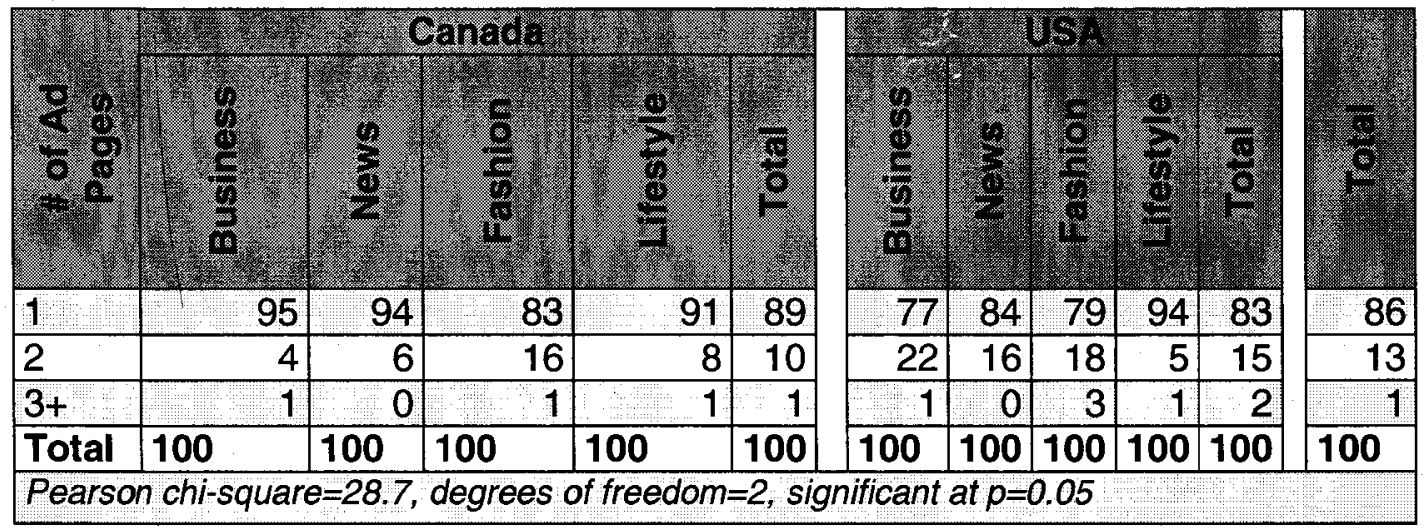

Statistically, a Pearson chi-square results in a significant difference between the distribution of single and multiple page advertisements in Canadian and American publications. What can be noted from these results is that Canadian publications tend to have multiple page advertisements less frequently $(10.3 \%$ of all Canadian advertisements use multiple pages), particularly in the business magazine selected for this sample (Canadian Business, $5 \%$ multiple page versus Fortune, $23 \%$ ). The Canadian fashion magazine, Glow, is the leading multiple page representative for the Canadian sample (17\% multiple page advertisements) which is still lower than its American counterpart (Glamour, 21\%). The larger proportion of multiple-page spreads overall in American publications may be attributed to the fact that the USA is a wealthier and larger market compared to Canada.

As an important component of this research it is essential to be aware of who is advertising within Canadian and American magazines. Within the sample, firms 
from 25 countries were catalogued as advertising in at least one of the countries. Canada had 15 while the USA had 23. The detailed frequency breakdown is provided in Table 13, which has been grouped by developed and transitional countries as was described earlier in section 7.9. The rank associated with each country represents the number of advertisements printed in each of the two countries within the sample. 
Table 13: Frequency of Advertiser's Home Countries

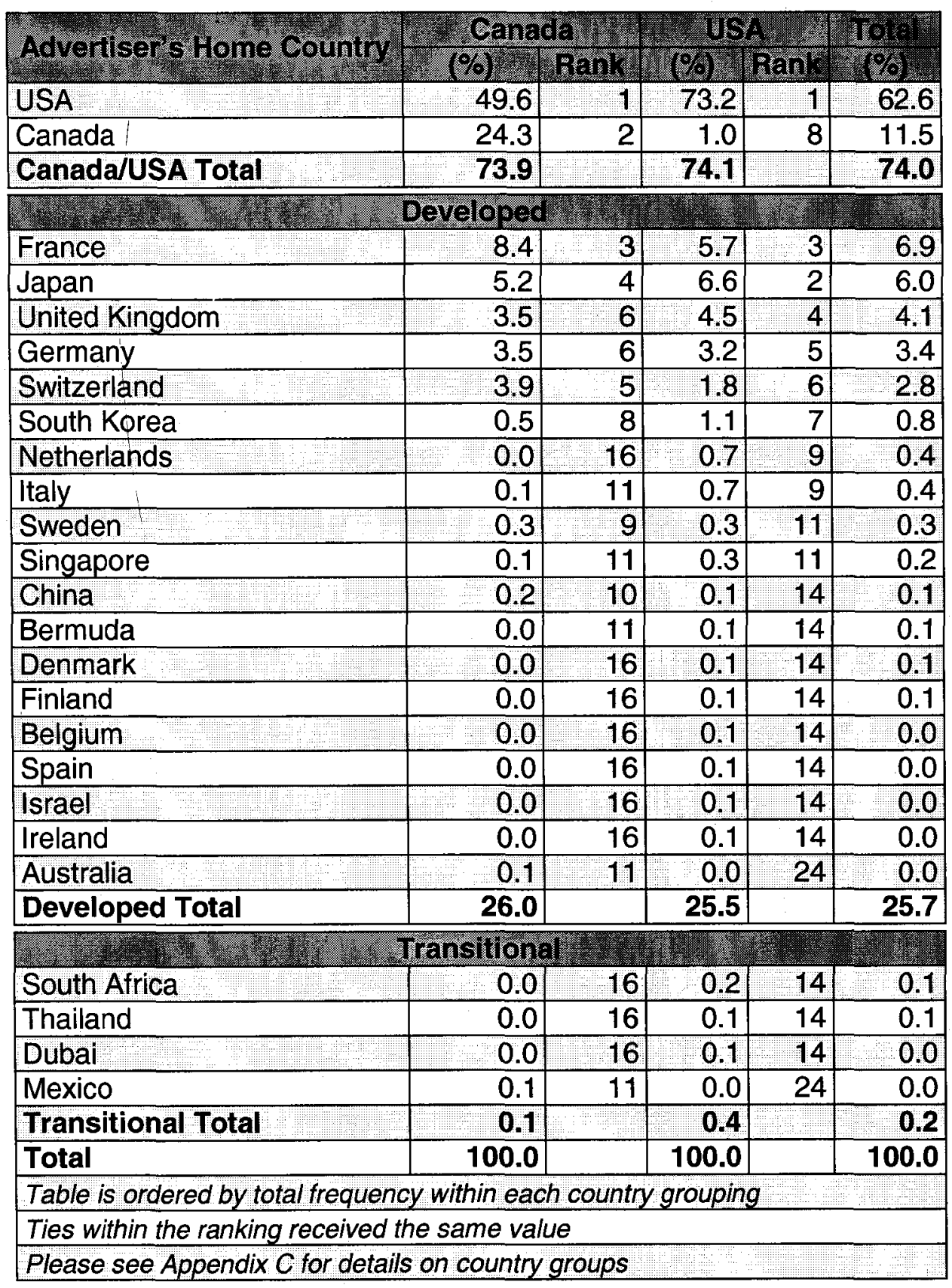

From the above table it should be highlighted that Mexican and Australian firms advertised only in Canadian publications and firms from the Netherlands, South Korea, Denmark, Ireland, Italy, Spain, Belgium, South Africa, Thailand, and Dubai advertised only in the USA. 
It is not surprising to find that American companies are the most prominent advertisers in Canadian and American publications and thus overall due to the overwhelming size and wealth of many of the leading American firms. It is expected to find Canada ranked second in Canadian publications and overall since one could assume that a large proportion of the advertisers in Canadian publications would be from Canada; however, it is worth mentioning that Canada ranks as the $8^{\text {th }}$ advertiser in American publications. Japan, France, the United Kingdom, Germany, Switzerland, and South Korea (in order) all place more advertisements in American publications than Canada. A potential explanation for this is the overall smaller size of Canadian corporations compared to various other international and American companies, and the possibility that Canadian firms may be using media other than magazines to advertise their products and services within America.

In selecting magazines which target business as well as consumers, the intent was to obtain a sample that would offer a reasonable amount of variance in type of advertisements. As detailed in Table 14, the sample has a skew to consumer related products and services overall. However, as the business and news magazines compose only $35 \%$ of the sample, having $16.5 \%$ of the advertisements within the sample directed to business consumers is substantial. The American publications, however, have over a fifth of their advertisements targeted to business customers.

\section{Table 14: Distribution of Business and Consumer Advertisements}

\begin{tabular}{|l|r|r|r|}
\hline Ad Type & Canada $(\%)$ & USA $(\%)$ & Total $\%$ \\
\hline Business & 9.7 & 22.1 & 16.5 \\
\hline Consumer & 90.3 & 77.9 & 83.5 \\
\hline Total & 100.0 & 100.0 & 100.0 \\
\hline
\end{tabular}


With respect to the types of organizations that are advertising, as Table 15 describes, the vast majority within the sample are private sector firms.

Table 15: Distribution of Advertising Organization Type

\begin{tabular}{|l|r|r|r|}
\hline Organization Type & Canada (\%) & USA (\%) & Total $\%$. \\
\hline Private Sector & 93.1 & 96.0 & 94.7 \\
\hline Association & 3.0 & 0.8 & 1.8 \\
\hline Government & 2.1 & 1.2 & 1.6 \\
\hline NGO & 0.9 & 1.9 & 1.4 \\
\hline Educational Institute & 0.9 & 0.1 & 0.5 \\
\hline Total & 100.0 & 100.0 & 100.0 \\
\hline Table is ordered by total frequency \\
\hline
\end{tabular}

Finally, an overview of the products observed is useful in understanding the sample. Table 16 provides the details of the frequency distribution of advertised products. 
Table 16: Frequency Distribution of Products Advertised

\begin{tabular}{|c|c|c|c|c|c|}
\hline \multirow{2}{*}{ (2) Product Class } & \multicolumn{2}{|c|}{ Canaba } & \multicolumn{2}{|c|}{ 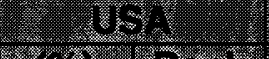 } & \multirow{2}{*}{ 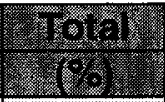 } \\
\hline & $1 \% 12$ & Rank & (\%). & Rank & \\
\hline Cosmetics & 15.6 & 1 & 9.1 & 1 & 12.0 \\
\hline Food & 10.5 & 4 & 8.8 & 2 & 9.6 \\
\hline Personal Health \& Care & 14.0 & 2 & 5.8 & 8 & 9.5 \\
\hline Toiletries & 10.9 & 3 & 6.3 & 6 & 8.4 \\
\hline Financial Service & 3.8 & 7 & 8.0 & 3 & 6.1 \\
\hline Medicines/Medical & 3.3 & 9 & 8.0 & 3 & 5.9 \\
\hline Cars \& Related & 4.4 & 5 & 5.8 & 8 & 5.2 \\
\hline Computer Hardware/Software & 3.1 & 10 & 6.4 & 5 & 4.9 \\
\hline Business Service & 2.4 & 14 & 6.0 & 7 & 4.4 \\
\hline Telecomm & 3.1 & 10 & 4.1 & 10 & 3.7 \\
\hline Retail & 4.3 & 6 & 2.5 & 14 & 3.3 \\
\hline Travel & 2.8 & 12 & 3.4 & 12 & 3.1 \\
\hline Issues, Charities, NGO's & 3.4 & 8 & 2.5 & 14 & 2.9 \\
\hline Apparel \& Accessories & 1.0 & 22 & 4.0 & 11 & 2.7 \\
\hline Entertainment & 2.4 & 14 & 2.5 & 14 & 2.5 \\
\hline Household Cleaners & 2.8 & 12 & 1.6 & 21 & 2.1 \\
\hline Other Products \& Service & 1.8 & 17 & 2.1 & 18 & 2.0 \\
\hline Home Décor \& Improvement & 1.8 & 17 & 2.1 & 18 & 1.9 \\
\hline Corporate & 0.7 & 23 & 2.7 & 13 & 1.8 \\
\hline Media & 2.1 & 16 & 1.4 & 22 & 1.7 \\
\hline Liquor \& Tobacco & 0.4 & 24 & 2.5 & 14 & 1.6 \\
\hline Consumer Electronics & 1.6 & 17 & 1.1 & 23 & 1.3 \\
\hline Watches \& Jewellery & 0.4 & 24 & 2.0 & 20 & 1.3 \\
\hline Appliances \& Furniture & 1.8 & 17 & 0.5 & 25 & 1.1 \\
\hline Education \& Training & 1.5 & 21 & 0.6 & 24 & 1.0 \\
\hline Total & 100.0 & & 100.0 & & 100.0 \\
\hline Table is ordered by total frequency & $2 \mathrm{al}$ & & & & \\
\hline Ties within the ranking received th & me valu & & & & \\
\hline
\end{tabular}

The cosmetics product class being observed as the most frequently advertised in the sample is understandable since the majority of the advertisements were obtained from consumer magazines, which are most likely to advertise such products. The same explanation can be used for the personal health \& care and toiletries classes, while the food class is high on the list due to its abundant use within lifestyle magazines, which represent the second largest proportion of advertisements in the sample. 
The overall frequency distribution of product classes is reasonable based on the distribution of advertisements obtained from the varying magazine types.

Further analysis and details of the PCl-specific components and their distribution throughout the sample with respect to country of publication, magazine, advertiser, and product class will be discussed in the subsequent sections.

\subsection{APPEAL ANALYSIS}

The advertising appeal refers to the reason why a consumer will accept and purchase a product or service. This section details the overall distribution of appeals within the sample and subsequently focuses on patriotism and its relationship with other variables.

The use of the various appeals is detailed in Table 17. It is reasonable that an analysis of the appeals resulted in the joy-body appeal being ranked first overall since a large majority of the sample was composed of ads from fashion and lifestyle magazines, and therefore cosmetic, health, etc. advertisements, which are more likely to use such an appeal. 
Table 17: Frequency Distribution of Appeals

\begin{tabular}{|c|c|c|c|c|c|c|c|}
\hline \multirow{2}{*}{\multicolumn{2}{|c|}{ (1) Apeal }} & \multirow{2}{*}{\multicolumn{2}{|c|}{ Canada }} & \multicolumn{2}{|c|}{$10 \mathrm{CH}$} & \multicolumn{2}{|c|}{2.301013} \\
\hline & & & & $\%$ & pronk & $(\%) \pi$ & \\
\hline & Joy-Body & 17.1 & 1 & 8.8 & 4 & 12.6 & 1 \\
\hline & Lifestyle & 10.7 & 3 & 9.5 & 2 & 10.0 & 2 \\
\hline & Humour & 8.1 & 5 & 10.8 & 1 & 9.6 & 4 \\
\hline & Caring & 4.3 & 8 & 3.0 & 13 & 3.6 & 10 \\
\hline & Fear & 2.4 & 12 & 3.5 & 11 & 3.0 & 11 \\
\hline & Joy-Health & 2.4 & 12 & 3.4 & 12 & 2.9 & 12 \\
\hline & Sex & 2.7 & 11 & 2.6 & 14 & 2.7 & 13 \\
\hline 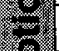 & Prestige & 1.3 & 16 & 3.8 & 9 & 2.7 & $\overline{13}$ \\
\hline & Altruism & 2.1 & 14 & 2.2 & 15. & 2.2 & 15 \\
\hline & Love & 1.3 & 16 & 1.6 & 18 & 1.5 & 17 \\
\hline & Pride & 1.3 & 16 & 1.3 & 21 & 1.3 & 18 \\
\hline & Success & 1.3 & 16 & 1.2 & 22 & 1.2 & 20 \\
\hline & Joy-Clothing & 0.2 & 24 & 1.9 & 16 & 1.2 & 20 \\
\hline & Joy-Food & 0.7 & 22 & 0.8 & 24 & 0.8 & 23 \\
\hline & Patriotism & 0.4 & 23 & 1.1 & 23 & 0.8 & 23 \\
\hline & notional Total & 56.1 & & 55.6 & & 55.8 & \\
\hline & Benefit & 11.0 & 2 & 8.8 & 4 & 9.8 & 3 \\
\hline & Information & 6.9 & 6 & 9.5 & 2 & 8.3 & 5 \\
\hline & Feature & 9.6 & 4 & 6.8 & 6 & 8.0 & 6 \\
\hline 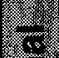 & Econ/Price/Value & 4.3 & 8 & 5.5 & 7 & 5.0 & 7 \\
\hline & Quality & 3.5 & 10 & 5.3 & 8 & 4.5 & 8 \\
\hline 9 & Convenience & 4.6 & 7 & 3.6 & 10 & 4.1 & 9 \\
\hline ff & Variety & 1.8 & 15 & 1.8 & 17 & 1.8 & 16 \\
\hline & Reliability & 1.2 & 20 & 1.5 & 19 & 1.3 & 18 \\
\hline & Tech Expertise & 0.9 & 21 & 1.5 & 19 & 1.2 & 20 \\
\hline & Availability & 0.1 & 25 & 0.2 & 25 & 0.2 & 25 \\
\hline & ational Total & 43.9 & & 44.4 & $=$ & 44.2 & \\
\hline To & tal & 100.0 & & 100.0 & & 100.0 & \\
\hline
\end{tabular}

Several of the appeals ranked similarly across Canadian and American publications. However, when the individual frequency is evaluated, in many cases there is an obvious tendency of specific appeals occurring more frequently in Canada or the USA. Joy-body is used nearly twice as often in advertisements in Canadian publications, and the feature and benefit appeals also occurred more often. In the US, prestige was used nearly twice as much as in Canada, and the humour and information appeals also occurred more frequently in American publications than in Canadian ones. 
As Table 17 demonstrates, patriotism is the lowest emotional appeal used and ties for $3^{\text {rd }}$ least used overall. In a sample of 3008 only 23 occurrences of patriotic appeals were observed $(0.8 \%)$. This small number does not allow any substantial analysis. However, several interesting patterns were observed from an exploratory viewpoint and are detailed later in this section.

It is interesting to note that the distribution of emotional and rational appeals across Canadian and American publications, as well as the overall total is very similar. However, a Pearson chi-square calculation resulted in a significant difference between the usages of appeals across the country of publication at the $p=0.05$ level. This is particularly interesting since, as Table 18 indicates, there is no statistically significant difference between the distribution of rational and emotional appeals across the countries of publication even though individual usage of appeals differs.

\section{Table 18: Use of Emotional/Rational Appeals}

\begin{tabular}{|c|c|c|c|c|c|c|c|}
\hline \multirow{2}{*}{ Appeal } & & Canacto & & & USt & \multicolumn{2}{|r|}{ Totel } \\
\hline & No & Expected & Chi: & N & Expected & al & \\
\hline Emotional & 760 & 755.8 & 0.02 & 919 & 923.2 & 0.02 & 1679 \\
\hline Rational & 594 & 598.2 & 0.03 & 735 & 730.8 & 0.02 & 1329 \\
\hline Total & 1354 & & & 1654 & & & 3008 \\
\hline & & & & $m=1$ & an & 0.05 & \\
\hline
\end{tabular}

The use of the patriotic appeal when compared against the other appeals indicated a significant difference in its frequency of use across Canadian and American publications as depicted in Table 19. The Pearson chi-square was significant at a $p=0.05$ level. The higher frequency of patriotic appeals used in advertisements within the USA is interesting and possibly due to the commonly accepted overall patriotic attitude of Americans. 
Table 19: Use of Patriotic Appeal

\begin{tabular}{|c|c|c|c|c|c|c|c|}
\hline & & Canado & & & & & nol \\
\hline & 70 & Expected & (chit: & Niv: & pexperted & (2) & (1) \\
\hline Patriotism & 5 & 10.4 & 2.8 & 18 & 12.7 & 2.3 & 23 \\
\hline Other & 1349 & 1343.7 & 0.1 & 1636 & 1641.4 & 0.0 & 2985 \\
\hline Total & 1354 & & & 1654 & 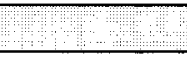 & & 3008 \\
\hline
\end{tabular}

When cross-tabulated against the product classes, only eight of the 25 classes were advertised using patriotic appeals with corporate and home décor \& improvement using them the most and in similar amounts. Table 20 lists the eight product classes, which used the patriotic appeal and provides the percentage of the advertisements within that class, which used it. It is curious that corporate advertising uses a relatively large amount of patriotic appeals. This may be due to the limited number of appeals that can be used when a specific product or service is not being advertised.

\section{Table 20: Use of Patriotic Appeal by Product Classification}

\begin{tabular}{|l|c|}
\hline \multicolumn{1}{|c|}{ Productclass } & \% of Al Appeals USEd \\
\hline Corporate & 5.5 \\
\hline Home Décor \& Improve & 5.2 \\
\hline Entertainment & 4.0 \\
\hline Issues, Charities, NGO'S & 3.5 \\
\hline Financial Services & 3.3 \\
\hline Cars \& Related & 2.0 \\
\hline Food & 0.4 \\
\hline Cosmetics & 0.3 \\
\hline $\begin{array}{l}\text { Please see Error! Reference source not found. for } \\
\text { more details }\end{array}$ \\
\hline
\end{tabular}

Of all the home countries of advertisers within the sample, only three used the patriotic appeal as detailed in Table 21. What is interesting to note is that the proportion of patriotic use compared to other appeals being used is not statistically significant. This indicates that the home country of the advertiser is a trivial variable in the use of patriotic appeal. 


\section{Table 21: Use of Patriotic Appeal by Advertiser's Home Country}

\begin{tabular}{|c|c|c|c|c|c|c|c|}
\hline \multirow{2}{*}{$\begin{array}{l}\text { Advertser S } \\
\text { Home County }\end{array}$} & \multicolumn{3}{|c|}{ Patriotism } & \multicolumn{2}{|r|}{ Ohipe : } & \multirow{2}{*}{ chil } & \multirow{2}{*}{$\frac{1969}{112}$} \\
\hline & N. & Expected: & Ch: & X & Expected & & \\
\hline Canada & 3 & 3.4 & 0.0 & 342 & 341.6 & 0.0 & 345 \\
\hline United Kingdom* & 3 & 1.2 & 2.7 & 120 & 121.8 & 0.0 & 123 \\
\hline USA & 17 & 18.4 & 0.1 & 1865 & 1863.6 & 0.0 & 1882 \\
\hline Total & 23 & & & 2327 & & & 2350 \\
\hline \multicolumn{8}{|c|}{ Note: only countries, which used patriotic appeals, were included in these findings. } \\
\hline \multicolumn{8}{|c|}{ Pearson chi-square $=2.85$, degree of freedom $=2$, significant at $p=0.05$} \\
\hline $\begin{array}{l}{ }^{*} A d v e r t i s e r ' s \text { from } L \\
\text { patriotism for } 1 / 3\end{array}$ & & & & & & & \\
\hline
\end{tabular}

In the case of the United Kingdom, the advertisements, which used patriotic appeals, associated with one of the counties of publication (Canada or the US) rather than the advertiser's country of origin (UK).

The specific details of which firms use patriotic appeals has very limited use as part of this research; however, since this study is part of a larger research project, it was felt that the usage of patriotic appeals by specific firms should be documented. Table 22 provides information on the top firms within the sample, which used patriotic appeals. While the majority of these firms use patriotic appeal in only one advertisement within the sample, it is interesting to note that in many cases, this is the only advertisement observed in the sample. Specific reasons as to why many of these organizations use the patriotic appeal for their only advertisement are difficult to guess; however, this is beyond the scope of the research. 
Table 22: Top Organizations to use Patriotic Appeal

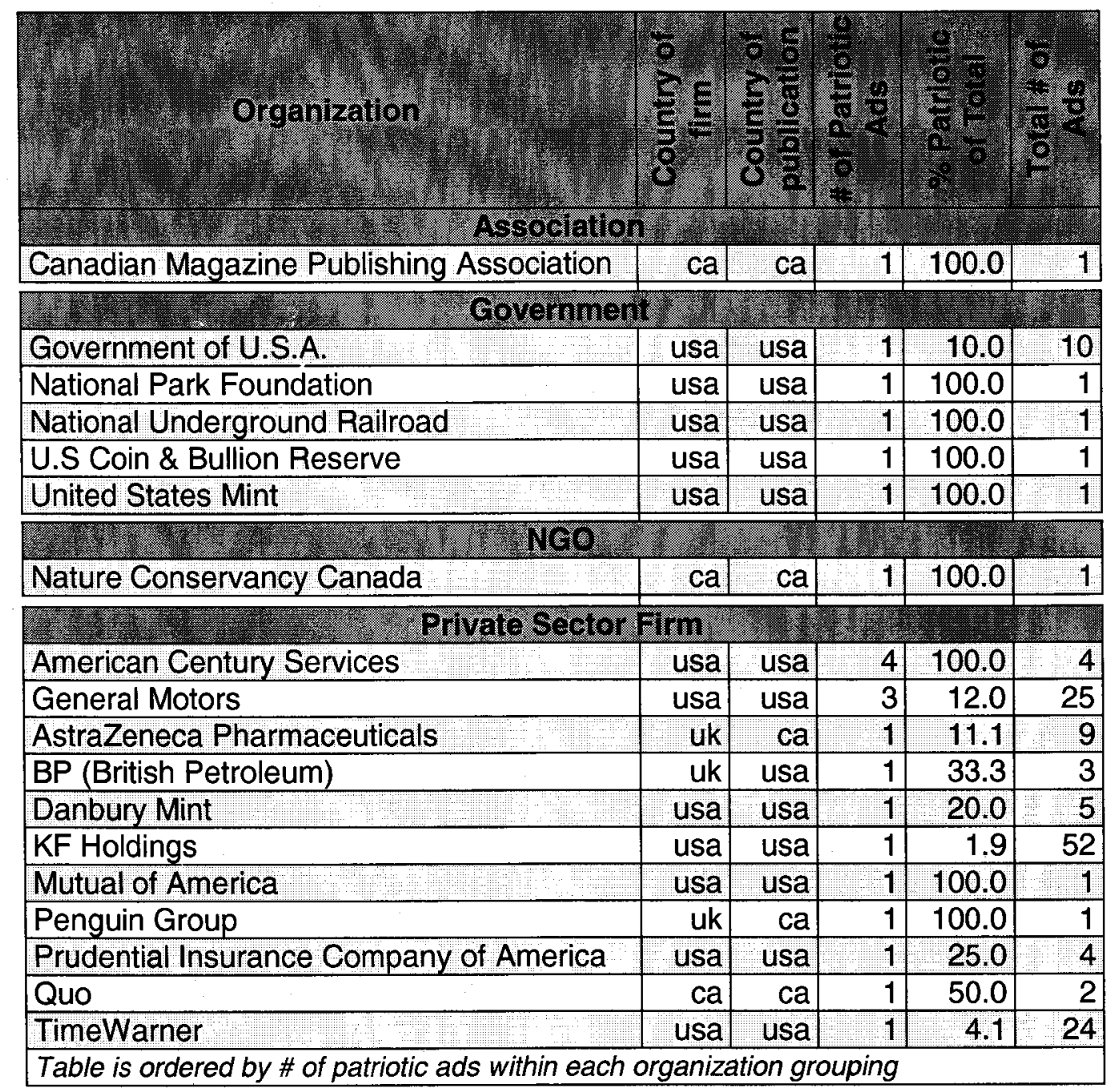

As a final component in determining the frequency and distribution of appeals used within the sample, and specifically the patriotic appeal, Pearson chi-square calculations were used to highlight significant differences associated with magazine types. Table 23 offers a summary of the test results across all the magazine types. For both the case when all the appeals were considered individually and the specific case when the patriotic appeal was considered against all other appeals used, the test proved to be significant at the $p=0.05$ level. This is not surprising as the magazine type would be expected to have an impact on the use of appeals. One would expect that business and news magazines would be more likely to use 
rational appeals while fashion and lifestyle magazines would be more likely to use emotional appeals.

\section{Table 23: Use of Appeals across Magazine Types}

\begin{tabular}{|l|r|r|r|}
\hline & ChI' & DF & P=0.051 \\
\hline All Appeals & 1466.4 & 168 & Significant \\
\hline Only Patriotic vs. Others & 41.3 & 3 & Significant \\
\hline Please see Appendix D for details and calculations \\
\hline
\end{tabular}

Similar calculations as listed above were conducted between the Canadian and American versions of each magazine type. The results of the Pearson chisquare tests are summarized in Table 24. What is very interesting is that the country of publication is a significant factor when all the appeals are considered, but when the patriotic appeal is isolated and compared to the remainder of the appeals the result is not significant. This indicates that the distribution of patriotic appeals within specific magazine types is similar. This may be due to the relatively low number of occurrences of patriotic appeal being used and causing the nonsignificant statistical result as the frequency approaches zero.

\section{Table 24: Use of Appeals within Magazine Types}

\begin{tabular}{|c|c|c|c|c|c|c|c|c|c|c|c|c|}
\hline & \multicolumn{3}{|c|}{ Business } & \multicolumn{3}{|c|}{ News } & \multicolumn{3}{|c|}{ Lifestyla } & \multicolumn{3}{|c|}{ Folmor } \\
\hline & $\frac{0}{4}$ & $\mathrm{~s}$ & $\frac{8}{8}$ & $\sqrt{8}$ & $\frac{11}{0}$ & $\frac{3}{8}$ & $\frac{8}{3}$ & $\frac{4}{8}$ & . & $\frac{1}{1}$ & (i) & . \\
\hline All Appeals & 54.9 & 25 & sig & 37.9 & 25 & sig & 94.2 & 25 & sig & 112.3 & 25 & sig \\
\hline $\begin{array}{l}\text { Only Patriotic } \\
\text { vs Others }\end{array}$ & 2.3 & 1 & not & 0.3 & 1 & not & 0.2 & 1 & not & 0.8 & 1 & not \\
\hline
\end{tabular}

As mentioned earlier, the relatively small proportion of advertisement, which used the patriotic appeal makes it impossible to make any specific claims about its use; however this section has been included as an exploratory stepping stone for future specific research. 


\subsection{EXECUTION STYLE ANALYSIS}

This section offers analysis pertaining to the execution style used within each advertisement. The execution style refers to the manner in which the message is communicated to the consumer. An overview of all the execution styles is provided and specific analysis in the use of $\mathrm{PCl}$ as an execution style follows.

Table 25 below provides a ranking of the usage of each execution style in Canadian and American publications as well as each style's ranking overall. The execution styles were grouped into common themes: product, consumer, straight forward, celebrity, $\mathrm{PCl}$, endorsement, spokesperson, and finally special effect in order to assess general patterns. 
Table 25: Frequency Distribution of Execution Style

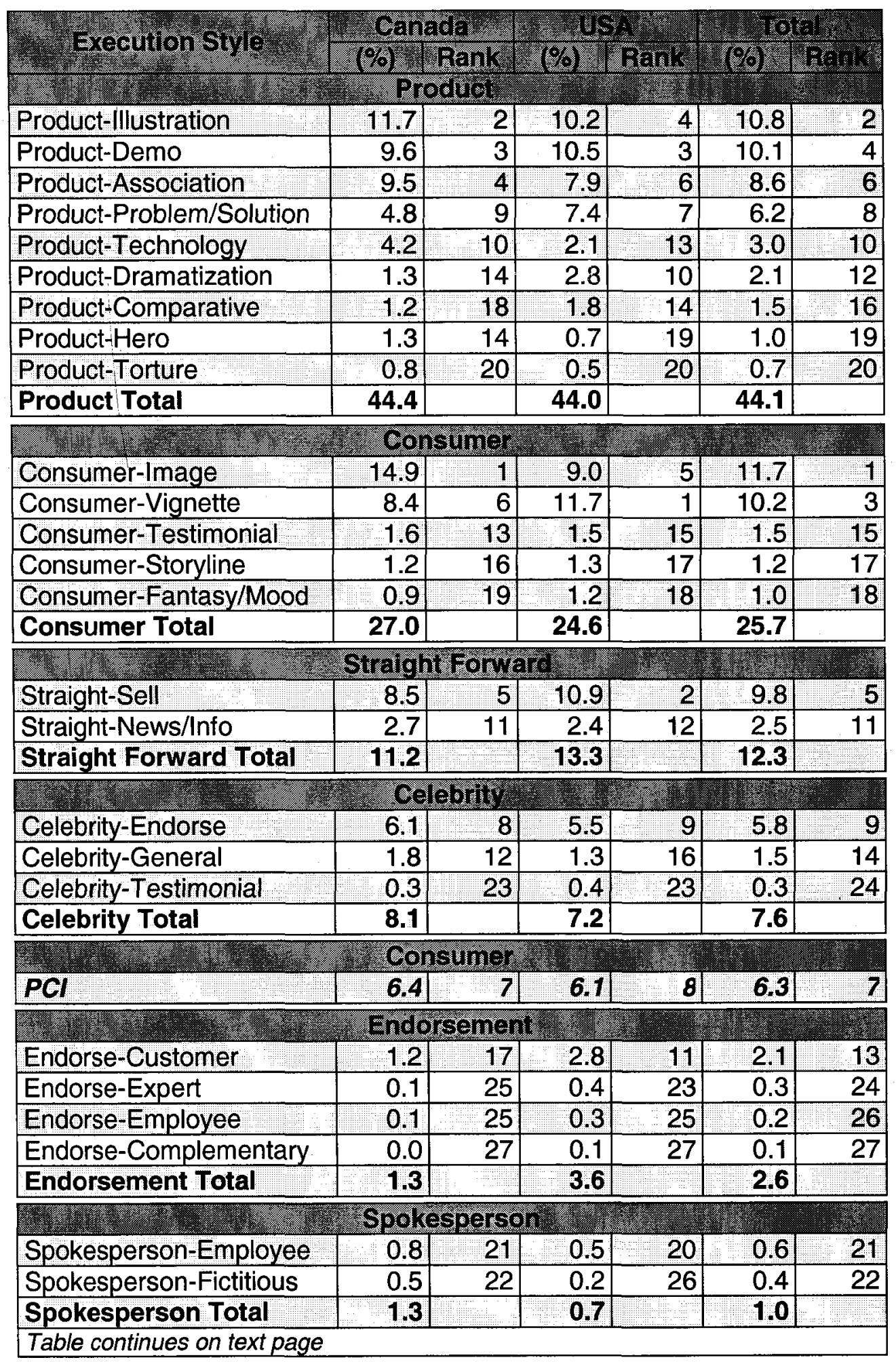




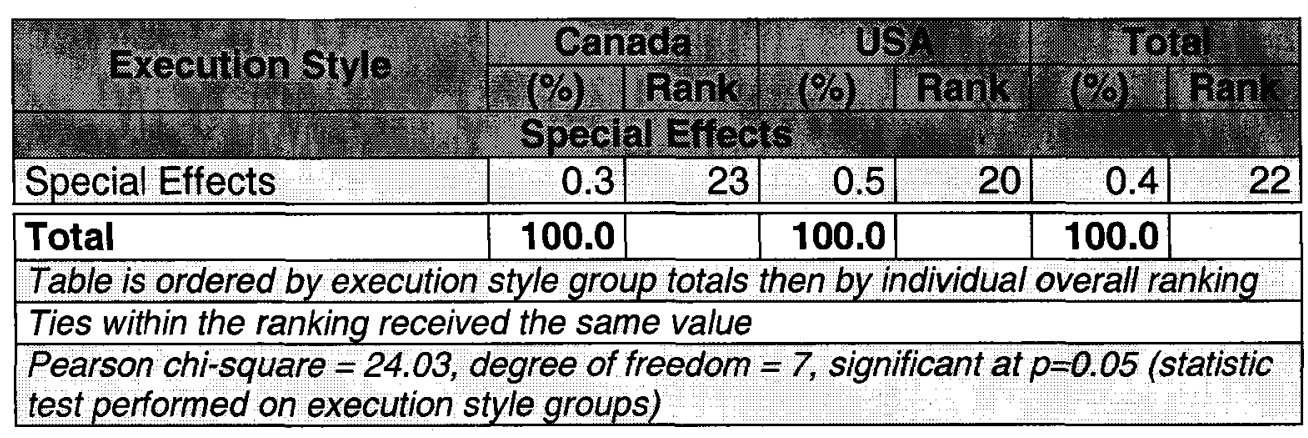

The Pearson chi-square test shows a significant difference between the frequency of advertisements, which use particular execution styles within Canadian versus American publications at the $p=0.05$ level. This is to be expected due to the high variance of execution styles used. However, even with a statistically significant difference between the two countries of publication, many of the execution styles rank similarly in the frequency in which they were used overall within both the Canadian and American publications.

Slightly over $6 \%$ of ads both in Canadian and American magazines use $\mathrm{PCl}$ as an execution style, which is very noteworthy considering that this ranks it as $7^{\text {th }}$ and $8^{\text {th }}$ respectively out of the 27 execution styles used. By isolating the $\mathrm{PCl}$ execution style and performing a Pearson chi-square test, the country of publication is not significant at the $\mathrm{p}=0.05$ level, as detailed in Table 26. This indicates that Canadian and American publications are very similar in the frequency of the number of advertisements which use $\mathrm{PCl}$ as an execution style.

\section{Table 26: Use of PCl Execution Style}

\begin{tabular}{|l|r|r|r|r|r|r|r|}
\hline Execution & \multicolumn{7}{|c|}{ Canada } \\
\cline { 2 - 8 } Style & N & Expected & ChI & N & Expected & Ch & P \\
\hline$P C I$ & 87 & 84.6 & 0.1 & 101 & 103.4 & 0.1 & 188 \\
\hline Other & 1267 & 1269.4 & 0.0 & 1553 & 1550.6 & 0.0 & 2820 \\
\hline Total & 1354 & & & 1654 & & & 3008 \\
\hline
\end{tabular}


A cross-tabulation of the execution styles against the product classes highlighted high frequency of use of particular styles (Error! Reference source not found.). Table 27 offers a listing of all the product classes which used $\mathrm{PCl}$ as an execution style. It is ordered by percentage of $\mathrm{PCl}$ execution used within the advertisements of that product class.

As one might expect, the travel category has the highest proportion of $\mathrm{PCl}$ execution usage within its class. The watches \& jewellery category is a close second, which can be attributed to the common acceptance of Swiss watch craftsmanship. Many of the watch advertisements within the sample emphasize their Swiss origins either actively through statements or passively through made-in information contained on the product itself. The liquor \& tobacco product class is also very high on the list, which is not surprising due to the distinction commonly made on origin of wines and spirits.

It is interesting to note that the financial services and business services product classes contain $12.5 \%$ and $9.1 \%$ proportions of $\mathrm{PCl}$ execution style usage respectively. Such services are not generally associated with country to promote increased value or quality. 
Table 27: Use of PCI Execution Style by Product Classification

\begin{tabular}{|l|c|}
\hline \multicolumn{1}{|c|}{ Rioduct Categoivy } & \% of ali Execution Styles Used \\
\hline Travel & 26.3 \\
\hline Watches \& Jewellery & 25.5 \\
\hline Liquor \& Tobacco & 18.8 \\
\hline Education \& training & 16.7 \\
\hline Entertainment & 16.0 \\
\hline Corporate & 14.5 \\
\hline Media & 13.5 \\
\hline Financial Services & 12.5 \\
\hline Business Services & 9.1 \\
\hline Cars \& Related & 8.3 \\
\hline Telecomm & 8.2 \\
\hline Home Décor \& Improve & 6.9 \\
\hline Issues, Charities, NGO'S & 6.9 \\
\hline Food & 5.9 \\
\hline Apparel \& Accessories & 3.8 \\
\hline Retail & 3.0 \\
\hline Appliances \& Furniture & 2.9 \\
\hline Cosmetics & 2.5 \\
\hline Personal Health \& Care & 2.5 \\
\hline Other Products \& Services & 1.7 \\
\hline Toiletries & 1.2 \\
\hline Medicines/Medical & 1.1 \\
\hline Please see Error! Reference source not found. \\
for more details
\end{tabular}

Understanding the origin countries of the firms that use country association is fundamental in $\mathrm{PCl}$ research. Table 28 provides an analysis of the origin countries comparing $\mathrm{PCl}$ to other execution styles. From the results, the advertiser's home country is significant in the distribution of frequency of use of $\mathrm{PCl}$ as an execution style compared to other execution styles at the $p=0.05$ level.

Of further note is that Canadian firms used $\mathrm{PCl}$ as an execution style more than twice as frequently as American firms ( $10.7 \%$ versus $4.8 \%$ respectively). Furthermore, of all the firms which had a noteworthy presence in the sample (more than 50 advertisements), those from Canada used $\mathrm{PCl}$ as an execution the most, followed by those from Switzerland, the UK, France, Japan, Germany, and finally 
the USA. Canada and Switzerland being at the top of this list may be due to the fact that it is commonly accepted that they enjoy a favourable view globally.

Table 28: Use of PCI Execution Style by Advertiser's Home Country

\begin{tabular}{|c|c|c|c|c|c|c|c|c|}
\hline \multirow{2}{*}{$\begin{array}{l}\text { Advertiser's } \\
\text { Home Country }\end{array}$} & \multicolumn{3}{|c|}{ 1.PCl? } & \multicolumn{3}{|c|}{ (1her } & \multicolumn{2}{|c|}{ 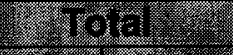 } \\
\hline & N18 & Expected & chl & 90 & Expected: & Pon: & 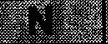 & (2) \\
\hline USA & 90 & 119.6 & 7.3 & 1792 & 1762.4 & 0.5 & 1882 & 4.8 \\
\hline Canada & 37 & 21.9 & 10.4 & 308 & 323.1 & 0.7 & 345 & 10.7 \\
\hline France & 14 & 13.2 & 0.0 & 194 & 194.8 & 0.0 & 208 & 6.7 \\
\hline Japan & 10 & 11.4 & 0.2 & 169 & 167.6 & 0.0 & 179 & 5.6 \\
\hline United Kingdom & 10 & 7.8 & 0.6 & 113 & 115.2 & 0.0 & 123 & 8.1 \\
\hline Germany & 5 & 6.4 & 0.3 & 96 & 94.6 & 0.0 & 101 & 5.0 \\
\hline Switzerland & 8 & 5.3 & 1.4 & 75 & 77.7 & 0.1 & 83 & 9.6 \\
\hline Italy & 4 & 0.8 & 13.7 & 8 & 11.2 & 0.9 & 12 & 33.3 \\
\hline Sweden & 1 & 0.6 & 0.3 & 8 & 8.4 & 0.0 & 9 & 11.1 \\
\hline Singapore & 2 & 0.4 & 6.9 & 4 & 5.6 & 0.5 & 6 & 33.3 \\
\hline Bermuda & 1 & 0.2 & 3.1 & 2 & 2.8 & 0.2 & 3 & 33.3 \\
\hline China & 3 & 0.3 & 29.7 & 1 & 3.8 & 2.0 & 4 & 75.0 \\
\hline Mexico & 1 & 0.1 & 13.8 & 0 & 0.9 & 0.9 & 1 & 100.0 \\
\hline Thailand & 2 & 0.1 & 27.6 & 0 & 1.9 & 1.9 & 2 & 100.0 \\
\hline Total & 188 & & & 2770 & & & 2958 & 6.4 \\
\hline \multirow{2}{*}{\multicolumn{9}{|c|}{ Table ordered by total number of advertisements within sample }} \\
\hline & & & & & & & & \\
\hline
\end{tabular}

A summary of the top organizations to use $\mathrm{PCl}$ as an execution style is shown in Table 29. For the purposes of this analysis, only organizations which employed the $\mathrm{PCl}$ execution style two or more times were included.' They were grouped into categories by type: government, NGO, and private firms. No associations used $\mathrm{PCl}$ as an execution style. 
Table 29: Top Organizations to use PCI Execution Style

\begin{tabular}{|c|c|c|c|}
\hline $\begin{array}{l}\text { Organization } \\
\text { Oovernment }\end{array}$ & $\begin{array}{l}\text { of PCI } \\
\text { Ads }\end{array}$ & Totali: & Total \\
\hline Government of Canada & 6 & 12 & 50.0 \\
\hline Government of Texas & 4 & 4 & 100.0 \\
\hline Government of Kissimmee-St. Cloud & 2 & 2 & 100.0 \\
\hline Government of St. Petersburg/Clearwater & 2 & 2 & 100.0 \\
\hline Government of Thailand & 2 & 2 & 100.0 \\
\hline NGO & & & \\
\hline PBS & 2 & 5 & 40.0 \\
\hline Private Secto & 83 & 20 & \\
\hline Canadian Imperial Bank of Commerce & 5 & 9 & 55.6 \\
\hline General Motors & 4 & 25 & 16.0 \\
\hline Honda & 4 & 21 & 19.0 \\
\hline Johnson \& Johnson & 4 & 104 & 3.9 \\
\hline Rogers & 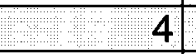 & 54 & 7.4 \\
\hline TimeWarner & 4 & 24 & 16.7 \\
\hline Tracfone Wireless & 4 & 4 & 100.0 \\
\hline American Century Services & 3 & 4 & 75.0 \\
\hline Dolce \& Gabbana & $=$ & 4 & 75.0 \\
\hline Ford & 3 & 28 & 10.7 \\
\hline Grey Goose Vodka & 3 & 3 & 100.0 \\
\hline HSBC & 3 & 4 & 75.0 \\
\hline Movado & 3 & 3 & 100.0 \\
\hline Alberto-Culver & 2 & 7 & 28.6 \\
\hline Breguet & 2 & 3 & 66.7 \\
\hline Coty & 2 & 44 & 4.6 \\
\hline CSC Brands & 2 & 6 & 33.3 \\
\hline Cushman \& Wakefield & 2 & 2 & 100.0 \\
\hline Danbury Mint & 2 & 5 & 40.0 \\
\hline Degussa & 2 & 4 & 50.0 \\
\hline DHL & 2 & 3 & 66.7 \\
\hline Diebold & 2 & 3 & 66.7 \\
\hline Goya & 2 & 2 & 100.0 \\
\hline KF Holdings & 2 & 52 & 3.9 \\
\hline Lincoln Financial Group & $=$ & 4 & 50.0 \\
\hline Marriott International & 2 & 7 & 28.6 \\
\hline P\&G & 2 & 343 & 0.6 \\
\hline Pepsico & 2 & 18 & 11.1 \\
\hline Pitney Bowes & 2 & 6 & 33.3 \\
\hline Toyota & 2 & 31 & 6.5 \\
\hline Unilever & 2 & 50 & 4.0 \\
\hline $\begin{array}{l}\begin{array}{l}\text { Only organizations, which had } 2 \text { or more ads, which } u \\
\text { included }\end{array} \\
\end{array}$ & & & \\
\hline
\end{tabular}


The above results are not of particular note but have been included to highlight the fact that governmental organizations tend to use large proportions of $\mathrm{PCl}$ as an execution. This is due to the fact that many of the advertisements in the sample developed by governmental organizations pertain to travel which, as noted earlier, is a high user of $\mathrm{PCl}$ execution styles. As mentioned, why particular organizations use $\mathrm{PCl}$ as an execution style is beyond the scope of this research but it is hoped that future studies will be able to address this.

To determine if the usage of execution styles was significant across the various magazine types a Pearson chi-square was conducted, which yielded significant results. This has been summarized in Table 30 , where both a test across all the execution styles, as well as an isolated test for the $\mathrm{PCl}$ execution style proved to be significant to the $p=0.05$ level.

\section{Table 30: Use of PCI Execution Style across Magazine Types}

\begin{tabular}{|c|c|c|c|}
\hline 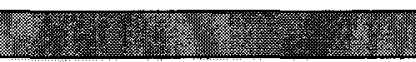 & 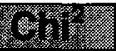 & DE & $=0.05$ \\
\hline All Execution Styles & 714.1 & 78 & Significant \\
\hline Only PCl vs. Others & 51.3 & 3 & Significant \\
\hline
\end{tabular}

Continuing from the above, statistical test were conducted to evaluate where a significant difference existed between Canadian and American publications. As summarized in Table 31 significant differences were observed when all the execution styles were used for all cases except the news magazines. This may be accounted for by the fact that the news magazines did not yield a large amount of advertisements, which limited the potential variability and also were limited in the execution styles which were used. The advertisements within Maclean's used only 17 of the 27 available execution styles. While the advertisements within Time used 
more execution styles, many of those used only, within Time were used very sparingly (details of this are included in Appendix E).

When the same statistics were conducted on the isolated $\mathrm{PCl}$ execution style within each magazine type, the results were not statistically significant. This indicated that Canadian and American versions of particular magazine types have similar frequency distributions of the $\mathrm{PCl}$ execution style. This may be due to the relatively limited use of $\mathrm{PCl}$ as an execution style overall.

Table 31: Use of PCI Execution Style within Magazine Types

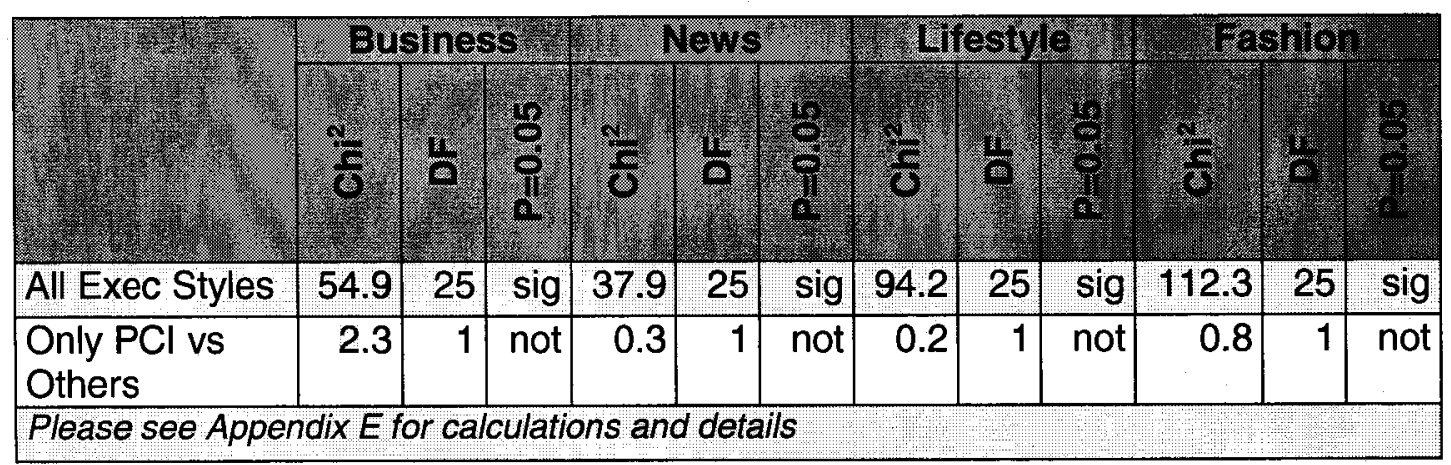

The inclusion of $\mathrm{PCl}$ as an execution was not expected to produce a high proportion of advertisements that used it within the sample; however, this research has demonstrated that it is used considerably compared to other execution styles. This indicates that practitioners tend to use $\mathrm{PCl}$ as the main proof for their advertisements over several other, more traditional, methods. Furthermore, it has been demonstrated that its frequency of use in Canadian and American publications is significantly similar.

\subsection{EXECUTION STYLE VS. APPEAL ANALYSIS}

The literature indicated that execution style and appeal are not correlated. Most execution styles can be used with most appeals in any particular situations. 
With respect to product country association though, there appears to be a correlation.

Execution style is significant in the distributions of appeals in magazine advertisements overall at the $p=0.05$ level. As may be expected, over $90 \%$ of all the patriotic appeals used within the sample also use a PCl execution (please see Appendix $\mathrm{H}$ for details).

From Table 32 below, the correlation between $\mathrm{PCl}$ execution and patriotic appeal can be seen. All the patriotic appeals used within the sample fall under product classes which also tend to use $\mathrm{PCl}$ as an execution style. 
Table 32: PCI Execution and Patriotic Appeal across Product Classes

\begin{tabular}{|c|c|c|c|c|c|c|c|c|}
\hline 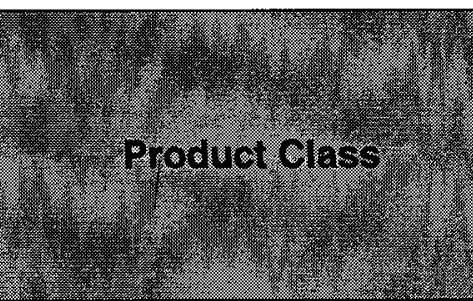 & $\frac{(5)}{\left(\frac{3}{5}\right)}$ & 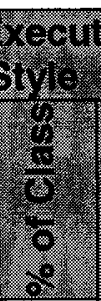 & $\frac{0 h}{6}$ & $\frac{6}{4}$ & $\frac{69}{8}$ & & & $\frac{5}{9}$ \\
\hline Apparel \& Accessories & 3 & 3.8 & 0.1 & & 0.0 & 0.0 & 80 & 2.7 \\
\hline Appliances \& Furniture & 1 & 2.9 & 0.0 & & 0.0 & 0.0 & 34 & 1.1 \\
\hline Business Services & 12 & 9.1 & 0.4 & & 0.0 & 0.0 & 132 & 4.4 \\
\hline Cars \& Related & 13 & 8.3 & 0.4 & 3 & 1.9 & 0.1 & 156 & 5.2 \\
\hline Computer Hard/Software & & 0.0 & 0.0 & & 0.0 & 0.0 & 148 & 4.9 \\
\hline Consumer Electronics & & 0.0 & 0.0 & & 0.0 & 0.0 & 39 & 1.3 \\
\hline Corporate & 8 & 14.5 & 0.3 & 3 & 5.5 & 0.1 & 55 & 1.8 \\
\hline Cosmetics & 9 & 2.5 & 0.3 & 1 & 0.3 & 0.0 & 362 & 12.0 \\
\hline Education \& Training & 5 & 16.7 & 0.2 & & 0.0 & 0.0 & 30 & 1.0 \\
\hline Entertainment & 12 & 16.0 & 0.4 & 3 & 4.0 & 0.1 & 75 & 2.5 \\
\hline Financial Services & 23 & 12.5 & 0.8 & 6 & 3.3 & 0.2 & 184 & 6.1 \\
\hline Food & 17 & 5.9 & 0.6 & 1 & 0.3 & 0.0 & 288 & 9.6 \\
\hline Household Cleaners & & 0.0 & 0.0 & & 0.0 & 0.0 & 64 & 2.1 \\
\hline Home Décor \& Improve & 4 & 6.9 & 0.1 & 3 & 5.2 & 0.1 & 58 & 1.9 \\
\hline Issues, Charities, NGO's & 6 & 6.9 & 0.2 & 3 & 3.4 & 0.1 & 87 & 2.9 \\
\hline Liquor \& Tobacco & 9 & 18.8 & 0.3 & & 0.0 & 0.0 & 48 & 1.6 \\
\hline Media & 7 & 13.5 & 0.2 & & 0.0 & 0.0 & 52 & 1.7 \\
\hline Medicines/Medical & 2 & 1.1 & 0.1 & & 0.0 & 0.0 & 178 & 5.9 \\
\hline Personal Health \& Care & 7 & 2.5 & 0.2 & & 0.0 & 0.0 & 285 & 9.5 \\
\hline Retail & 3 & 3.0 & 0.1 & & 0.0 & 0.0 & 99 & 3.3 \\
\hline Telecomm & 9 & 8.2 & 0.3 & & 0.0 & 0.0 & 110 & 3.7 \\
\hline Toiletries & 3 & 1.2 & 0.1 & & 0.0 & 0.0 & 252 & 8.4 \\
\hline Travel & 24 & 25.5 & 0.8 & & 0.0 & 0.0 & 94 & 3.1 \\
\hline Watches \& Jewellery & 10 & 26.3 & 0.3 & & 0.0 & 0.0 & 38 & 1.3 \\
\hline Other Products \& Services & 1 & 1.7 & 0.0 & & 0.0 & 0.0 & 60 & 2.0 \\
\hline Total & 188 & 6.3 & 6.3 & 23 & 0.8 & 0.8 & 3008 & 100.0 \\
\hline
\end{tabular}

\subsection{PCI CUE ANALYSIS}

As described earlier in section 7.6 the $\mathrm{PCl}$ cues observed in this research were separated along two variables: brand/non-brand and prominent/fine print. This section will offer a summary of the fine print $\mathrm{PCl}$ cues used; however, the main focus will be on the distribution of prominent $\mathrm{PCl}$ cues by product class, 
execution style, appeal, magazine type, advertisement type, organization type and country of association.

Preliminary analysis of the sample offers substantial evidence that advertisements use $\mathrm{PCl}$ cues extensively. As detailed in Table $33,87.6 \%$ of all advertisements within the sample used some form of $\mathrm{PCl}$ cue. This is even more noteworthy in Canadian publications where nearly $92 \%$ of advertisements utilized some form of country association.

Table 33: Frequency Distribution of Advertisements with PCI Cues

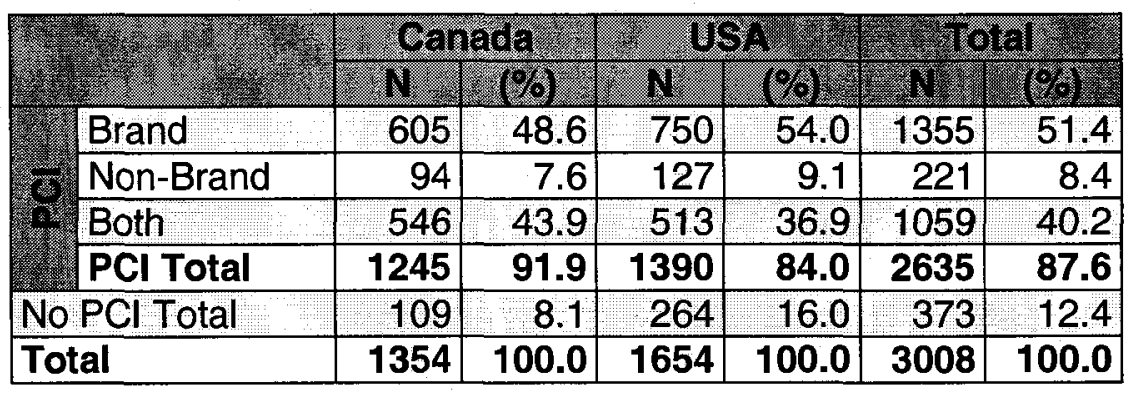

When combined with the results detailed in Table 34, which describes the distribution of all the country cues within the sample, the magnitude of country cue usage is made apparent. Using the classification detailed in section 7.6 , the prominent, non-brand cues account for $5238 \mathrm{PCl}$ cues. On their own, this represents almost two cues per advertisement within the sample. If the fine print non-brand cues are included, this category represents $31.7 \%$ of the $\mathrm{PCl}$ cues observed.

The remaining $68.3 \%$ of the cues observed were considered to be brand country cues. These referred to country imagery directly associated with the firm, brand, or other product or service name within each advertisement. Brand cues are important since they can often outweigh negative views that the consumer may 
have about other aspects of the product or service (Phau and Prendergast, 2002) as discussed in section 2.3.

Table 34: Frequency Distribution of PCI Cues

\begin{tabular}{|c|c|c|c|c|c|c|}
\hline \multirow{2}{*}{$x^{2} x^{2}$} & \multicolumn{2}{|c|}{ Prominent } & \multicolumn{2}{|c|}{ Fine min } & \multicolumn{2}{|c|}{ 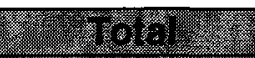 } \\
\hline & $\mathrm{N}^{2}$ & $(\%)$ & M & $6 \%$ & EN= & (\%) \\
\hline Brand & 9549 & 48.9 & 3801 & 19.5 & 13350 & 68.3 \\
\hline Non-Brand & 5238 & 26.8 & 949 & 4.9 & 6187 & 31.7 \\
\hline Total & 14787 & 75.7 & 4750 & 24.3 & 19537 & 100.0 \\
\hline
\end{tabular}

The prominent class of country cues refers to those which were observed in the main section of the advertisement (heading, slogan, body text, graphics, etc.) and encompassed $75.7 \%$ of the sample. The remaining $24.3 \%$, which were recorded as fine print country cues refer to such country indications as website URLs, copyright information, etc. An overview of their distribution is provided in Table 35.

It is critical to note that nearly 20,000 cues were observed overall which translates to over 6.5 cues per advertisement in the sample, or, more specifically, almost 7.5 cues per advertisement where $\mathrm{PCl}$ was used (excluding the $12.4 \%$ of advertisements which did not use $\mathrm{PCl}$ cues at all as detailed in Table 33).

Table 35: Frequency Distribution of Fine Print PCI Cues

\begin{tabular}{|c|c|c|c|c|c|c|c|}
\hline & \multicolumn{2}{|c|}{ Canara } & \multicolumn{2}{|c|}{ 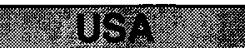 } & \multicolumn{2}{|c|}{ Tolal } \\
\hline & & N. & $(96)$ & N. & $-(\%)$ & 2102 & $(\%)$ \\
\hline $\mathrm{Bre}$ & ind & 1614 & 81.5 & 2187 & 79.0 & 3801 & 80.0 \\
\hline & Country Reference & 183 & 49.9 & 300 & 51.5 & 483 & 50.9 \\
\hline 9 & Address & 68 & 18.5 & 140 & 24.1 & 208 & 21.9 \\
\hline & Other Brand & 89 & 24.3 & 75 & 12.9 & 164 & 17.3 \\
\hline at & URL Suffix & 20 & 5.4 & 48 & 8.2 & 68 & 7.2 \\
\hline 9 & URL Body & 7 & 1.9 & 19 & 3.3 & 26 & 2.7 \\
\hline & Non-Brand Total & 367 & 18.5 & 582 & 21.0 & 949 & 20.0 \\
\hline To & & 1981 & 100.0 & 2769 & 100.0 & 4750 & 100.0 \\
\hline
\end{tabular}


As the above table indicates, the majority $(80.0 \%)$ of all the fine print country cues were observed as brand cues. This referred to copyright or other legal information, which may have included potential country cues. The remainder of the fine print cues were primarily concentrated in direct country references (e.g.: Canada, Canadian, etc.).

To ensure a conservative view of any relationships or correlations observed in this research, for the remainder of this section, only prominent country cues were analysed. This was done since many of the fine print cues in the sample may have been included within the advertisements in a passive sense, that is to say, that they were included for legal or other technical reasons.

Table 36 provides an overview of the distribution of prominent country cues within the sample. As detailed earlier in Table 34, brand cues represent the majority of the $\mathrm{PCl}$ cues observed. Specifically in the prominent category, brand cues represent $65 \%$ of the total. Furthermore, this is common among Canadian and American publications.

The brand related made-in $\mathrm{PCl}$ cue refers to geographic references directly within the firm, brand, or other product name (e.g.: Maybelline New York, American Century, etc.) and accounts for over half of all the prominent brand cues observed in the sample.

Of the non-brand $\mathrm{PCl}$ cues, which are described in section 7.6 , the operations cue is used most frequently, followed by language, country reference and symbol $(6.4 \%, 4.6 \%, 4.0 \%$, and $4.0 \%$ respectively). The more frequent use of these cues may be due to the more direct association to the country that they provide. The less directly a $\mathrm{PCl}$ cue connects to a specific country, the less that cue appears to be used throughout the sample. 
Finally it should be noted that the distribution of specific cues is similar between Canadian and American publications.

\section{Table 36: Frequency Distribution of Prominent PCI Cues}

\begin{tabular}{|c|c|c|c|c|c|c|}
\hline \multirow{2}{*}{$f(x)=0$} & \multicolumn{2}{|c|}{ eanada= } & \multicolumn{2}{|c|}{ (1) } & \multirow{2}{*}{\multicolumn{2}{|c|}{ rofal }} \\
\hline & & $(\%)$ & 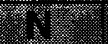 & & & \\
\hline Made In & 4193 & 55.6 & 4133 & 57.1 & 8326 & 56.3 \\
\hline Language & 365 & 4.8 & 269 & 3.7 & 634 & 4.3 \\
\hline Culture & 284 & 3.8 & 305 & 4.2 & 589 & $\overline{4.0}$ \\
\hline Total Brand & 4842 & 64.2 & 4707 & 65.0 & 9549 & 64.6 \\
\hline 9.1. Operations & 516 & 6.8 & 429 & 5.9 & 945 & 6.4 \\
\hline Language & 503 & 6.7 & 184 & 2.5 & 687 & 4.6 \\
\hline Country Reference & 206 & 2.7 & 382 & 5.3 & 588 & 4.0 \\
\hline Symbol & 306 & 4.1 & 291 & 4.0 & 597 & 4.0 \\
\hline Made in & 306 & 4.1 & 272 & 3.8 & 578 & 3.9 \\
\hline Serve & 262 & 3.5 & 266 & 3.7 & 528 & 3.6 \\
\hline Other Brand & 214 & 2.8 & 187 & 2.6 & 401 & 2.7 \\
\hline Best Claim & 191 & 2.5 & 165 & 2.3 & 356 & 2.4 \\
\hline Culture & 63 & 0.8 & 129 & 1.8 & 192 & 1.3 \\
\hline Flag & 85 & 1.1 & 56 & 0.8 & 141 & 1.0 \\
\hline Scenery (Nature) & 32 & 0.4 & 69 & 1.0 & 101 & 0.7 \\
\hline Model & 4 & 0.1 & 57 & 0.8 & 61 & 0.4 \\
\hline Scenery (Manmade) & 15 & 0.2 & 48 & 0.7 & 63 & 0.4 \\
\hline Total Non-Brand & 2703 & 35.8 & 2535 & 35.0 & 5238 & 35.4 \\
\hline Total & 7545 & 100.0 & 7242 & 100.0 & 14787 & 100.0 \\
\hline
\end{tabular}

An analysis of the use of prominent cues against the various product classes echoed previous results that Canadian publications are more likely to use $\mathrm{PCl}$ cues than American ones (Please see Table 37 for details). The advertisements in the cars \& related and education \& training product categories both yielded $100 \%$ use of prominent $\mathrm{PCl}$ cues. However, the Canadian publications contained eight other product classes where $100 \%$ of the advertisements used country cues: appliances \& furniture, computer hardware \& software, consumer electronics, financial services, liquor \& tobacco, media, telecomm, and watches \& jewellery.

It is noteworthy that the product class, which had the lowest proportion of advertisements, which used prominent $\mathrm{PCl}$ cues, was medicines/medical in both 
Canadian and American publications. However, well over half of these advertisements still used at least one prominent country cue.

Overall, nearly $92 \%$ of advertisements published within Canada used some form of prominent $\mathrm{PCl}$ cue. This is a sizable difference from the still high $84 \%$ of advertisements found in American publications. 
Table 37: Use of Prominent PCI Cues by Product Class

\begin{tabular}{|c|c|c|c|c|c|c|c|c|c|c|c|c|c|c|}
\hline 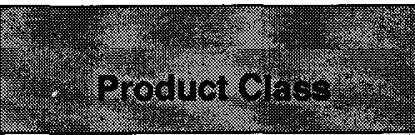 & 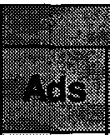 & $\sqrt[3]{2} \cdot \sqrt{2}$ & 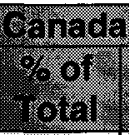 & 2916 & 20 & 25 & 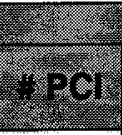 & 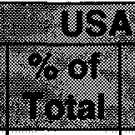 & 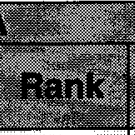 & 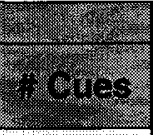 & & 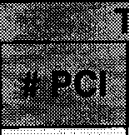 & 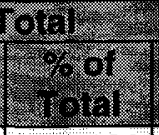 & 2. \\
\hline Cars \& Related & 60 & 60 & 100 & 1 & 369 & 96 & 96 & 100 & 1 & 471 & 156 & 156 & 100 & 840 \\
\hline Education \& Training & 20 & 20 & 100 & 1 & 281 & 10 & 10 & 100 & 1 & 109 & 30 & 30 & -100 & 390 \\
\hline Media & 29 & 29 & 100 & 1 & 226 & 23 & 22 & 96 & 5 & 133 & 52 & 51 & 98 & 359 \\
\hline Liquor \& Tobacco & 6 & 6 & 100 & 1 & 15 & 42 & 41 & 98 & 4 & 233 & 48 & 47 & 98 & 248 \\
\hline Travel & 38 & 37 & 97 & 11 & 687 & 56 & 52 & 93 & 7 & 413 & 94 & 89 & 95 & 1100 \\
\hline Cosmetics & 211 & 204 & 97 & 13 & 1035 & 151 & 138 & 91 & 8 & 730 & 362 & 342 & 95 & 1765 \\
\hline Telecomm & 42 & 42 & 100 & 1 & 400 & 68 & 62 & 91 & 9 & 405 & 110 & 104 & 95 & 805 \\
\hline Financial Service & 51 & 51 & 100 & 1 & 509 & 133 & 121 & 91 & 10 & 673 & 184 & 172 & 94 & 1182 \\
\hline Retail & 58 & 53 & 91 & 17 & 243 & 41 & 39 & 95 & 6 & 139 & 99 & 92 & 93 & 382 \\
\hline Entertainment & 33 & 32 & 97 & 12 & 278 & 42 & 37 & 88 & 11 & 288 & 75 & 69 & 92 & 566 \\
\hline Appliances \& Furniture & 25 & 25 & 100 & 1 & 119 & 9 & 6 & 67 & 23 & 27 & 34 & 31 & 91 & 146 \\
\hline Computer Hard/Software & 42 & 42 & 100 & 1 & 279 & 106 & 93 & 88 & 13 & 570 & 148 & 135 & 91 & 849 \\
\hline Issues, Charities, NGO's & 46 & 37 & 80 & 22 & 354 & 41 & 41 & 100 & 1 & 194 & 87 & 78 & 90 & 548 \\
\hline Watches \& Jewellery & 5 & 5 & 100 & 1 & 21 & 33 & 29 & 88 & 12 & 143 & 38 & 34 & 90 & 164 \\
\hline Toiletries & 147 & 142 & 97 & 14 & 704 & 105 & 82 & 78 & 21 & 324 & 252 & 224 & 89 & 1028 \\
\hline Personal Health \& Care & 189 & 170 & 90 & 19 & 647 & 96 & 80 & 83 & 17 & 269 & 285 & 250 & 88 & 916 \\
\hline Consumer Electronics & 21 & 21 & 100 & 1 & 162 & 18 & 13 & 72 & 22 & 62 & 39 & 34 & 87 & 224 \\
\hline Business Service & 33 & 31 & 94 & 15 & 248 & 99 & 84 & 85 & 14 & 582 & 132 & 115 & 87 & 830 \\
\hline Other Products \& Service & 25 & 23 & 92 & 16 & 103 & 35 & 29 & 83 & 18 & 157 & 60 & 52 & 87 & 260 \\
\hline Household Cleaners & 38 & 33 & 87 & 20 & 27 & 26 & 22 & 85 & 15 & 166 & 64 & 55 & 86 & 193 \\
\hline Corporate & 10 & 9 & 90 & 18 & 47 & 45 & 38 & 84 & 16 & 236 & 55 & 47 & 86 & 283 \\
\hline Food & 142 & 123 & 87 & 21 & 547 & 146 & 116 & 80 & 19 & 513 & 288 & 239 & 83 & 1060 \\
\hline Home Décor \& Improve & 24 & 10 & 42 & 25 & 142 & 34 & 27 & 79 & 20 & 77 & 58 & 37 & 64 & 219 \\
\hline Apparel \& Accessories & 14 & 9 & 64 & 24 & 29 & 66 & 40 & 61 & 24 & 91 & 80 & 49 & 61 & 120 \\
\hline Medicines/Medical & 45 & 31 & 69 & 23 & 73 & 133 & 72 & 54 & 25 & 237 & 178 & 103 & 58 & 310 \\
\hline Total & 1354 & 1245 & 92 & & 7545 & 1654 & 1390 & 84 & & 7242 & 3008 & 2635 & 88 & 14787 \\
\hline \multicolumn{15}{|c|}{$\begin{array}{l}\text { Table ordered by \% of total advertisements which } \\
\text { Ties within the ranking received the same value }\end{array}$} \\
\hline
\end{tabular}


Across the appeals, only two had $100 \%$ of the advertisement that used them use $\mathrm{PCl}$ cues: availability and patriotism. As with the other cross-tabulations, several of the appeal classes used by advertisements within Canadian publications contained additional categories where all the advertisements used at least one PCI cue. Table 38 offers details of the distribution of the country cues by appeals.

It is interesting to note that of the appeals where large clustering of $\mathrm{PCl}$ cues occurred, joy-body and humour are the only ones classified as emotional. The remaining appeals where a large number of country cues were used were all considered rational appeals (benefits, econ/price/value, feature, information, and lifestyle). 
Analysis of the distribution of prominent country cues across the various execution styles used within the sample yielded similar results to those described above. The execution styles used by advertisements within Canadian publications appear to be more saturated with $\mathrm{PCl}$ cues than American ones. Overall, more execution style classes have $100 \%$ of the advertisements which use them containing country cues as detailed in Table 39.

The percentage of advertisements per execution style, which use prominent $\mathrm{PCl}$ cues, is very high. All the advertisements which used the endorsecomplimentary, endorse-customer, $\mathrm{PCl}$, and product-torture execution styles had at least one prominent $\mathrm{PCl}$ cue. In the Canadian publications, an additional eight execution classes had $100 \%$ saturation of advertisements, which used country cues: celebrity-general, celebrity-testimonial, consumer-storyline, consumertestimonial, endorse-employee, endorse-expert, product-hero, and special effect. In the American publications, all the advertisements, which used the spokespersonfictitious style, also used country cues.

By excluding the endorsement-complementary execution style from the Canadian publications, as no ads used it, the spokesperson-fictional style had the lowest percent of advertisements, which contained country cues but still had a very high ratio $(71.4 \%)$ in Canada. In the American advertisements, consumertestimonial had the lowest usage with only over half of the advertisements having used country cues (58.3\%). 
Table 39: Use of Prominent PCl Cues by Execution Style

\begin{tabular}{|c|c|c|c|c|c|}
\hline & & & & & \\
\hline nplementary & 0 & 0 & 0 & 21 & \\
\hline Endorse-Customer & 16 & 16 & 100 & 1. & 110 \\
\hline $\mathrm{PCI}$ & 87 & 87. & 100 & 1 & 1443 \\
\hline Product-Torture & 11 & 11 & 100 & 1 & 49 \\
\hline Celebrity-General & 24 & 24 & 100 & 1 & 67 \\
\hline Celebrity-Endorse & 82 & 81 & 99 & 12 & 435 \\
\hline Product-Demo & 130 & 123 & 95 & 14 & 761 \\
\hline Product-Technology & 57 & 51 & 90 & 19 & 221 \\
\hline Product-Association & 129 & 122 & 95 & 14 & 593 \\
\hline Consumer-Storyline & 16 & 16 & 100 & 1 & 139 \\
\hline Product-Illustration & 158 & 144 & 91 & 17 & 521 \\
\hline Endorse-Expert & 1 & 1 & 100 & 1 & 6 \\
\hline Straight-Sell & 115 & 109 & 95 & 13 & 908 \\
\hline Straight-News/lnfo & 36 & 33 & 92 & 16 & 151 \\
\hline Product-Hero & 17 & 17 & 100 & 1 & 72 \\
\hline Consumer-Image & 202 & 179 & 89 & 20 & 809 \\
\hline Endorse-Employee & 1 & 1 & 100 & 1 & 2 \\
\hline Special Effects & 4 & 4 & 100 & 1 & 10 \\
\hline Consumer-Vignette & 114 & 89 & 78 & 25 & 475 \\
\hline Spokesperson-Fictitious & 7 & 5 & 71 & 26 & 34 \\
\hline Celebrity-Testimonial & 4 & 4 & 100 & 1 & 31 \\
\hline Consumer-Testimonial & 22 & 22 & 100 & 1 & 180 \\
\hline Product-Comparative & 16 & 13 & 81 & 24 & 39 \\
\hline Product-Dramatization & 17 & 15 & 88 & 21 & 91 \\
\hline Product-Problem/Solution & 65 & 59 & 91. & 18 & 309 \\
\hline Spokesperson-Employee & 11 & 9 & 82 & 23 & 53 \\
\hline Consumer-Fantasy/Mood & 12 & 10 & 83 & 22 & 36 \\
\hline Total & 1354 & 1245 & 92 & & 7545 \\
\hline
\end{tabular}

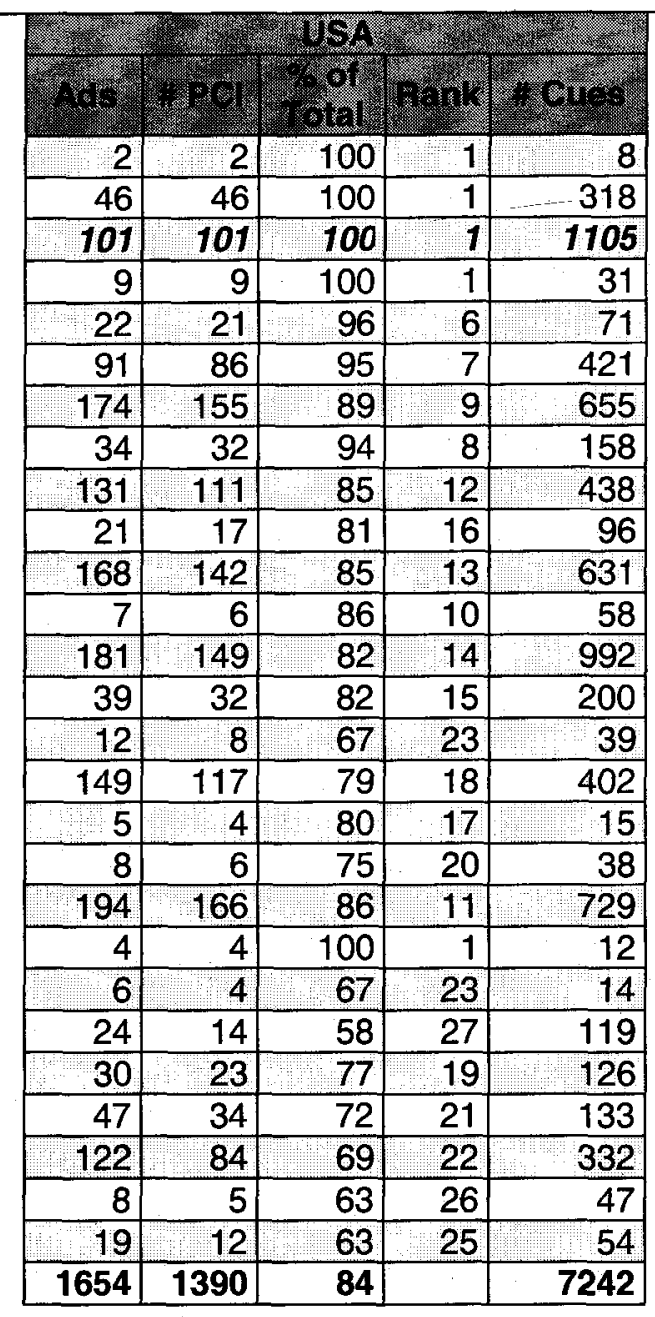

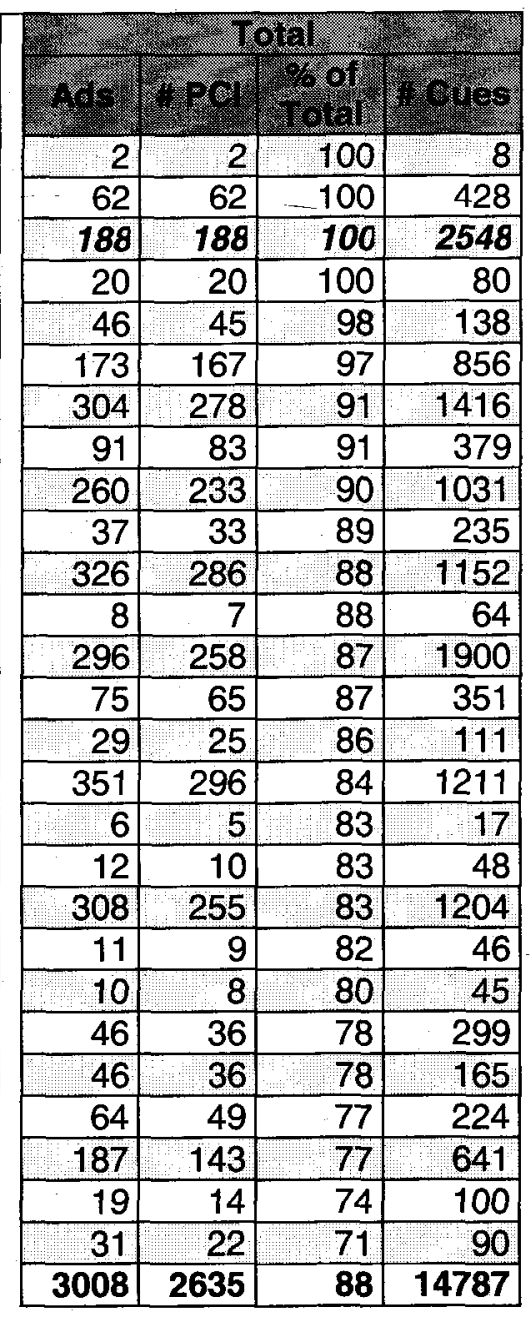


When comparing the usage of prominent country cues across magazines, previous results are reconfirmed. The data demonstrates a tendency for the business and news magazines to contain a higher percentage of advertisements which use country cues, and a higher overall presence of such of cues altogether (please see Table 40 for details). This is important since $\mathrm{PCl}$ is commonly considered emotional while business is generally thought of as rational. Thus, one might expect that business magazines would use fewer PCl cues.

However, it should be noted that the overall percentages of advertisements, which use prominent cues are very high. Lifestyle magazines in the sample represented the lowest ratio of advertisements which utilized country cues, yet the percentage is still remarkably high ( $84.1 \%$ overall).

Table 41 summarizes the distribution of prominent $\mathrm{PCl}$ cues by advertisement type: consumer versus business. Although the sample is composed primarily of consumer based advertisements, more business advertisements used prominent country cues and each advertisement used more cues individually. 
Table 40: Use of Prominent PCI Cues across Magazine Type

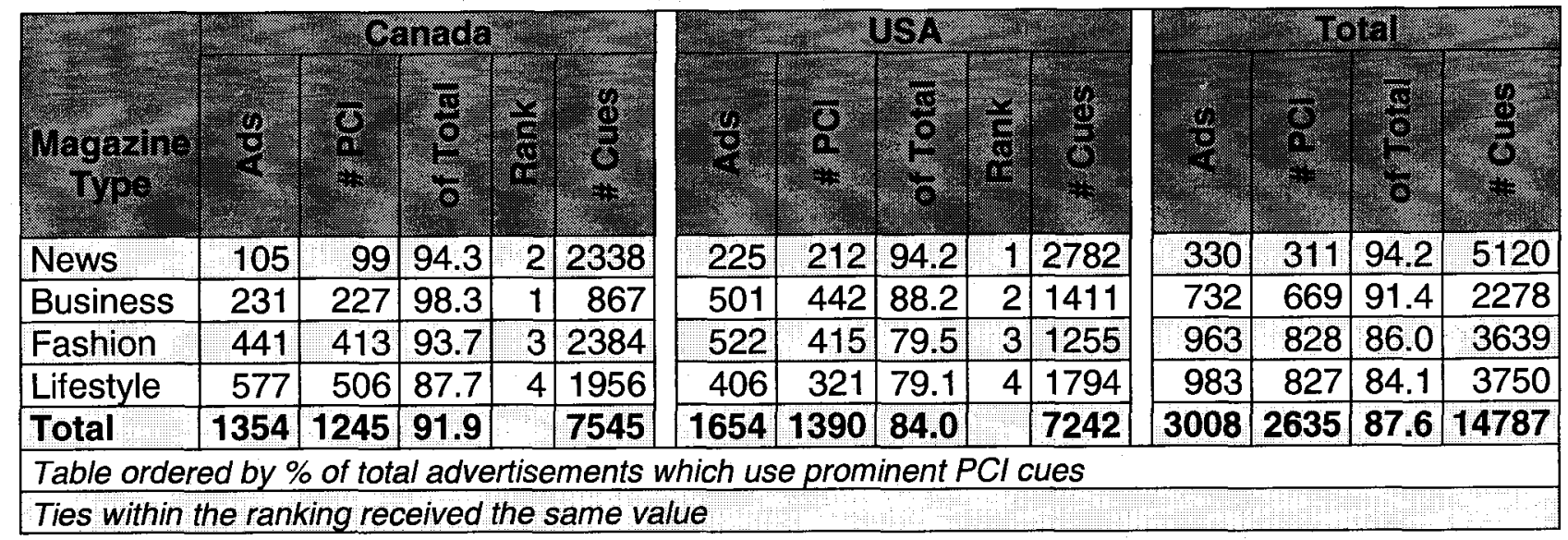

\section{Table 41: Use of Prominent PCI Cues by Advertisement Type}

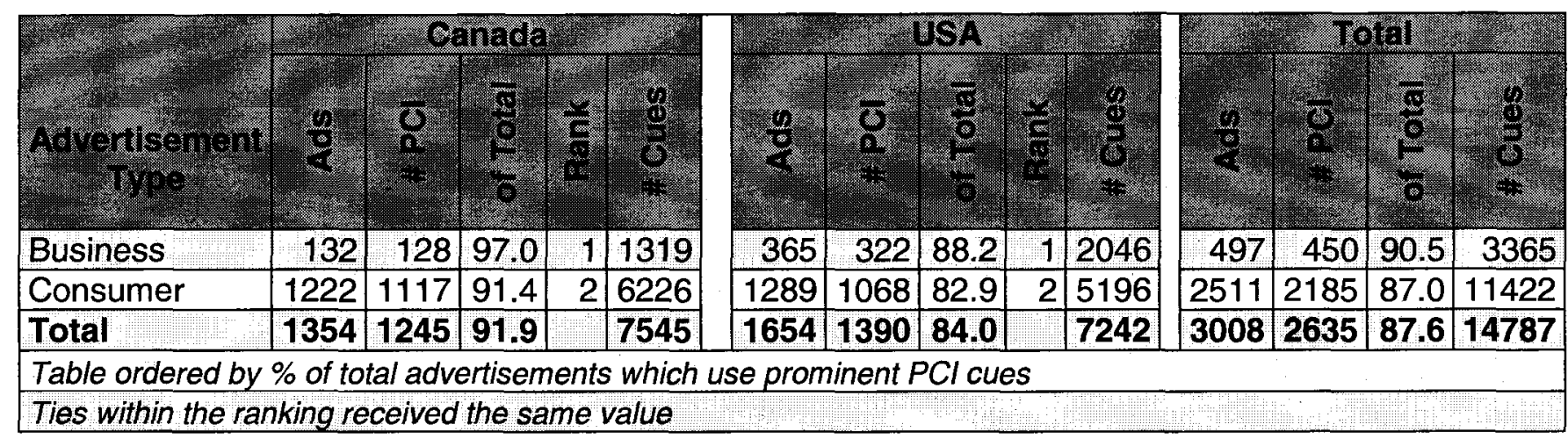


Finally, when comparing the usage of prominent $\mathrm{PCl}$ cues against the advertising firm types, educational institutions and governmental firms had $100 \%$ of their advertisement using prominent cues, as detailed in Table 42. Most probably, there exist correlations between these firms advertising travel and education \& training products and services, which as discussed earlier, have high levels of $\mathrm{PCl}$ usage.

Unlike the previous analysis, the American publications had more classes across firm type where all the advertisements within them used $\mathrm{PCl}$ cues than the Canadian counterparts. Advertisements placed in American magazines by associations and NGO's also demonstrated $100 \%$ saturation of PCl usage. 
Table 42: Use of Prominent PCI Cues by Organization Type

\begin{tabular}{|c|c|c|c|c|c|c|c|c|c|c|c|c|c|c|}
\hline organzation ype & 8 & $\frac{-69}{9}$ & 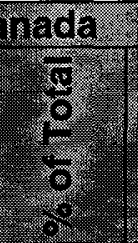 & 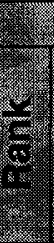 & $\frac{y}{3}=$ & 3 & 9 & $\frac{15 A}{\frac{\pi}{2}}$ & $\frac{\mathrm{d}}{\mathrm{c}}$ & $\frac{-8}{8}$ & $\frac{9}{9}$ & 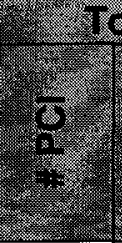 & $\frac{t a l}{\frac{\sigma}{9}}$ & $\frac{3}{6}$ \\
\hline Educational Institute & 12 & 12 & 100.0 & 1 & 136 & 2 & 2 & 100.0 & 1 & 29 & 14 & 14 & 100.0 & 165 \\
\hline Government & 29 & 29 & 100.0 & 1 & 346 & 20 & 20 & 100.0 & 1 & 163 & 49 & 49 & 100.0 & 509 \\
\hline NGO & 12 & 11 & 91.7 & 4 & 162 & 31 & 31 & 100.0 & 1 & 243 & 43 & 42 & 97.7 & 405 \\
\hline Association & 40 & 38 & 95.0 & 3 & 322 & 13 & 13 & 100.0 & 1 & 33 & 53 & 51 & 96.2 & 355 \\
\hline Private Sector & 1261 & 1155 & 91.6 & 5 & 6579 & 1588 & 1324 & 83.4 & 5 & 6774 & 2849 & 2479 & 87.0 & 13353 \\
\hline Total & 1354 & 1245 & 91.9 & & 7545 & 1654 & 1390 & 84.0 & & 7242 & 3008 & 2635 & 87.6 & 14787 \\
\hline
\end{tabular}


As a final element of the analysis of prominent $\mathrm{PCl}$ cues, the non-brand specific cues were classified by which country they associate with. Only prominent non-brand cues were used since these cues allow the advertisers the highest degree of flexibility. Unlike brand names, which may contain embedded cues which are difficult to change in specific advertisements, non-brand cues can vary from advertisement to advertisement.

As can be seen in Table 37, the general distribution of country association is similar between Canadian and American publications. Statistically, the association to various countries has a significant difference between advertisements published in Canada versus the USA. A Pearson chi-square yield a significant result at the $p=0.05$ level.

It is important to mention that within Canadian magazines $9.5 \%$ of the prominent non-brand cues associate with the USA, while conversely only $0.8 \%$ of cues found in American magazines associate with Canada. The low number of prominent Canadian country cues in American publications is of potential concern, since the research indicates that Canadians tend to use and be the target of more $\mathrm{PCl}$ cues generally. Why so few Canadian-associated cues are used within the USA is very interesting and worth of further research.

\section{Table 37: Country Association of Prominent Non-Brand PCl Cues}

\begin{tabular}{|c|c|c|c|c|c|c|c|c|c|c|}
\hline \multirow{2}{*}{ P. } & \multicolumn{4}{|c|}{ Canade } & \multicolumn{4}{|c|}{ US: } & \multicolumn{2}{|c|}{ 10101810 } \\
\hline & $n=$ & $(\%)$ & Exp & Chi & Vil: & $(\%)$ & E18. & $\mathrm{Cal}$ & 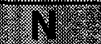 & 60818 \\
\hline Domestic PCl & 1247 & 46.1 & 1239 & 0.1 & 1153 & 45.5 & 1162 & 0.1 & 2400 & 45.8 \\
\hline Neighbour $\mathrm{PCl}^{\star}$ & 258 & 9.5 & 144 & 90.3 & 21 & 0.8 & 135 & 96.3 & 279 & 5.3 \\
\hline WW PCl & 408 & 15.1 & 470 & 8.1 & 502 & 19.8 & 440 & 8.6 & 910 & 17.4 \\
\hline Other $\mathrm{PCl}$ & 790 & 29.3 & 851 & 4.4 & 859 & 33.9 & 798 & 4.7 & 1649 & 31.5 \\
\hline Total & 2703 & 100 & & & 2535 & 100 & & & 5238 & 100 \\
\hline
\end{tabular}


From this analysis, it is obvious that the usage of $\mathrm{PCl}$ cues within magazine advertisements is quite substantial, with nearly 20,000 cues being observed in this sample and averaging over six cues per advertisement. It is interesting to find that more advertisements within Canadian publications tend to use $\mathrm{PCl}$ cues in general and more of them within each advertisement. Whether this has any connection to Canada being generally considered more of a "multicultural mosaic", and thus more accepting of favourable country association versus the American "melting pot", warrants further study.

\subsection{PCI INTENSITY ANALYSIS}

A total of all the $\mathrm{PCl}$ cues observed in each advertisement was recorded as the $\mathrm{PCl}$ intensity. This value was normalized, as explained in section 0 , to produce a 10-point scale, upon which analysis could be conducted.

This section begins with an overview of the $\mathrm{PCl}$ intensity observed overall and specifically comparing Canadian and American publications. Subsequently, in an attempt to determine if $\mathrm{PCl}$ intensity is influenced by any other factors, plots and cross-tabulations were produced to highlight potential correlations with respect to product category, execution style, appeal, advertiser's home country, and magazine type.

In comparing the $\mathrm{PCl}$ intensity between Canadian and American publications it appears that Canada is the target of more intense PCl advertisements, as detailed in Table 38. Statistical significance tests resulted in the country of publication being significant in the distribution of $\mathrm{PCl}$ intensity at the $p=0.05$ level. 
Table 38: Frequency Distribution of PCI Intensity

\begin{tabular}{|c|c|c|c|c|c|c|c|c|c|c|c|}
\hline \multicolumn{2}{|c|}{ (1ntensity } & \multicolumn{3}{|c|}{ Canada } & & & \multicolumn{2}{|c|}{ US: } & \multicolumn{3}{|c|}{ Total } \\
\hline 200 & Fange & N. & Exp: & Chit & $(\%)$ & N. & Ey. & ch & $(\%)$ & $M=$ & $(\%)$ \\
\hline 0 & 0 & 159 & 204 & 9.7 & 11.7 & 293 & 249 & 8.0 & 17.7 & 452 & 15.0 \\
\hline 1 & $1-8.2$ & 978 & 957 & 0.4 & 72.2 & 1149 & 1170 & 0.4 & 69.5 & 2127 & 70.7 \\
\hline 2 & $8.2-16.5$ & 162 & 146 & 1.8 & 12.0 & 162 & 178 & 1.5 & 9.8 & 324 & 10.8 \\
\hline 3 & $16.5-24.7$ & 33 & 28 & 0.9 & 2.4 & 29 & 34 & 0.8 & 1.8 & 62 & 2.1 \\
\hline 4 & $24.7-32.9$ & 4 & 7 & 1.4 & 0.3 & 12 & 9 & 1.2 & 0.7 & 16 & 0.5 \\
\hline 5 & $32.9-41.1$ & 9 & 6 & 1.2 & 0.7 & 5 & 8 & 0.9 & 0.3 & 14 & 0.5 \\
\hline 6 & $41.1-49.4$ & 3 & 2 & 0.8 & 0.2 & 1 & 2 & 0.7 & 0.1 & 4 & 0.1 \\
\hline 7 & 49.4-57.6 & 1 & 2 & $\overline{0.4}$ & 0.1 & 3 & 2 & 0.3 & 0.2 & 4 & 0.1 \\
\hline 8 & $57.6-65.8$ & 3 & 1 & 2.0 & 0.2 & 0 & 2 & 1.6 & 0.0 & 3 & 0.1 \\
\hline 9 & $65.8-74.0$ & 0 & 0 & 0.0 & 0.0 & 0 & 0 & 0.0 & 0.0 & 0 & 0.0 \\
\hline & $74.0-82.3$ & 2 & 1 & 1.3 & 0.1 & 0 & 1 & 1.1 & 0.0 & 2 & 0.1 \\
\hline To & tal & 1354 & & & 100 & 1654 & & & 100 & 3008 & 100 \\
\hline
\end{tabular}

It is interesting to note that only $15 \%$ of the sample contained no $\mathrm{PCl}$ cues with over $70 \%$ falling into the lowest category (1-7 cues per advertisement) overall. The highest recorded raw intensity in the sample was over $77 \mathrm{PCl}$ cues in a single advertisement, but only two such advertisements were observed in the Canadian publications and none in the American ones.

The distribution of intensity across product classes is more concentrated in Canadian publications, as can be observed in Figure 1. The majority of $\mathrm{PCl}$ cues were located in the cosmetics, food, personal health \& care, and toiletries categories in Canadian publications, while the American publication yielded a broader distribution of cues among the product classes.

High $\mathrm{PCl}$ intensity was observed in the education \& training and travel product classes in both Canadian and American publications. It is not surprising that these categories use $\mathrm{PCl}$ cues intensively since both rely heavily on country to draw potential clientele. The entertainment, financial services, toiletries, and issues, charities, NGO's product classes also displayed high usage of $\mathrm{PCl}$ cues in 
the Canadian publications, while the business services, home décor \& improvement, and telecomm were among the high users in the American publications (please see Appendix I for the detailed data of normalized PCI intensity by product class).

As expected, the $\mathrm{PCl}$ execution style was used in advertisements which had the highest $\mathrm{PCl}$ intensity scores both in Canadian and American publications. The straight-sell execution category also yielded high $\mathrm{PCl}$ cues usage in both countries, which could be associated to the notion that direct country correlation was used to promote quality and the direct sell approach (please see Appendix $\mathrm{J}$ for the detailed data).

From Figure 2 and the detailed data in Appendix $\mathrm{K}$, the econ/price/value, information, and lifestyle appeals represent the highest $\mathrm{PCl}$ intense advertisements. As with the execution style analysis, Canadian and American publication tend to follow a similar distribution of the usage of the intensity of $\mathrm{PCl}$ cue usage. The benefit, features, humour, information, joy-body, and lifestyle appeals represent advertisement which used $\mathrm{PCl}$ cues 


\section{Figure 1: Normalized PCI Intensity by Product Class}

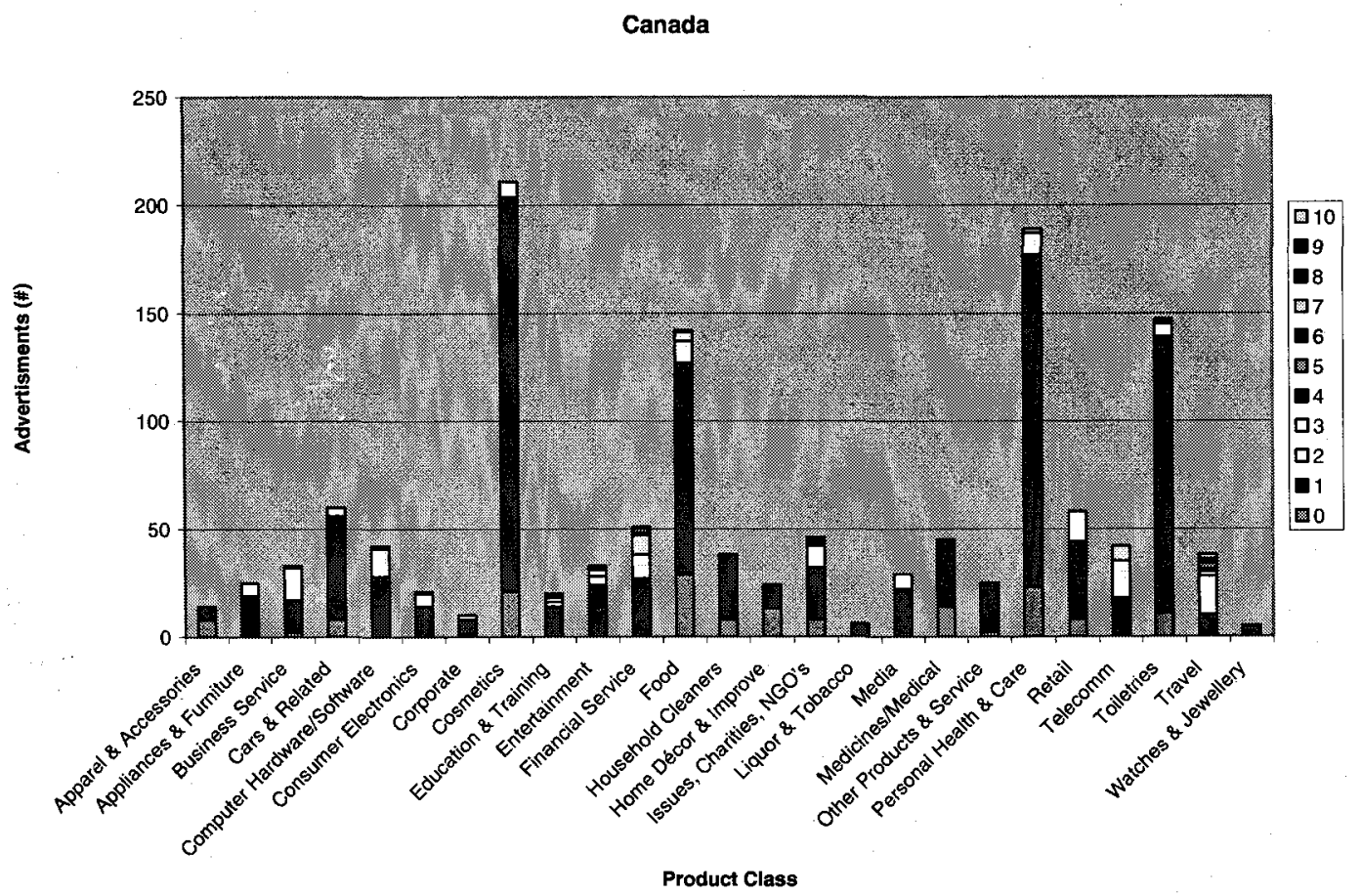

USA

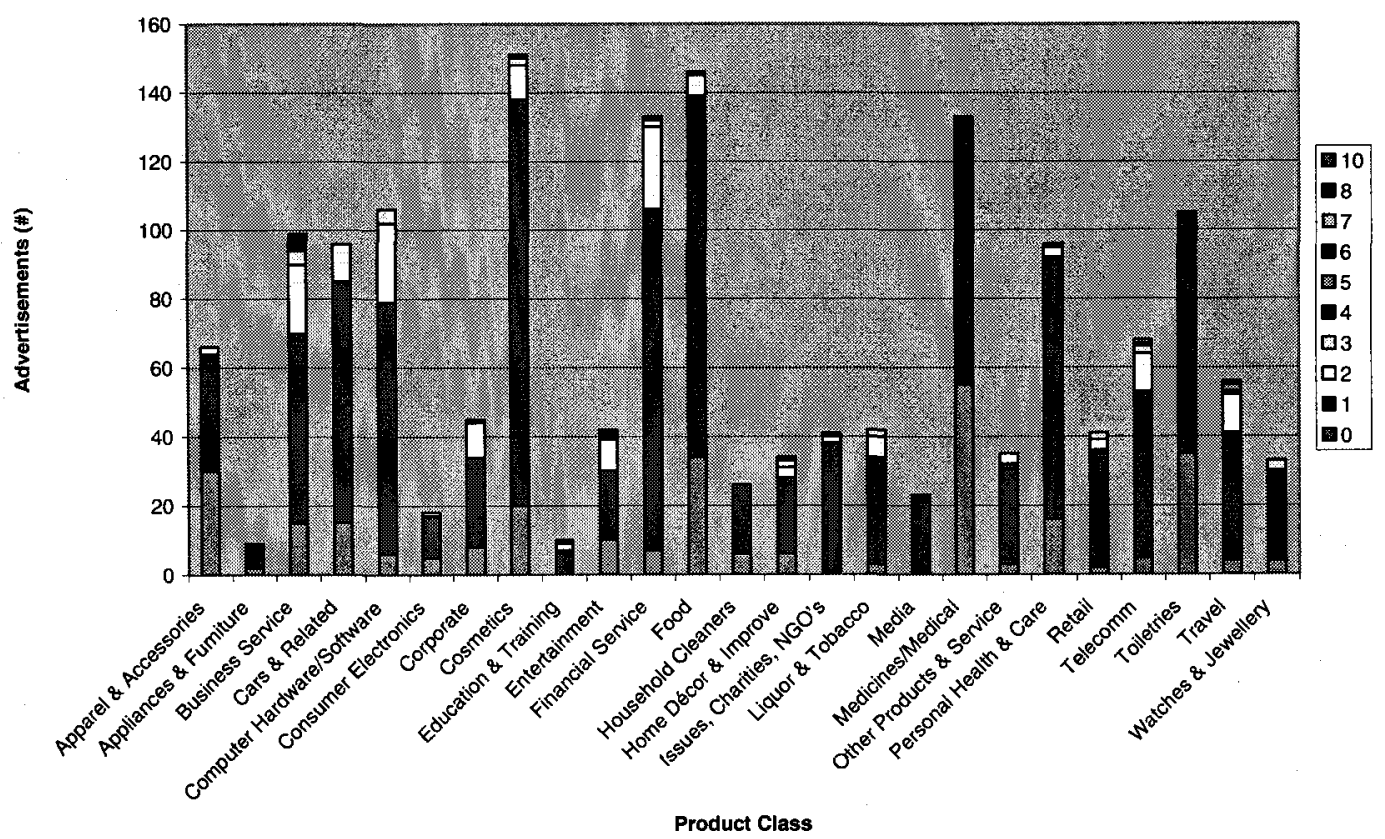




\section{Figure 2: Normalized PCI Intensity by Appeal}

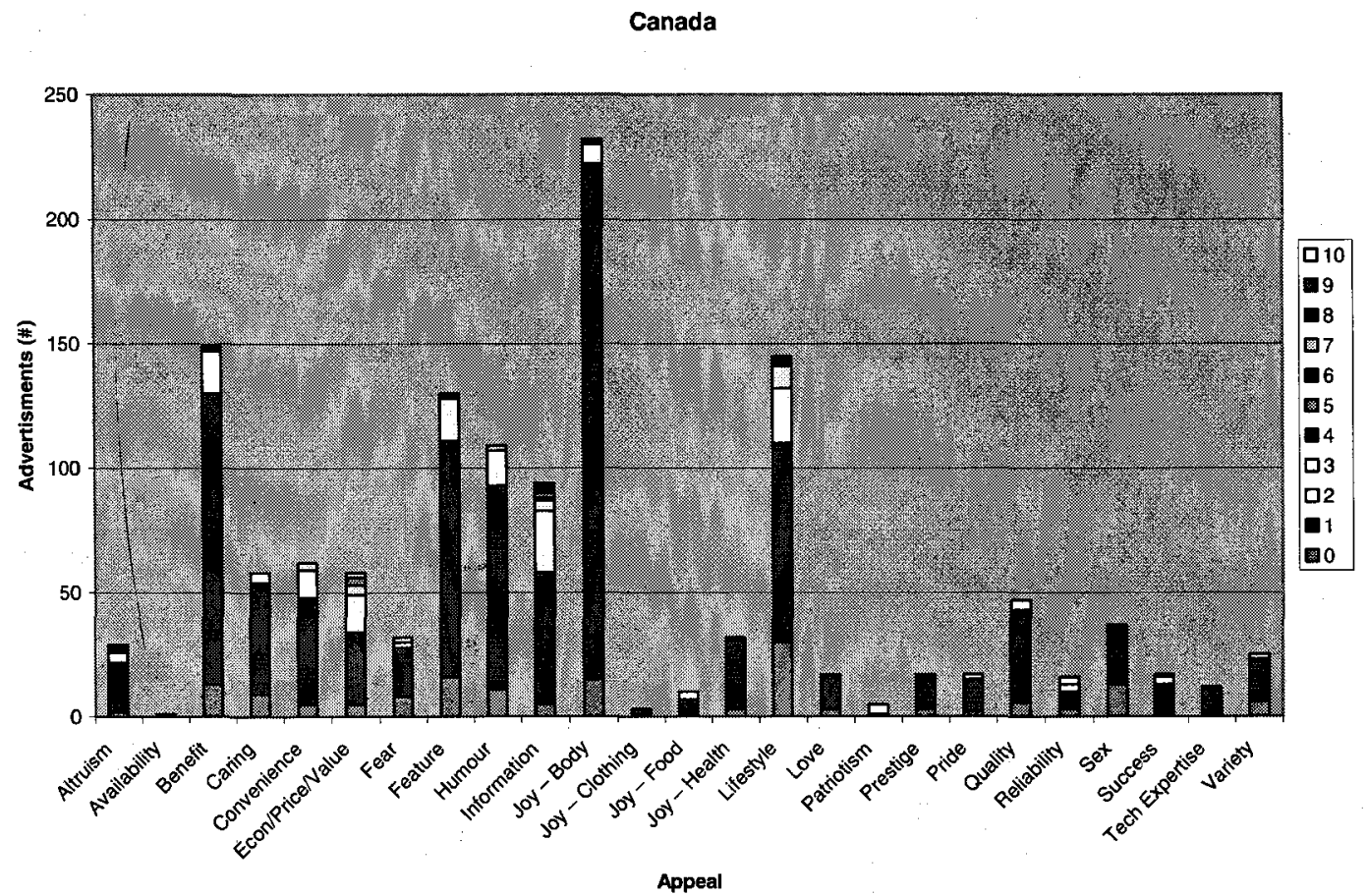

USA

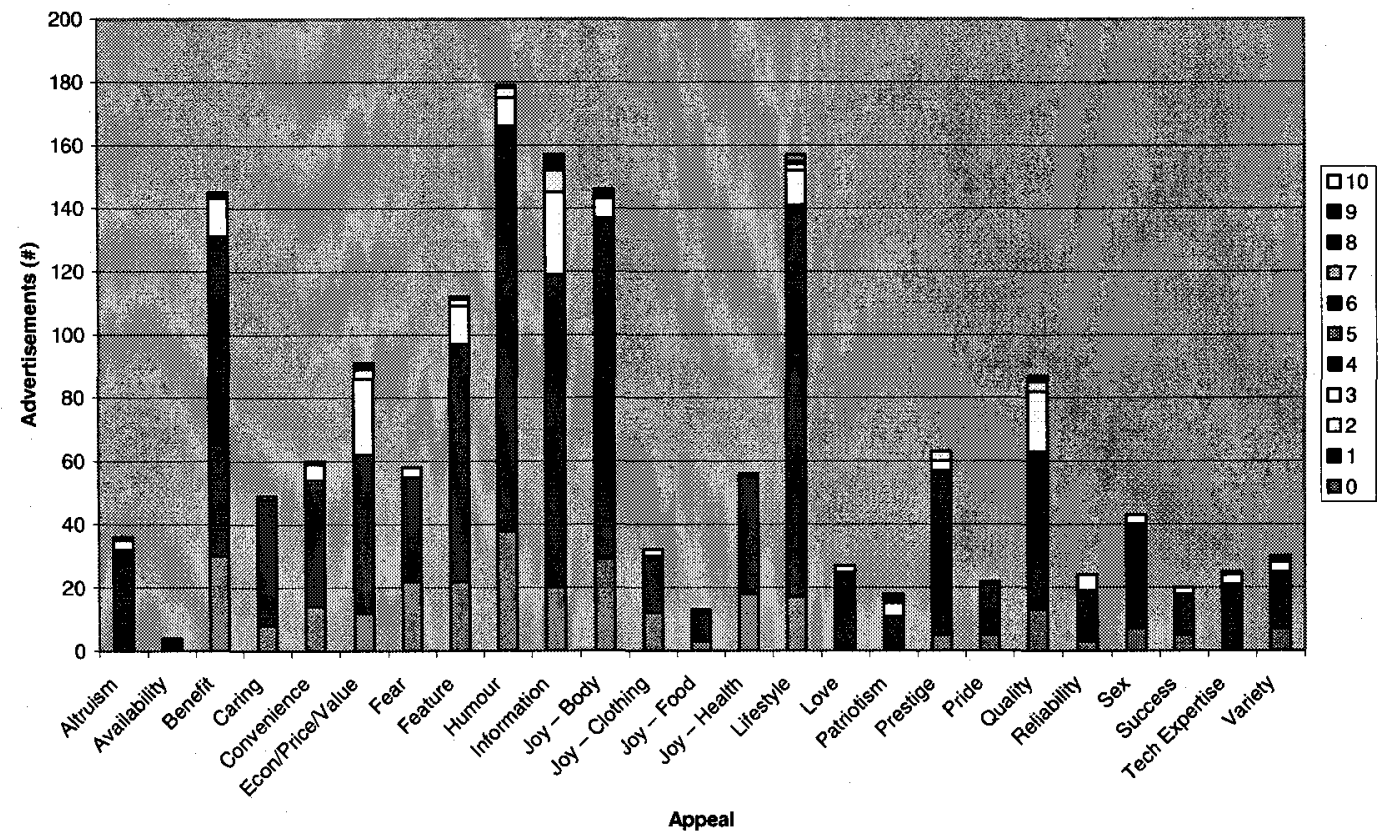

Figure 3 represents the distribution of $\mathrm{PCl}$ intensity among the execution styles. From the figure it can be seen that Canadian and American publications 
have a very similar distribution of the quantity of $\mathrm{PCl}$ usage. The consumer-image, consumer-vignette, product-association, product-demonstration, and productillustration product classes represent the high users of $\mathrm{PCl}$ cues in both countries of publication within the sample.

In the analysis of the advertiser's home country influence on the intensity of $\mathrm{PCl}$ cue usage, it is interesting to note that Canadian firms advertising in Canada used a great deal of $\mathrm{PCl}$ intense advertisements, while not advertising much in the USA nor using intense advertisements (please see details in Appendix $L$ for the detailed data). Conversely, American advertisers advertising in both Canada and the USA used a great deal of $\mathrm{PCl}$ cues, using more cue saturated advertisements in Canada. This is summarized in Figure 4 below. 


\section{Figure 3: Normalized PCI Intensity by Execution Style}

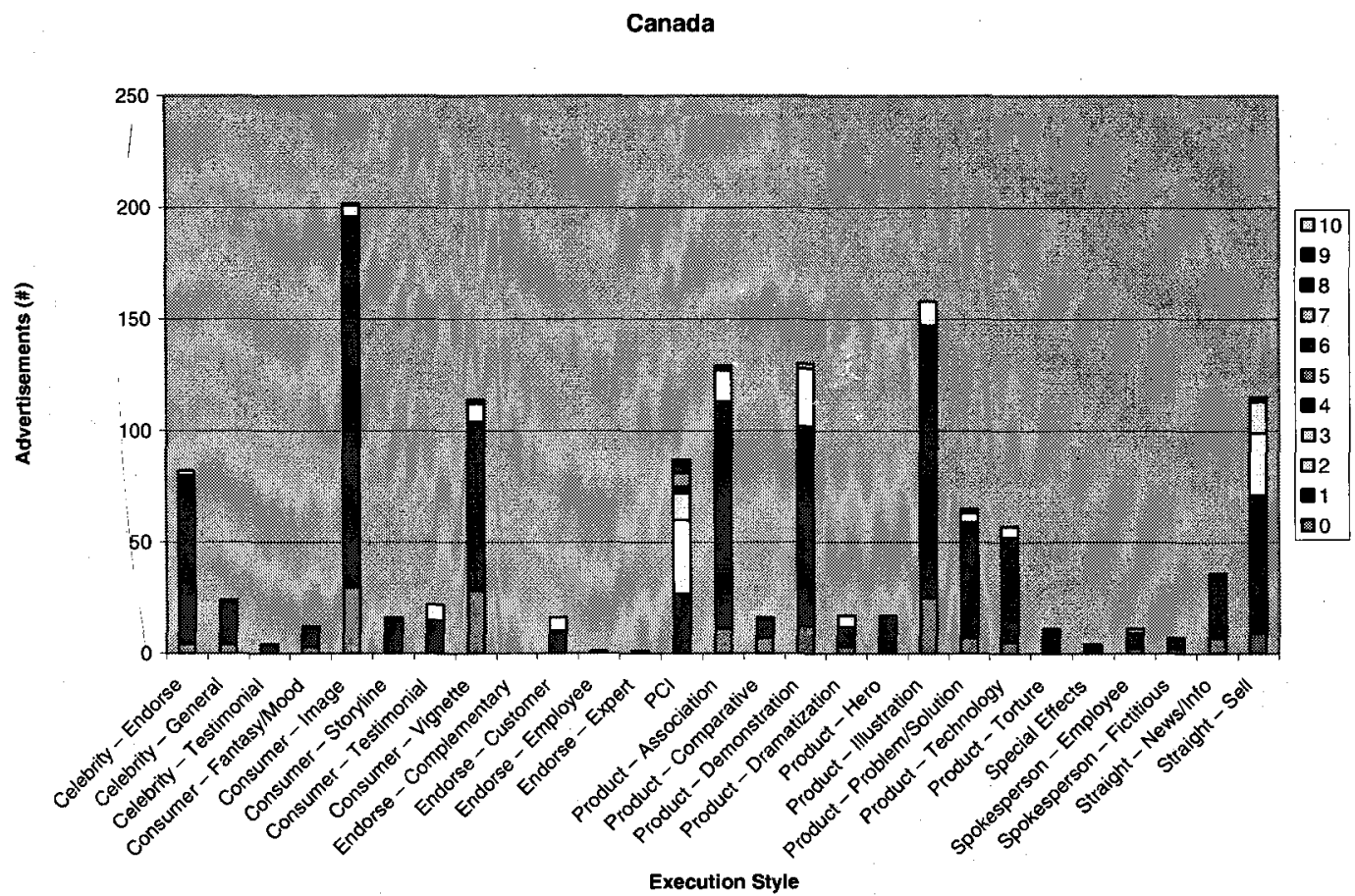

USA

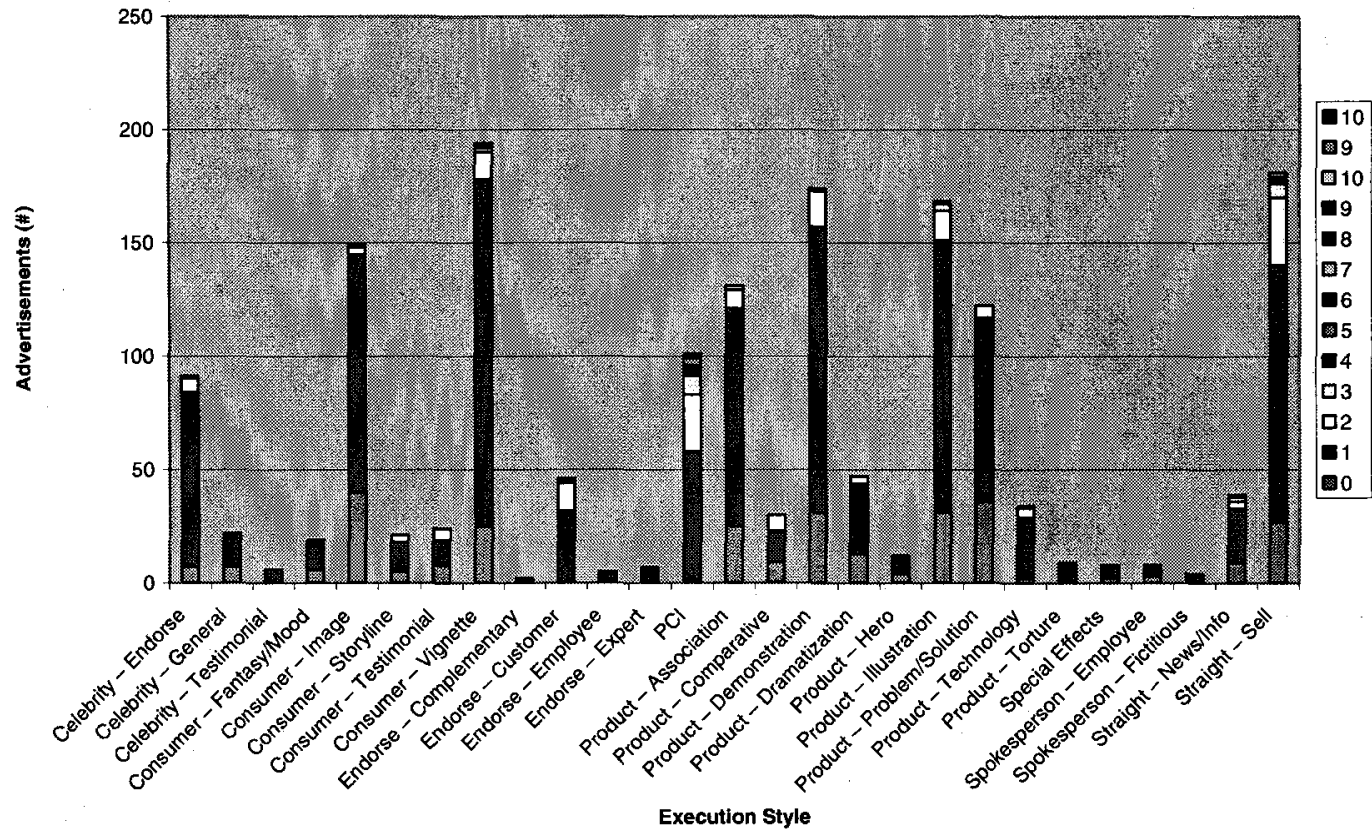


Figure 4: Normalized PCI Intensity by Advertiser's Home Country

Canada

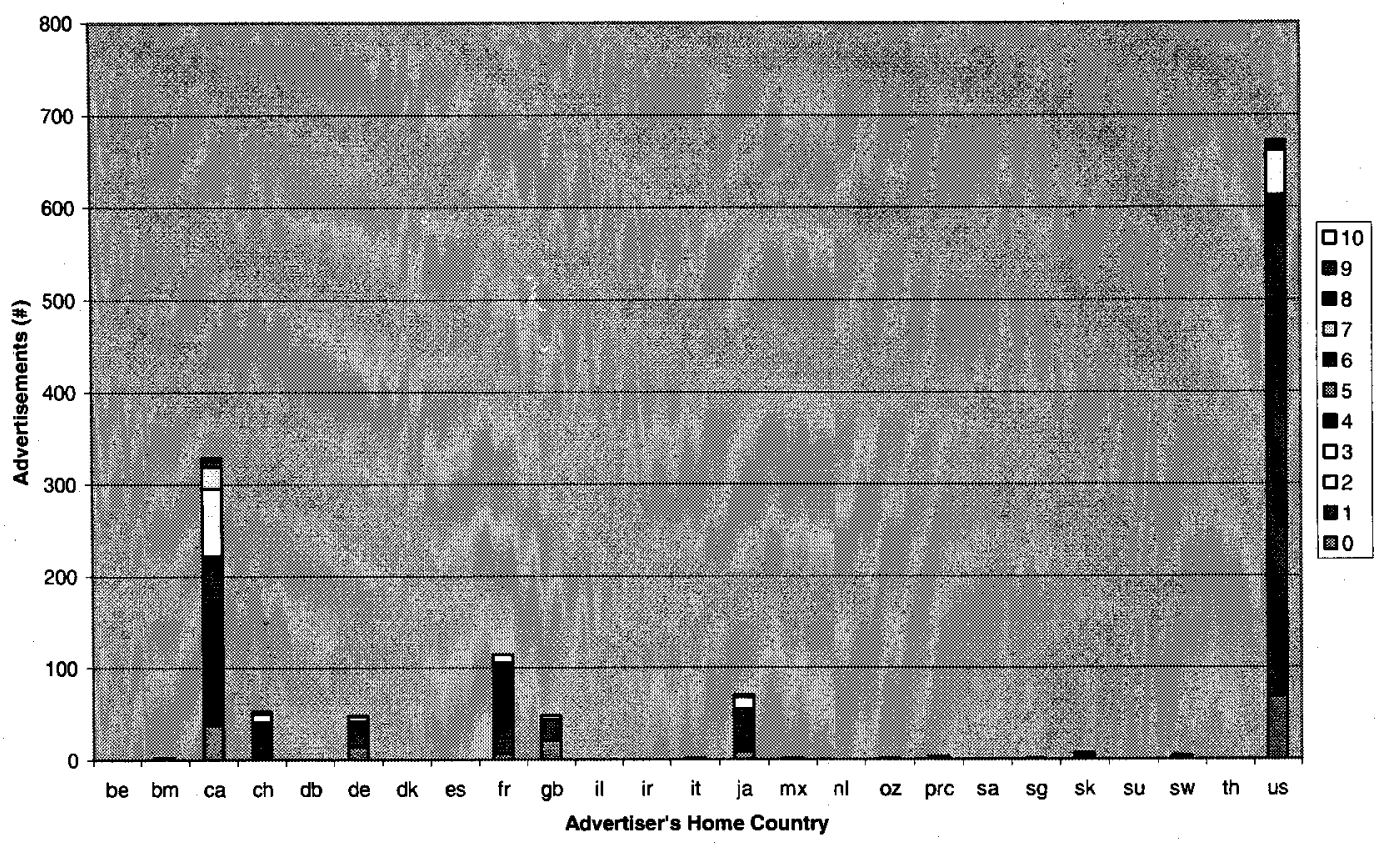

USA

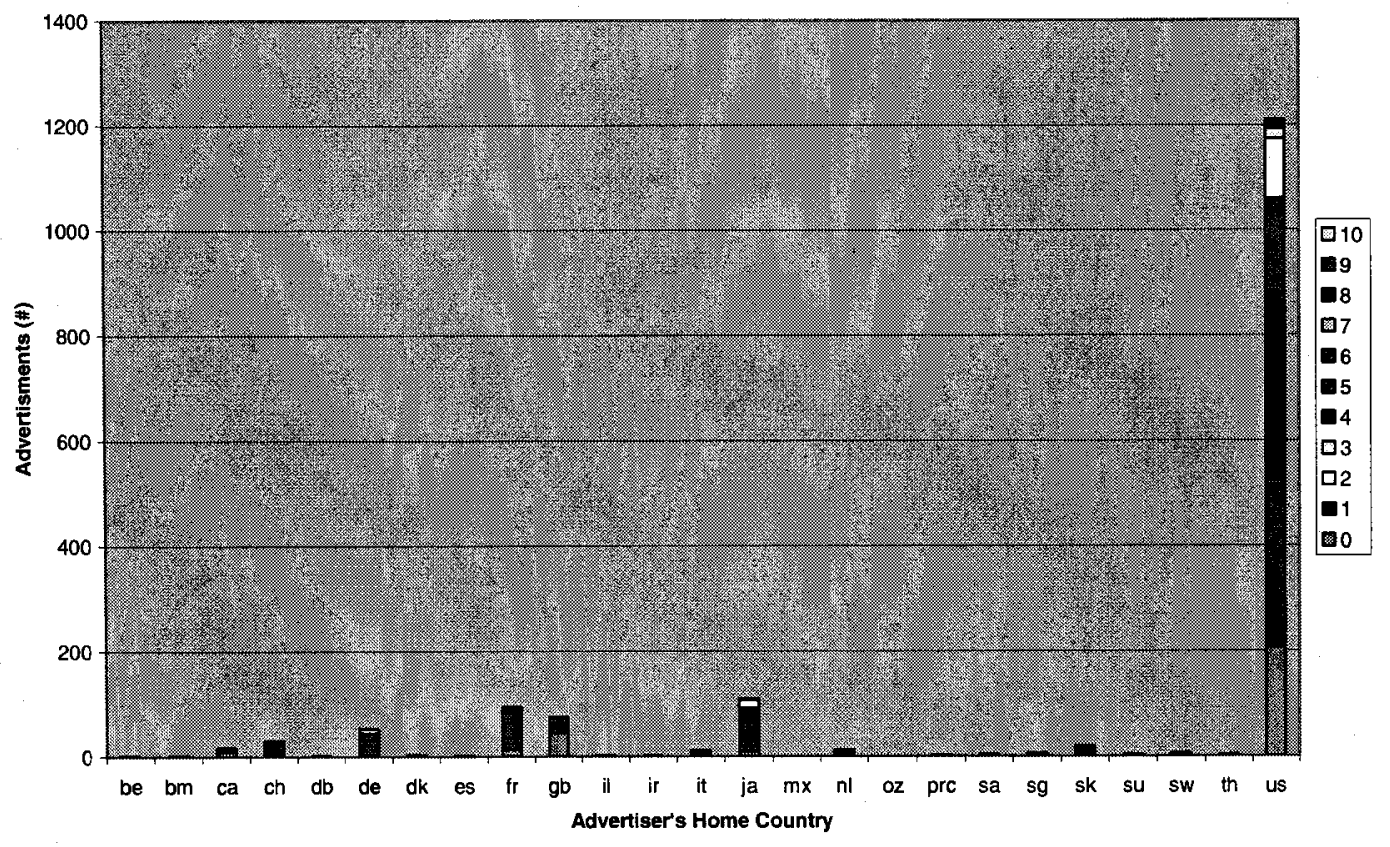

Analysis of the $\mathrm{PCl}$ intensity across the magazine types resulted in business magazines having the most $\mathrm{PCl}$ saturated advertisements with news magazines 
ranked second. Perhaps this can be accounted to the readers of business and news magazines being predominantly higher educated and thus more likely to accept country association (please see Appendix $M$ for the detailed data). This pattern was observed in both Canadian and American publications, as summarized in Figure 5.

\section{Figure 5: Normalized PCI Intensity by Magazine Type}

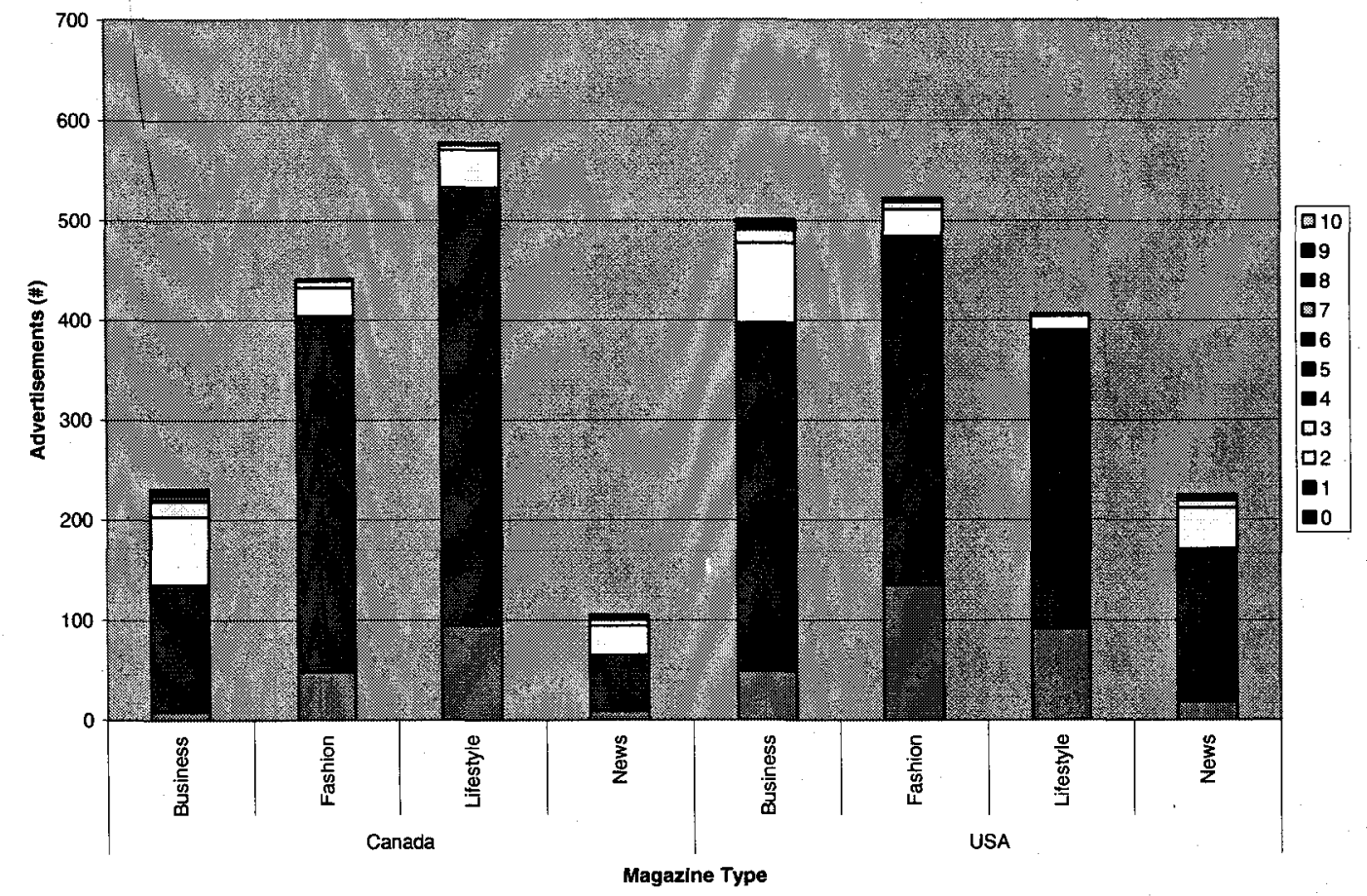

The Canadian fashion magazine, Glow, contained more $\mathrm{PCl}$ intense advertisements than the American counterpart; similar results were observed with lifestyle magazines; however, in both the fashion and lifestyle magazines much lower $\mathrm{PCl}$ intensity was observed.

From these results, it appears that Canada is the target of more $\mathrm{PCl}$-intense advertisements. It is not surprising that the analysis resulted in high $\mathrm{PCl}$ intensity being observed in travel and education \& training advertisements in both Canadian 
and American publications. Similarly it is not surprising to find that advertisements, which used $\mathrm{PCl}$ as an execution style, were also observed as having high $\mathrm{PCl}$ intensity.

\subsection{PCI STRENGTH ANALYSIS}

The $\mathrm{PCl}$ strength was a subjective qualitative measurement of how strong the overall country association was within an advertisement. The rating ranged from 17 for all advertisements which contained $\mathrm{PCl}$ cues as detailed in section 7.8. This section will provide details of the overall distribution of the strength within the sample. Afterwards, product class, execution style, appeals, advertiser's home country, and magazine type will be cross-tabulated to point out patterns in the overall sample and between Canadian and American publications. The section will conclude with an overview of the $\mathrm{PCl}$ strength used in business versus consumer advertisements and across product, services, places, and corporate advertisements.

The analysis of the strength was initially judged for just the non-brand $\mathrm{PCl}$ cues. On the initial subjective count, the level of full agreement (no differences between the judges) was $63.2 \%$, with a marginal level (a difference in subjective judging of 1 ) of $81.7 \%$. The Scott's Pi calculation yielded $78.7 \%$ agreeability. As the literature has indicated, a level of agreeability of greater than $80 \%$ should be sufficient for most cases while Lombard, Snyder-Duch, and Bracken (2002) have argued that a level of $70 \%$ is sufficient for exploratory research and have further maintained that more liberal criteria can be used for Scott's Pi measures. Therefore, it is considered that the initial measure has high inter-judge agreeability and subsequently reliability. 
The brand $\mathrm{PCl}$ cues were also examined and combined to generate an overall $\mathrm{PCl}$ strength for each advertisement. Due to time limitations, only one judge was able to perform a subjective analysis on the brand $\mathrm{PCl}$ cues and combine the score. However, the high levels of agreeability in the non-brand cues and through the other classifications, suggests that the single-judge final measure is inlikely to differ substantively from a combined two-judge assessment. This combined score was used for the analysis of the relative $\mathrm{PCl}$ strength.

The overall distribution of the relative strength approached a normal distribution curve, as can be seen in Figure 6, except for a large number of advertisements which were rated as 1 on the scale. This suggests that a noteworthy portion of advertisers (25.4\%) may have included $\mathrm{PCl}$ cues within their advertisements passively, either for legal reasons or incidentally rather than as part of a specific strategy. Overall the mean subjective rating on the 1-7 scale was 3.0.

\section{Figure 6: Frequency Distribution of PCI Strength}

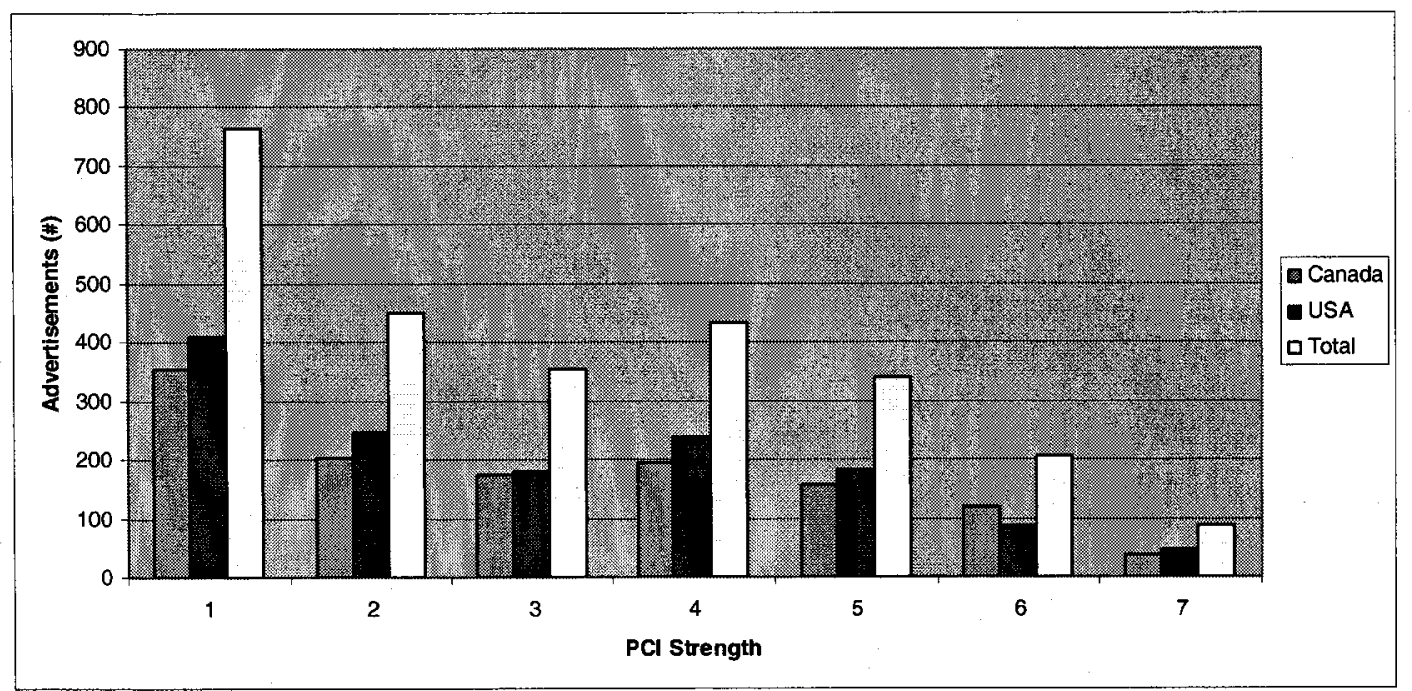


In order to highlight patterns of note, throughout this section, all values within the subsequent tables which are more than one standard deviation away from the mean are highlighted.

A look at PCl strength across product categories offers similar results to the use of execution styles, as indicated in section 8.2. Table 45 provides details of the average $\mathrm{PCl}$ strength observed in each product class. Travel, liquor \& tobacco, education \& training, cars \& related, watches \& jewellery, and media are the topmost classes which match with several of the product classes that used $\mathrm{PCl}$ as an execution the most. On the other end of the scale toiletries, medicines/medical, and home décor \& improvement had the lowest $\mathrm{PCl}$ strength observed. Of these classes, toiletries and medicine/medical did not use $\mathrm{PCl}$ as an execution style in very many of the advertisements in the sample (please see Appendix F for details). 
Table 39: Average PCI Strength by Product Class

\begin{tabular}{|l|c|c|c|}
\hline \multicolumn{1}{|c|}{ Product Class } & Candor & USA & To \\
\hline Travel & 5.3 & 4.3 & 4.7 \\
\hline Liquor \& Tobacco & 4.5 & 4.7 & 4.7 \\
\hline Education \& Training & 4.7 & 3.5 & 4.3 \\
\hline Cars \& Related & 4.3 & 4.1 & 4.2 \\
\hline Watches \& Jewellery & 3.0 & 4.3 & 4.1 \\
\hline Media & 4.8 & 2.9 & 4.0 \\
\hline Financial Services & 4.5 & 3.6 & 3.9 \\
\hline Corporate & 4.0 & 3.5 & 3.6 \\
\hline Entertainment & 3.8 & 3.2 & 3.5 \\
\hline Telecomm & 3.8 & 3.1 & 3.4 \\
\hline Business Services & 3.1 & 3.2 & 3.2 \\
\hline Other Products \& Services & 3.3 & 3.1 & 3.2 \\
\hline Retail & 3.5 & 2.7 & 3.2 \\
\hline Issues, Charities, NGO's & 3.9 & 2.4 & 3.1 \\
\hline Computer Hardware/Software & 3.0 & 2.8 & 2.9 \\
\hline Consumer Electronics & 2.8 & 3.1 & 2.9 \\
\hline Cosmetics & 3.0 & 2.8 & 2.9 \\
\hline Food & 2.8 & 2.9 & 2.9 \\
\hline Household Cleaners & 2.3 & 3.2 & 2.9 \\
\hline Apparel \& Accessories & 3.0 & 2.6 & 2.7 \\
\hline Personal Health \& Care & 2.6 & 2.1 & 2.5 \\
\hline Appliances \& Furniture & 2.2 & 2.0 & 2.2 \\
\hline Toiletries & 1.9 & 1.8 & 1.9 \\
\hline Medicines/Medical & 1.9 & 1.7 & 1.8 \\
\hline Home Décor \& Improvement & 1.3 & 1.0 & 1.2 \\
\hline Total & 3.1 & 3.0 & 3.0 \\
\hline Standard Deviation & 1.0 & 0.9 & 0.9 \\
\hline Highlighted values are more than a standard deviation away \\
from the mean & & & \\
\hline Table ordered by total PCl strength & & & \\
\hline
\end{tabular}

When $\mathrm{PCl}$ strength was compared against execution style it is not surprising that the $\mathrm{PCl}$ execution was ranked as first overall by over three standard deviations. The details of this can be seen in Table 40 . Most of the remaining executions had $\mathrm{PCl}$ strengths around the mean except for the endorsementcomplementary style which was considerably higher than the mean and the product-hero, celebrity-testimonial, and product torture styles which were all quite lower than the mean. 
Table 40: Average PCI Strength by Execution Style

\begin{tabular}{|l|c|c|c|}
\hline PCI & Canadecution Style & US & Tot \\
\hline Endorse-Complementary & $\mathbf{6 . 0}$ & 5.9 & 5.9 \\
\hline Spokesperson-Employee & 3.9 & 4.0 & 4.0 \\
\hline Celebrity-Endorse & 4.1 & 3.0 & 3.7 \\
\hline Endorse-Expert & 4.0 & 3.5 & 3.6 \\
\hline Product-Dramatization & 3.5 & 3.7 & 3.6 \\
\hline Consumer-Fantasy/Mood & 3.5 & 3.5 & 3.5 \\
\hline Endorse-Customer & 3.7 & 2.9 & 3.1 \\
\hline Special Effects & 1.3 & 4.3 & 3.1 \\
\hline Spokesperson-Fictitious & 4.2 & 1.8 & 3.1 \\
\hline Product-Association & 3.0 & 2.9 & 3.0 \\
\hline Straight-News/Info & 2.6 & 3.4 & 3.0 \\
\hline Consumer-Testimonial & 2.7 & 3.2 & 2.9 \\
\hline Product-Illustration & 2.8 & 3.0 & 2.9 \\
\hline Straight-Sell & 3.4 & 2.6 & 2.9 \\
\hline Consumer-Storyline & 2.6 & 3.1 & 2.8 \\
\hline Endorse-Employee & 2.0 & 3.0 & 2.8 \\
\hline Product-Demo & 2.8 & 2.7 & 2.8 \\
\hline Product-Technology & 2.7 & 2.7 & 2.7 \\
\hline Celebrity-General & 2.8 & 2.4 & 2.6 \\
\hline Consumer-Vignette & 2.3 & 2.7 & 2.6 \\
\hline Product-Problem/Solution & 2.6 & 2.5 & 2.6 \\
\hline Product-Comparative & 2.1 & 2.7 & 2.5 \\
\hline Consumer-Image & 2.5 & 2.2 & 2.4 \\
\hline Product-Hero & 2.2 & 1.9 & 2.1 \\
\hline Celebrity-Testimonial & 1.8 & 2.0 & 1.9 \\
\hline Product-Torture & 1.5 & 2.1 & 1.8 \\
\hline Total & 3.1 & 3.0 & 3.0 \\
\hline Standard Deviation & 1.2 & 0.8 & 0.8 \\
\hline Highlighted values are more than & a standard deviation away \\
from the mean & & & \\
\hline Table ordered by totalPCl strength & & \\
\hline & & & \\
\hline
\end{tabular}

Similarly to the execution style comparison, when $\mathrm{PCl}$ strength was compared to the appeals used within each advertisement the patriotism appeal was ranked near the top, $2^{\text {nd }}$ overall. The variety appeal contained advertisements with the highest average strength in the sample. As can been seen in Table 41, the variety appeal's $\mathrm{PCl}$ strength averages more than three standard deviations above the mean. The sex appeal class also contains advertisements which had a higher strength of $\mathrm{PCl}$ usage than the average. 
Table 41: Average PCI Strength by Appeal

\begin{tabular}{|l|c|c|c|}
\hline \multicolumn{1}{|c|}{ Appeal } & Canada & USA & Total \\
\hline Variety & 6.6 & 6.2 & 6.3 \\
\hline Patriotism & 4.2 & 4.4 & 4.3 \\
\hline Sex & 4.4 & 3.8 & 4.1 \\
\hline Lifestyle & 4.1 & 3.6 & 3.8 \\
\hline Altruism & 4.3 & 2.9 & 3.5 \\
\hline Econ/Price/Value & 3.9 & 3.1 & 3.4 \\
\hline Joy-Food & 2.9 & 3.8 & 3.4 \\
\hline Information & 3.7 & 3.1 & 3.3 \\
\hline Quality & 3.0 & 3.5 & 3.3 \\
\hline Reliability & 3.5 & 2.9 & 3.2 \\
\hline Humour & 3.1 & 3.0 & 3.1 \\
\hline Success & 3.5 & 2.9 & 3.1 \\
\hline Joy-Health & 3.6 & 2.6 & 3.0 \\
\hline Prestige & 2.8 & 3.2 & 3.0 \\
\hline Pride & 2.6 & 3.3 & 3.0 \\
\hline Convenience & 2.5 & 3.0 & 2.7 \\
\hline Tech Expertise & 2.4 & 2.9 & 2.7 \\
\hline Feature & 2.7 & 2.4 & 2.6 \\
\hline Joy-Body & 2.7 & 2.3 & 2.6 \\
\hline Joy-Clothing & 4.0 & 2.4 & 2.6 \\
\hline Benefit & 2.5 & 2.5 & 2.5 \\
\hline Caring & 2.6 & 2.5 & 2.5 \\
\hline Love & 2.3 & 2.7 & 2.5 \\
\hline Availability & 4.0 & 2.0 & 2.4 \\
\hline Fear & 2.2 & 2.1 & 2.2 \\
\hline Total & 3.1 & 3.0 & 3.0 \\
\hline Standard Deviation & 1.2 & 1.2 & 1.0 \\
\hline $\begin{array}{l}\text { Highlighted values are more than a standard deviation away } \\
\text { from the mean }\end{array}$ & \multicolumn{3}{|l}{} \\
\hline Table ordered by total PCl strength & & \\
\hline & \multicolumn{3}{|l}{} \\
\hline
\end{tabular}

As can be seen above, the sex appeal has the weakest strength associated with it but still using $\mathrm{PCl}$ cues.

The relative strength of $\mathrm{PCl}$ classified by the advertisers' home country was an interesting observation. Table 42 summarizes this, where it becomes clear that several countries have firms which generate advertisements with very high $\mathrm{PCl}$ strengths. Ireland, Singapore, Thailand, China, and Mexico, who are at the top of the list, correspond to very few advertisements within the sample $(1,6,2,4$, and 1 
respectively) and the level of $\mathrm{PCl}$ use is not surprising since the advertisements were about tourism, investment attraction, and other place-bound offerings. Conversely, several highly developed countries such as Switzerland, France, and Germany, which are generally viewed favourably, did not correspond with advertisements with strong $\mathrm{PCl}$ usage.

Table 42: Average PCI Strength by Advertiser's Home Country

\begin{tabular}{|l|c|c|c|}
\hline & Canada & USt & Total \\
\hline Canada & 3.9 & 3.5 & 3.9 \\
\hline USA & 2.3 & 2.7 & 2.5 \\
\hline
\end{tabular}

\begin{tabular}{|l|c|c|c|}
\hline & \multicolumn{3}{l|}{} \\
\hline Ireland & & 7.0 & $\mathbf{7 . 0}$ \\
\hline Singapore & 6.0 & 6.6 & 6.5 \\
\hline China & 6.3 & 4.0 & 5.8 \\
\hline Bermuda & 4.5 & 5.0 & 4.7 \\
\hline Sweden & 3.0 & 6.0 & 4.7 \\
\hline Italy & 1.0 & 4.9 & 4.5 \\
\hline Switzerland & 4.1 & 4.5 & 4.3 \\
\hline France & 4.3 & 3.9 & 4.2 \\
\hline Denmark & & 4.0 & 4.0 \\
\hline Germany & 3.5 & 4.1 & 3.9 \\
\hline Japan & 3.5 & 3.7 & 3.6 \\
\hline United Kingdom & 3.7 & 3.5 & 3.6 \\
\hline Israel & & 3.0 & 3.0 \\
\hline South Korea & 2.6 & 2.9 & 2.8 \\
\hline Spain & & 2.0 & 2.0 \\
\hline Netherlands & & 2.0 & 2.0 \\
\hline Finland & & 2.0 & 2.0 \\
\hline Belgium & & 1.0 & 1.0 \\
\hline Australia & 1.0 & & 1.0 \\
\hline
\end{tabular}

\begin{tabular}{|l|c|c|c|}
\hline \multicolumn{3}{|c|}{ Transitional } \\
\hline Thailand & & 6.5 & 6.5 \\
\hline Mexico & 6.0 & & 6.0 \\
\hline Dubai & & 5.0 & 5.0 \\
\hline South Africa & & 2.0 & 2.0 \\
\hline Grand Total & 3.1 & 3.0 & 3.0 \\
\hline Standard Deviations & 1.3 & 1.8 & 1.9 \\
\hline $\begin{array}{l}\text { Highlighted values are more than a standard deviation away } \\
\text { from the mean }\end{array}$ \\
\hline \multicolumn{4}{|l|}{ Table ordered by total PCl strength } \\
\hline
\end{tabular}


The $\mathrm{PCl}$ strength of advertisements by magazine type is detailed in Table 43 . What is interesting to note is that business and news magazines tend to have advertisements with a higher $\mathrm{PCl}$ strength. This is interesting from two different perspectives; product class and target consumer.

One would expect that travel, entertainment, watches \& jewellery, and liquor \& tobacco products, which represented the highest $\mathrm{PCl}$ strength as detailed earlier, would be primarily found in consumer magazines (fashion and lifestyle). However, as indicated, fashion and lifestyle magazine have a lower PCl strength.

With respect to target consumer, $\mathrm{PCI}$ is commonly considered an emotional construct while the literature tends to refer to business consumers as acting rational. Thus the observed pattern in $\mathrm{PCl}$ strength is noteworthy since the use of an emotional cue on a rational consumer is interesting. This topic will be touched on more in the discussion and concluding chapter of this research.

\section{Table 43: Average PCI Strength by Magazine Type}

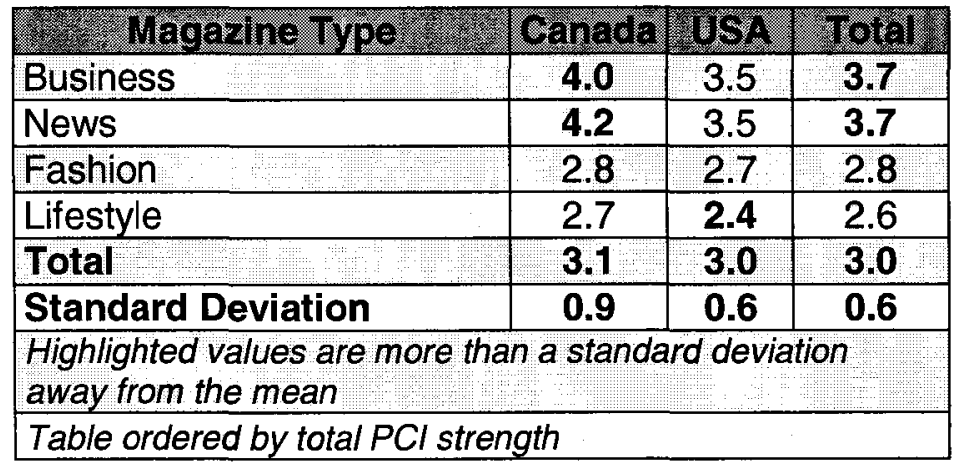

In comparing the relative strength of $\mathrm{PCl}$ usage between business and consumer advertisements, business targeted advertisements have a slightly higher strength as is summarized in Table 44. In the Canadian publications the difference is more pronounced with business targeted advertisements have a higher relative $\mathrm{PCl}$ strength. As mentioned above, this may have to do with target markets and the 
assumption that business consumers have a higher education and thus more likely to understand and make positive country associations. Additionally, this may be due to the abundance of "global" claims by business consumer advertisers.

Table 44: Average PCI Strength by Advertisement Type

\begin{tabular}{|l|c|c|c|}
\hline Advertisement Type & Canada & USA & Total \\
\hline Business & 3.7 & 2.9 & 3.1 \\
\hline Consumer & 2.8 & 2.4 & 2.6 \\
\hline Total & 2.8 & 2.5 & 2.7 \\
\hline Standard Deviation & 0.8 & 0.4 & 0.4 \\
\hline $\begin{array}{l}\text { Highlighted values are more than a standard deviation } \\
\text { away from the mean }\end{array}$ \\
\hline \multicolumn{4}{|l|}{ Table ordered by total $P C l$ strength } \\
\hline
\end{tabular}

Finally the $\mathrm{PCl}$ strength was evaluated across the varying product and service types. Four classes of advertisements were distinguished in the sample: corporate, place, product, and service. From the results listed in Table 45, place advertisements have an observably higher $\mathrm{PCl}$ strength on average than the remainirig advertisement classes. This coincides with the travel product class being the highest users of $\mathrm{PCl}$ as an execution style. The remaining advertisement types do not yield any major differences in their $\mathrm{PCl}$ strength.

\section{Table 45: Average PCI Strength by Product Type}

\begin{tabular}{|l|c|c|c|}
\hline \multicolumn{1}{|c|}{ Product Type } & Canada & USA & Totat \\
\hline Place & 6.3 & 5.9 & 6.1 \\
\hline Service & 3.7 & 3.0 & 3.3 \\
\hline Corporate & 3.6 & 3.1 & 3.2 \\
\hline Product & 2.5 & 2.3 & 2.4 \\
\hline Total & 2.8 & 2.5 & 2.7 \\
\hline Standard Deviation & 2.1 & 1.8 & 1.8 \\
\hline $\begin{array}{l}\text { Highlighted values are more than a standard deviation } \\
\text { away from the mean }\end{array}$ \\
\hline
\end{tabular}

The $\mathrm{PCl}$ strength represented a qualitative and subjective evaluation of the strength of usage of country association within each advertisement. It is not 
surprising that when correlated with the various other variables, high $\mathrm{PCl}$ strength was noted in advertisements which utilized $\mathrm{PCl}$ as an execution style, used the patriotic appeal, or advertised from the travel product class. It is interesting to note that many of the countries who represented few advertisements in the sample tended to use $\mathrm{PCl}$ very strongly. 


\section{CHAPTER 9 DISCUSSION AND CONCLUSION}

The effectiveness of country association on consumers' buying behaviour has been the focus of extensive research over the last 40 years. The purpose of this research has been to examine how practitioners use the influence that $\mathrm{PCl}$ can have on promoting the value, quality, and acceptance of products and services by the consumer. It has also highlighted several differences in the use of country association in Canadian and American advertising. This section discuses specific examples of advertisements, which use country imagery as well as summarizing the overall purpose of this research, which was to address the frequency by which $\mathrm{PCl}$ is used as an execution style, appeal, and as individual country cues.

The combination approach is very apparent within magazine advertising. L'Oréal Paris, for example, ran the same advertisement in Canadian and American lifestyle magazines. Within the Canadian version however the brand appeared as Excellence Crème while the same advertisement in the American magazine appeared as Excellence Creme, without the 'é'. The reasons behind why such a subtle difference was included in the different version of the advertisement is unknown based upon this research, as it focused on examining what is occurring in advertising not why, but it does demonstrate an active effort by practitioners to adapt advertisements on a country basis. Appendix F contains a copy of both advertisements for reference.

This is similar to a Maybelline New York advertisement, where its American version has the title Maybelline New York on the package shot, while the Canadian version simply reads Maybelline. (Please see Appendix $G$ for the specific advertisements). 
Various other interesting observations were made, as well. For instance, out of the three major Japanese automotive manufactures, which advertised within the sample, the luxury division of Toyota, Lexus, never associated itself with its parent company. Honda's Acura division contained five American advertisements, of which four associated with the parent firm, while four Canadian advertisements for the same division did not. Finally, Infiniti, Nissan's luxury division, closely associated itself with Nissan in American advertisement but did not in Canadian ones.

These subtle differences are very interesting and warrant further research to determine why they occur.

The data has made it apparent that $\mathrm{PCl}$ is being widely used in magazine advertising. With almost 20,000 country cues observed in the sample and almost $90 \%$ of all advertisements containing some form of $\mathrm{PCl}$ cue, it is obvious that practitioners are aware of the influences that $\mathrm{PCl}$ can have on buyer's behaviour.

As one might expect, many of these cues focus on travel, education \& training, and liquor \& tobacco products. However, it is noteworthy that Canadian publications are the recipients of more advertisements using $\mathrm{PCl}$ as an execution style and contain more $\mathrm{PCl}$ cues overall. Additionally, it is interesting that there is a much higher concentration of country cues in business and news magazines. This may be explained by the assumed higher education of business and news magazine readers and therefore their increased likelihood of positive product country associations.

Furthermore, it is noteworthy that advertisers from countries that contribute few advertisements within Canadian and American publications tend to use $\mathrm{PCI}$ more. Perhaps this is in an attempt to differentiate themselves from local 
advertising or that the advertisements are limited to travel and other $\mathrm{PCl}$ intense product classes.

The more frequent, intense, and strong use of $\mathrm{PCl}$ cues in advertisements published within business and news magazines is unexpected since most literature classifies $\mathrm{PCl}$ as being emotional and extrinsic. However, the literature commonly describes business consumers as acting rationally and evaluating intrinsic properties of products or services in their purchasing behaviour. While many of the advertisements within business and news magazines were for products or services that could logically be associated with high PCl content, for instance travel, other product classes, such as financial and business services, also represented high $\mathrm{PCl}$ usage. This is interesting since it appears that an emotional cue is being used for a rational consumer.

This research also suggests that the strength of the usage of $\mathrm{PCl}$ cues within advertising tends to be deliberately intensive in some cases and incidental on others. While many advertisers use the patriotic appeal, $\mathrm{PCl}$ execution style, and various other strong county cues, many others use them only as "additional" elements in a particular advertisement (e.g.: a price-based advertisement may include an incidental PCl cue, just like a PCl-based one may use an incidental price cue).

Overall, this research has shown that $\mathrm{PCl}$ is being used extensively in magazine advertisements in the form of specific execution styles and individual country cues. 


\section{CHAPTER 10 BENEFITS, LIMITATIONS \& FURTHER}

\section{RESEARCH}

While significant research has been conducted in the area of $\mathrm{PCl}$, it has focused on the consumer. This research project in its entirety aims to research the marketers, looking at $\mathrm{PCl}$ use in advertising. The benefits which this work offers are mainly determining how frequently and how strongly practitioners utilise the proven influence of $\mathrm{PCl}$ when promoting various products and services. Providing an answer to this question gives direction to future $\mathrm{PCl}$ studies.

To date, no quantitative or other measure has been used to provide a concrete indication of the degree of $\mathrm{PCl}$ used in advertising. The results of this work will give researchers a tool by which to approach practitioners directly for further, more specific research.

The content analysis of advertisements has been undertaken by many researchers in the past, but these have been primarily limited in their scope, depth, and breath. As such, the various classifications used in cataloguing advertisements in preceding studies have been insufficient for a study of this magnitude. In order to complete this study several new classifications were developed drawing from previous work, but also extending it significantly. This is among this project's major contributions to future studies.

As with any study, this work has certain limitations. First, several areas of research were studied in order to formulate the foundation for this study. Due to the broad literature analysis required for this research, the examination of existing studies in each area was necessarily limited. 
Second, a major component of the research focuses on advertising appeals and execution styles. This caused an inherent limitation in the reliability of the research since it is generally accepted by advertising practitioners that a complete list of either appeals or execution styles is impossible to develop. Many researchers contradict one another in developing such lists and offer classifications, which place certain categories as both an appeal and an execution style. Additionally, advertisements may be catalogued under multiple appeals and multiple execution styles, which can cause content analysis judging to be difficult and potentially result in lower agreement levels between judges. In order to address these concerns new classifications were developed for this study by amalgamating and advancing work in the respective area. The high level of agreeability between the judges lends itself to the belief that the categories were sufficiently broad and well documented to minimize misclassification during the analysis of the sample.

The methodological choice to use content analysis is itself a third potential limitation. Content analysis allows for the systematic evaluation of material to determine what techniques or content are currently being used. This allows researchers to generate a framework of the overall tendencies of practitioners. Nevertheless, content analysis cannot answer the vital question of 'why'. As Taylor (2002) indicated, the assumption made by conducting content analysis research on international advertising is that what is observed as being done in advertising represents the best strategy. In order to mitigate these concerns, this research was not intended to answer whether or not what is being done is effective, but specifically what is currently being done. 
The fourth limitation is that only two countries were used in the content analysis. As such, any results obtained through the analysis of data are limited in its generalizability on a global scale. Continuation of this research project should address this by including several additional countries in the sample.

Lastly, further to the issue of generalizability, since only magazine advertisements were used in this research, different patterns may exist if the advertising media is changed to include, for example, television, newspapers, or billboards. Any such potential differences can be explained by the differing target markets which are available to each form of media.

In cataloguing the advertisements used within the sample and through the development of several new classifications, which offer a much wider range of categories than previously available to researchers, an immense amount of data was collected and sampled. This research focused on the product country associations only and ignored the higher level information available in the form of other appeal and execution style usage. This was done consciously due to research limitations but must be stressed as a potentially vital area of future research.

The research conducted in this study was a stepping-stone for continued research in the area. It has already been documented through past research that $\mathrm{PCl}$ is an influential criterion for consumers during the purchasing decision process. Further study must be conducted from the practitioners' side. As noted by Papadopoulos and Heslop (2002), "the frequent use of origin images in marketing suggests that many producers believe that their target buyers share their enthusiasm about the image used. Ascertaining whether this is actually so is a key challenge". The hope is that the data and results from this work will allow future 
researchers to perform studies on how actively and consciously international advertising uses PCI. Additionally, it will allow researchers to address what kinds of country image considerations and to what degree, both in a positive and negative light, are used during the development and creation of domestic and international advertisements. 


\section{REFERENCES}

Agrawal, Madhu, Review of A 40-Year Debate In International Advertising, (International Marketing Review, 1995, Vol. 12 Issue 1)

Ahmed, Sadrudin. A.; Alain d'Astous, and Mostafa El Adraoui, Country-of Origin Effects on Purchasing Managers' Product Perceptions, (Industrial Marketing Management, Oct 1994, Vol. 23, Issue 4)

Albers-Miller, Nancy D. and Besty D. Gleb, Business Advertising Appeal as a Mirror of Cultural Dimensions: A Study of Eleven Countries, (Journal of Advertising, winter 1996, Vol. 25,Issue 4)

Alden, Dana L., Jan-Benedict E.M. Stennkamp, and Rejeev Batra, Brand Positiioning Through Advertsing in Asia, North America, and Europe: The Role of Global Consumer Culture, (Journal of Marketing, Jan 1999, Vol. 63).

Al-Sulaiti, Khalid I. and Michael J. Baker, Country of Origin Effects: a Literature Review, (Marketing Intelligence \& Planning, May-June 1998, Vol. 16, Issue 3)

Armstrong, Gary; Philip Kotler; Peggy H. Cunningham and Peter Mitchell, Marketing: an Introduction, (Pearson Education Canada, Toronto, Ontario, 2004)

Backhaus, Klaus, Katrin Muhlfeld, and Jenny Van Doorn, Consumer Perspectives on Standardization in International Advertising: A Student Sample, (Journal of Advertising Research, Sept-Oct 2001, Vol. 41, Issue 5)

Baker, Michael J. and Lorna Ballington, Country of Origin As A Source of Competitive Advantage, (Journal of Strategic Marketing, Jun 2002, Vol. 10, Issue 2)

Bawa, Anupam, Consumer Ethnocentrism: CETSCALE calidaction and Measurement of Extent, (The Journal for Decision Makers, Sept 2004, Vol. 29, No. 3)

Belch, George E.; Michael A. Belch and Michael Guolla, Advertising \& Promotion (second edition), (McGraw-Hill, Ryerson, 2005)

Campbell, David ; Beck Cornelia, and Philip Shrives, A Note On Comparative Language Interrogation For Content Analysis: The example of English vs. German, (British Accounting Review, Sep 2005, Vol. 37, Issue 3) 
Cook, William A., Here's to Europe 1992 and Global Glue, (Journal of Advertising Research, Jan-Feb 1992, Vol. 32, Issue 1)

Decady, Y. J. and D. R. Thomas, A Simple Test of Association for Contingeny Tables wth Multiple Column Responses, (Biometrics, Sept 2000, Vol. 56)

Duncan, Tom and Jyotika Ramaprasad, Standardized Multinational Advertising: The Influencing Factors, (Journal of Advertising, Fall 1995, Vol. 24, Issue 3)

Erickson, Gary M.; Johny Johansson, and Paul Chao, Image Variables in MultiAttribute Product Evaluations: Country-of-Origin Effects, (Journal of Consumer Research, Sep 1984, Vol. 11, Issue 2)

Faber, Ronald, A Glance Backward and the View Ahead, (Journal of Advertising, Winter 2002)

Fatt, Arthur C., The Danger of "Local" International Advertising, (Journal of Marketing, Jan 1967, Vol. 31, Issue 1)

Hallaq, John H. and Kathy Pettit, The Relationship of Product Type, Preferred Evaluative Criteria, and the Order of Consumption to the Evaluation of Consumer Products, (Advances in Consumer Research, 1983, Vol. 10, Issue 1)

Han, C. Min and Vern Terpstra, Country of Origin Effects for Uni-National and BiNational Products, (Journal of International Business Studies, summer 1988, Vol. 19, No. 2)

Han, C. Min, Country Image: Halo or Summary Construct?, (Journal of Marketing Research, May 89, Vol. 26, Issue 2)

Han, C. Min, Testing the Role of Country Image in Consumer Choice Behaviour, (European Journal of Marketing, Jun 1990, Vol. 24, Issue 6)

Harwood, Tracy and Tony Garry, An Overview of Content Analysis, (Marketing Review, Winter 2003, Vol. 3, Issue 4)

Hite, Robert E. and Cynthia Fraser, International Advertising Strategies of Multinational Corporations, (Journal of Advertising Research, Aug-Sep 1988, Vol. 28, Issue 4)

Hodock, Calvin L., Copy Testing and Strategic Postitioning, (Journal of Advertsiting Research, Feb 1980, Vol. 20, Issue 1) 
Holbrook, Morris B., More on Content Analysis in Consumer Research. (Journal of Consumer Research, Dec 1977, Vol. 4 Issue 3)

Hornik, J. and S. Rubinow, Experts Respondent's Synthesis for International Advertising Research, (Journal of Advertising Research, 1981, Vol. 21, Num 3)

IAA World Congress in Dublin article, The Global Challenge of Advertising (republished: Journal of Advertising, 1974- republished, Vol. 3, No. 1)

Jamal, Ahmad and Mark Goode, Consumers' Product Evaluation: A Study of the Primary Evaluative Criteria in the Precious Jewellery Market in the UK, (Journal of Consumer Behaviour, Nov 2001, Vol. 1, Issue 2)

James, William L. and John S. Hill, International Advertising Messages: To Adapt or Not to Adapt (that is the question), (Journal of Advertising Research, JunJul 1991, Vol. 31, Issue 3)

Johansson, Johny K.; Susan P. Douglas, and Ikujiro Nonaka, Assessing the Impact of Country of Origin on Product Evaluations: $A$ New Methodological Perspective, (Journal of Marketing Research, Nov 1985, Vol. 22, Issue 4)

Kanso, Ali, International Advertising Strategies: Global Commitment to Local Vision, (Journal of Advertising Research, Jan-Feb 1992, Vol. 32, Issue 1)

Kassarjian, Harold H., Content Analysis in Consumer Research, (Journal of Consumer Research, Jun 1977, Vol. 4, Issue 1)

Kleppe, Ingeborg Astrid; Nina M. Iversen, and Inger G. Stensaker, Country Images In Marketing Strategies: Conceptual Issues And An Empirical Asian Illustration, (Brand Management, Sept 2002, Vol. 10, No. 1)

Kleppner, Otto, Thomas Russell, Gleen Verrill, and Byron Collins, Otto Kleppner's Advertising Procedure (canadian edition), (Prentice-Hall Canada Inc., Scarborough, Ontario, 1984)

Knight, Gary A. and Roger J. Calantone, A Felxible Model of Consumer Country-ofOrigin Perceptions: A Cross-Cultural Investigation, (International Marketing Review, Nov 2000, Vol. 17, Issue 2)

Kolbe, Richard H. and Melissa S. Burnett, Content Analysis Research: An Examination of Applications With Directives For Improvement Research Reliability and Objectivity, (Journal of Consumer Research, Sept 1991, Vol. 18, Issue 2) 
Kotler, P., Marketing Management: Analysis, Planning, Implementation and Control, (Upper Saddle River: Prentice Hall, 1997)

Kotler, Philip and David Gertner; Country as Brand, Product, And Beyond: A Place Marketing And Brand Management Perspective, (Brand Management, April 2002, Vol. 9, No. 4)

Kotler, Philip and Ronald E. Turner, Management: Analysis, Planning, Implementation and Control, (Prentice-Hall Canada, Scarborough, Ontario, 1989)

Krippendorff, Klaus, Reliability in Content Analysis: Some Common Misconceptions and Recommendations, (Human Communication Research, July 2004, Vol. 30, No. 3).

Lamb, Charles W.; Joseph F. Hair, Jr., Carl McDanial and A. J. Faria, Marketing (third edition), (Nelson-Thomson Canada, 2006)

Laroche, Michel, Nicolas Papadopoulos, Louise Heslop, and Jasmin Bergeron, Effects of Subcultural Differences on Country and Product Evaluations, (Journal of Consumer Behaviour, Mar 2003, Vol. 2, Issue 3)

Lerman, Dawn and Michael Callow, Content Analysis In Cross-Cultural Advertising Research: Insightful or Superficial?, (International Journal of Advertising, 2004, Vol. 23, Issue 4)

Levitt, Theodore, The Globalization of Markets, (Harvard Business Review, MayJun 1983, Vol. 63, Issue 3)

Lidder, Sandeep, Towards a Content Anaysis of Product - Country Image Cues in Advertising: An Exploratiroy Review of Cues, Issues and Problems, (MBA final project, Eric Sprott School of Business, Jan 2005)

Lombard, Matthew, Jennifer Snyder-Duch, and Cheryl Campanella Bracken, Content Analysis in Mass Communication, (Human Communication Research, Oct 2002, Vol. 28, No. 4)

Mohomad, Osman, Zafar U. Ahmed, Earl D. Honeycutt, Jr., and Taizoon Hyder Tyebkhan, Does 'Made In...' Matter to Consumers? A Malaysian Study of Country of Origin Effect, (Multinational Business Review, 2005)

Moriarty, Sandra, Creative Advertising: Theory \& Practice, (Prentice-Hall Canada, Endcliffe, Nova Scotia, 1986) 
Mueller, Barbara, Standardization vs. Specialization: An Examination of Westernization in Japanese Advertising, (Journal of Advertising Research, Jan-Feb 1992, Vol. 32, Issue 1)

Nagashima, Akira, A Comparison of Japanese and U.S. Attitudes Toward Foreign Products, (Journal of Marketing, Jan 1970, Vol. 34, Issue 1)

Nebenzahl, Israel and Eugene Jaffe, Measuring the Joint Effect of Brand and Country Image in Consumer Evaluation of Global Products, (International Marketing Review, 1996, Vol. 13, Issue 4)

Nevett, Terence, Differences between American and British Television Advertising: Explanations and Implications, (Journal of Advertising, Dec 1992, Vol. 21, Issue 4)

O'Conner, James, International Advertising, (Journal of Advertising, Vol. 3, Issue 2.)

Onkvisit, S. and J. Shaw, Standardized International Advertising: Some Research Issues and Implications, (Journal of Advertising Research, Nov-Dec 1999, Vol. 39, Issue 6)

Papadopoulos, Nicolas and Louise Heslop, Country Equity and Country Branding: Problems and Prospects, (Journal of Brand Management, Apr 2002, Vol. 9, Issue 4/5)

Papadopoulos, Nicolas, Countries as Brands, (lvey Business Journal, Nov-Dec 2000, Vol. 65, Issue 2)

Papadopoulos, Nicolas, Place Branding: Evolution, Meaning and Implications, (Place Branding, April 2004, Vol. 1, Issue 1)

Papadopoulos, Nicolas, What "Made-in" Images Are Made OF: An In-depth Examination of the Content Behind Product-Contry Evaluations, (unpublished paper submitted to Academy of Marketing Science Annual Conference, 2007)

Papadopoulos, Nicolas; L.A. Heslop, and The IKON Research Group, A CrossNational and Longitudinal Study of Product-Country Images with a Focus on the U.S. and Japan, (Marketing Science Institute Reports, 2000)

Papadopoulos, Nicolas; Louise Heslop and Jozsef Beracs, National Stereotypes and Product Evaluations in a Socialist Country, (International Marketing Review, Jan-Feb 1990, Vol. 7, Issue 1) 
Phau, lan and Gerard Prendergast, Conceptualizing the Country of Origin of Brand, (Journal of Marketing Communications, 2000)

Pollay, Richard W., Measuring the Cultural Values Manifest in Advertising, (in Current Issues and Research in Advertising, 1983, Vol. 6, Issue 1).

Richards, Jef I. and Catharine M. Curran, Oracles on 'Advertising': Searching for a Definition, (Journal of Advertising, Summer 2002)

Robertson, Bill, Ten Rules Of Product Positioning, (Medical Marketing \& Media, May 2005, Vol. 40, Issue 5)

Roostal, Ilmar, Standardization of Advertising for Western Europe, (Journal of Marketing, Oct 1963, Vol. 27, Issue 4)

Rosen, B., J. Boddewyn and E. Louis, Participation by U.S. Agencies in International Brand Advertising: An Empirical Study, (Journal of Advertising, 1998, Vol. 7, Issue 4)

Rothschild, Micheael L., Advetising, (D.C. Heath and Company, Toronto, Ontario, 1987)

Ryans Jr., John K and James H. Donnelly Jr., Standardized Global Advertising, a Call As Yet Unanswered, (Journal of Marketing, Apr 1969, Vol. 33, Issue 2)

Seixas, Taissa, Top-of-Mind Awareness (TOMA) and Product-Country Image (PCI): An Exploritory Study, (MBA final project, Eric Sprott School of Business, March 2003)

Shimp, T. A. and Sharma, S., Consumer Ethnocentrism: Construction And Validation Of The Cetscale, (Journal of Marketing Research, 1987, Vol. 24, Issue 3).

Sonpar, Karan and Karen Golden-Biddle, Role Of Content Analysis In Developing Adolescent Theories, (Academy of Management Proceedings, 2005)

Stewart, David W. and Kevin J. McAuliffe, Determinates of International Media Purchasing: A Survey of Media Buyers, (Journal of Advertising, 1988, Vol. 17, Issue 3)

Tai, Susan H. C., Factors Effecting Advertising Approach in Asia, (Journal of Current Issues \& Research in Advertising, spring 1998, Vol. 20, Issue 1).

Taylor, Charles and Shintaro Okazaki, Who Standardizes Advertising More Frequently, and Why Do They Do So? A Comparison of U.S. and Japanese 
Subsidiaries' Advertising Practices in the European Union, (Journal of International Marketing, 2006, Vol. 14, Issue 1)

Taylor, Charles, Moving International Advertising Research Forward, (Journal of Advertising, 2005, Vol. 34,Issue 1)

Taylor, Charles, What is Wrong with International Advertising Research?, (Journal of Advertising Research, Nov-Dec 2002, Vol. 42, Issue 6)

Teodorescu, Manuela, International Marketing Strategy and Product - Country Images, (MBA final project, Eric Sprott School of Business, May 2005)

Theodosiou, Marios and Leonidas C. Leonidou, Standardization Versus Adaptation Of International Marketing Strategy: An Integrative Assessment Of The Empirical Research, (International Business Review, Apr 2003, Vol. 12, Issue 2)

Vida, Irean and Ann Fairhurst, Factors Underlying The Phenomenon of Consumer Ethnocentricity: Evidence From Four Central European Countries, (International Review of Retail, Distribution \& Consumer Research, Oct 1999, Vol. 9, Issue 4)

Weilbacher, William M., Advertising (second edition), (Macmillan Publishing Company, New York, New York, 1984)

Wiles, Judith A.; Charles R. Wiles and Anders Tjernlund, A Comparison Of Gender Role Portrayals In Magazine Advertising: The Netherlands, Sweden And The USA, (European Journal of Marketing, 1995, Vol. 29, Issue 11)

Wind, Yoram, The Myth of Globalization, (Journal of Consumer Marketing, spring 1986, Vol. 3 Issue 2)

Yin, J., International Advertising Strategies in China: A Worldwide Survey of Foreign Advertisers (Journal of Advertising Research, Nov-Dec 1999, Vol. 39, Issue 6)

Zou, Shaoming, Contributions to International Advertising Research, (Journal of Advertising, 2005, Vol. 34, No. 1)

\section{WEBSITES}

Canada.com (www.canada.com)

Readership Institute - Northwestern University (www.readership.org) 
The Baking association of Canada (www.BakingAssocCanada.com) 


\begin{tabular}{|c|c|}
\hline 1. Appeal & 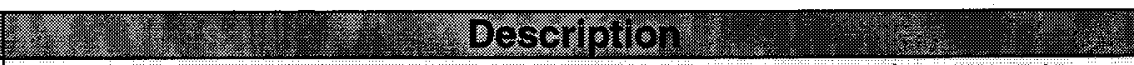 \\
\hline Effective & $\begin{array}{l}\text { Feasible, workable, useful, pragmatic, appropriate, functional, } \\
\text { consistent, efficient, helpful, comfortable (clothing), tasty (food), } \\
\text { strength, longevity of effect }\end{array}$ \\
\hline Durable & $\begin{array}{l}\text { Long-lasting, permanent, stable, enduring, strong, powerful, } \\
\text { hearty, tough }\end{array}$ \\
\hline Convenient & Handy, time-saving, quick, easy, suitable, accessible, versatile \\
\hline Ornamental & $\begin{array}{l}\text { Beautiful, decorative, ornate, adorned, embellished, detailed, } \\
\text { designed, styled }\end{array}$ \\
\hline Cheap & $\begin{array}{l}\text { Economical, inexpensive, bargain, cut-rate, penny-pinching, } \\
\text { discounted, at cost, undervalued, a good value }\end{array}$ \\
\hline Dear & $\begin{array}{l}\text { Expensive, rich, valuable, highly regarded, costly, extravagant, } \\
\text { exorbitant, luxurious, priceless }\end{array}$ \\
\hline Distinctive & $\begin{array}{l}\text { Rare, unique, unusual, scarce, infrequent, exclusive, tasteful, } \\
\text { elegant, subtle, esoteric, hand-crafted }\end{array}$ \\
\hline Popular & $\begin{array}{l}\text { Commonplace, customary, well-know, conventional, regular, } \\
\text { usual, ordinary, normal, standard, typical, universal, general, } \\
\text { everyday }\end{array}$ \\
\hline Traditional & $\begin{array}{l}\text { Classic, historical, antique, legendary, time-honoured, long- } \\
\text { standing, venerable, nostalgic }\end{array}$ \\
\hline Modern & $\begin{array}{l}\text { Contemporary, modern new, improved, progressive, advanced, } \\
\text { introducing, announcing... }\end{array}$ \\
\hline Natural & $\begin{array}{l}\text { References to the elements, animals, vegetables, minerals, } \\
\text { farming, unadulterated, purity (of product), organic, grown, } \\
\text { nutritious }\end{array}$ \\
\hline Technological & $\begin{array}{l}\text { Engineered, fabricated, formulated, manufactured, constructed, } \\
\text { processed, resulting from science, invention, discovery, research, } \\
\text { containing secret ingredients }\end{array}$ \\
\hline Wisdom & $\begin{array}{l}\text { Knowledge, education, awareness intelligence, curiosity, } \\
\text { satisfaction, comprehension, sagacity, expertise, judgement, } \\
\text { experience }\end{array}$ \\
\hline Magic & $\begin{array}{l}\text { Miracles, magic, mysticism, mystery, witchcraft, wizardry, } \\
\text { superstitions, occult sciences, mythic characters, to mesmerize, } \\
\text { astonish, bewitch, fill with wonder }\end{array}$ \\
\hline Productivity & $\begin{array}{l}\text { References to achievement, accomplishment, ambition, success, } \\
\text { careers, self-development, being skilled, accomplished, proficient, } \\
\text { pulling your weight, contributing, doing your share }\end{array}$ \\
\hline Relaxation & $\begin{array}{l}\text { Rest, retire, retreat, loaf, contentment, be at ease, be laid-back, } \\
\text { vacations, holiday, to observe }\end{array}$ \\
\hline Enjoyment & $\begin{array}{l}\text { To have fun, laugh, be happy, celebrate, to enjoy games, parties, } \\
\text { feasts and festivities, to participate }\end{array}$ \\
\hline \multicolumn{2}{|l|}{ Table continues } \\
\hline
\end{tabular}




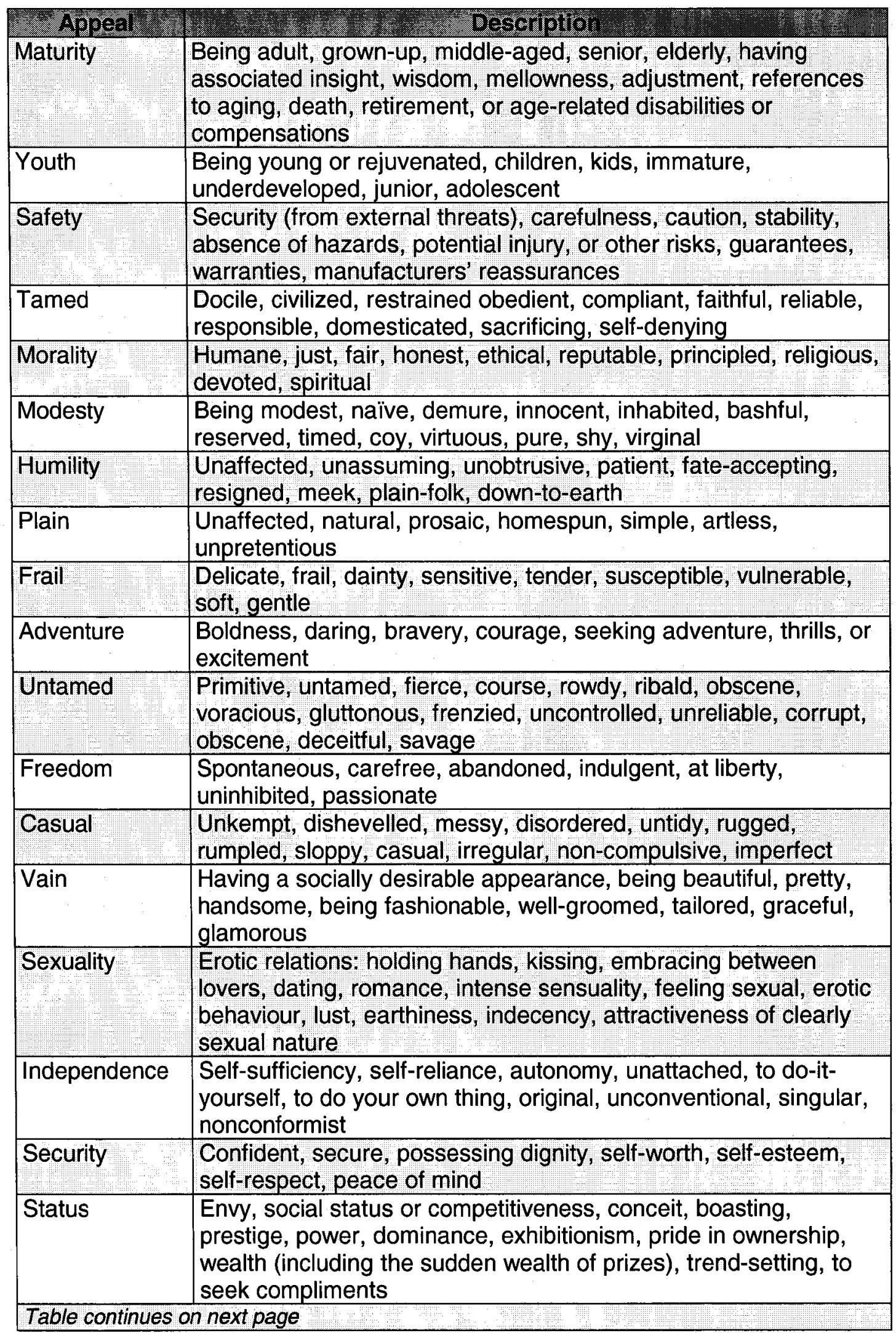




\begin{tabular}{|l|l|}
\hline \multicolumn{1}{|c|}{ Appeal } & \multicolumn{1}{c|}{ Description } \\
\hline Affiliation & $\begin{array}{l}\text { To be accepted, liked by peers, colleagues, and community at } \\
\text { large, to associate or gather with, to be social, to join, unite, or } \\
\text { otherwise bond in friendship, fellowship, companionship, } \\
\text { cooperation, reciprocity, to conform to social customs, have } \\
\text { manners, social graces and decorum, tact and finesse }\end{array}$ \\
\hline Nurturance & $\begin{array}{l}\text { To give gifts, especially sympathy, help love, charity, support, } \\
\text { comfort, protection, nursing, consolation, or otherwise care for the } \\
\text { weak, disabled, inexperienced, tired, young, elderly, etc. }\end{array}$ \\
\hline Succorance & $\begin{array}{l}\text { To receive expressions of love (all expression except sexuality), } \\
\text { gratitude, pats on the back, to feel deserving }\end{array}$ \\
\hline Family & $\begin{array}{l}\text { Nurturance within the family, having a home, being at home, } \\
\text { family privacy, companionship of siblings, kinship, getting married }\end{array}$ \\
\hline Community & $\begin{array}{l}\text { Relating to community, state, national publics, public spiritedness, } \\
\text { group unity, national identity, society, patriotism, civic and } \\
\text { community organizations or other than social organization }\end{array}$ \\
\hline Healthy & $\begin{array}{l}\text { Fitness, vim, vigour, vitality, strength, heartiness, to be active, } \\
\text { athletic, robust, peppy, free from disease, illness, infection, or } \\
\text { addiction }\end{array}$ \\
\hline Neat & $\begin{array}{l}\text { Orderly, neat, precise, tidy, clean, spotless, unsoiled, sweet- } \\
\text { smelling, bright, free from dirt, refuse, pests, vermin, stains and } \\
\text { smells, sanitary }\end{array}$ \\
\hline Source: Albers-Miller and Gleb (1996) adapted from Pollay (1996)
\end{tabular}




\section{APPENDIX B: DEVELOPMENT OF FINAL PRODUCT CLASSIFICATION USED}

\begin{tabular}{|c|c|}
\hline Product Gass & 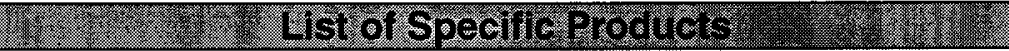 \\
\hline Apparel \& Accessories & clothing, eyeglasses, hair elastics, purse, shoes \\
\hline Appliances \& Furniture & $\begin{array}{l}\text { coffee maker, furniture, home appliance, kitchen } \\
\text { appliances, lamp, vacuum, water filter }\end{array}$ \\
\hline Business Service & $\begin{array}{l}\text { business computer consulting, business consulting, } \\
\text { business health care, business health service, business } \\
\text { net security, business service, courier service, destination } \\
\text { - business, facility management, food service, HR service }\end{array}$ \\
\hline Cars \& Related & $\begin{array}{l}\text { car, car cleaner, car service, RV campers, tires, used car } \\
\text { sales }\end{array}$ \\
\hline $\begin{array}{l}\text { Computer } \\
\text { Hardware/Software }\end{array}$ & $\begin{array}{l}\text { business computer h/ware, business computer s/ware, } \\
\text { business electronics, business printer/copier, cons } \\
\text { computer h/ware, cons computer s/ware, cons } \\
\text { printer/copier }\end{array}$ \\
\hline Cons Electronics & $\begin{array}{l}\text { camera, car sound system, cons electronics, DVD player, } \\
\text { portable music player, TV set }\end{array}$ \\
\hline Corporate & whole organization \\
\hline Cosmetics & $\begin{array}{l}\text { beauty products, cons products, cosmetics, hair care, hair } \\
\text { colour, hair spray, leg makeup, lipstick, makeup, makeup } \\
\text { brushes, nail polish, perfume, tooth whitening }\end{array}$ \\
\hline Education \& Training & $\begin{array}{l}\text { business seminar, business training, cons seminar, } \\
\text { school, teaching, university }\end{array}$ \\
\hline Entertainment & $\begin{array}{l}\text { book, book club, concert, DVD, DVD club, event, gala, golf } \\
\text { tournament, golfing membership, movie, museum, radio } \\
\text { program, TV program/station }\end{array}$ \\
\hline Financial Service & $\begin{array}{l}\text { business bank, business bank service, business credit } \\
\text { card, business fin consult, business fin service, business } \\
\text { insurance, business invest service, business leasing } \\
\text { service, business service, Canada savings bonds, cons } \\
\text { bank, cons brokerage, cons credit card, cons finance } \\
\text { service, cons insurance, cons invest service, estate } \\
\text { planning, real estate, wealth management }\end{array}$ \\
\hline
\end{tabular}




\begin{tabular}{|c|c|}
\hline Product Class & Whe List of Specific Products \\
\hline Food & $\begin{array}{l}\text { almonds, baby food, bread, butter \& margarine, candy, } \\
\text { cereal, cheese, chocolate, coffee, coffee additive, coffee } \\
\text { additive, cold cuts, condensed milk, diet-cereal, diet-food, } \\
\text { diet-snack, dressing, eggs, food, health food, healthy } \\
\text { snack, ice-cream, instant cake topping, instant dinner, } \\
\text { instant lunch, jam, meat, milk, non-alcoholic drink, } \\
\text { oranges, pasta, peanut butter, raisins, sauce, sausages, } \\
\text { snack, soup, soy milk, soy products, sugar substitute, } \\
\text { syrup, tea, water flavouring, yogurt }\end{array}$ \\
\hline Household Cleaners & $\begin{array}{l}\text { air freshener, bags, bug spray, carpet cleaner, cleaning } \\
\text { products, dish detergent, fabric softener, home cleaning, } \\
\text { laundry detergent, laundry related, paper towels, shower } \\
\text { cleaner }\end{array}$ \\
\hline $\begin{array}{l}\text { Home Décor \& } \\
\text { Improvement }\end{array}$ & $\begin{array}{l}\text { art, art (coin), bedding, central air, couch covers, event, } \\
\text { faucets, fireplaces, flat wear, flooring, home décor, home } \\
\text { insulation, lawn mower, paint, plant food }\end{array}$ \\
\hline $\begin{array}{l}\text { Issues, Charities, } \\
\text { NGO's }\end{array}$ & $\begin{array}{l}\text { army, business issue, charity, environmental research, } \\
\text { health issue, issue }\end{array}$ \\
\hline Liquor \& Tobacco & beer, liquor, tobacco, wine \\
\hline Media & magazine, online media, TV program/station \\
\hline Medicines/Medical & $\begin{array}{l}\text { artificial hips, band-aid, birth control - meds, cons health } \\
\text { care, contacts, face cream - meds, feminine hygiene - } \\
\text { meds, glucose monitor, medicine, pregnancy test, quit } \\
\text { smoking gum, quit smoking medicine, quit smoking } \\
\text { service, skin cream - meds, weight loss meds }\end{array}$ \\
\hline $\begin{array}{l}\text { Personal Health \& } \\
\text { Care }\end{array}$ & $\begin{array}{l}\text { condoms, contact lens cleaner, diapers, face cream, } \\
\text { feminine hygiene, fitness centre, foot cream, hand cream, } \\
\text { hand sanitizer, lip balm, skin cream, skin products, } \\
\text { tissues, vitamins, warming pads for cramps, workout } \\
\text { machine }\end{array}$ \\
\hline Retail & $\begin{array}{l}\text { restaurant - coffee, restaurant - fast food, ret - clothing, ret } \\
\text { - dept, ret - discount, ret - drugstore, ret - electronics, ret - } \\
\text { hardware, ret - home improve, ret - jewel, ret - office } \\
\text { supplies, ret - online, ret - pet store }\end{array}$ \\
\hline Telecomm & $\begin{array}{l}\text { business cell, business hi-sp internet, business telecomm, } \\
\text { cons cell, cons hi-sp internet, cons telecomm, digital } \\
\text { cable, digital PVR }\end{array}$ \\
\hline Toiletries & $\begin{array}{l}\text { deodorant, face cleaner, hair gel, hair product, hair } \\
\text { products, hair removal cream, razor blade, } \\
\text { shampoo/condition, shaving gel, soap, toothbrush, } \\
\text { toothpaste }\end{array}$ \\
\hline Travel & $\begin{array}{l}\text { airline, amusement park, business travel mgmt, cons } \\
\text { travel mgmt, destination - tourism, hotel, timeshare } \\
\text { aircraft, travel agent }\end{array}$ \\
\hline
\end{tabular}




\begin{tabular}{|l|l|}
\hline \multicolumn{1}{|c|}{ Product Class } & \multicolumn{1}{c|}{ List of Specific Products } \\
\hline Watches \& Jewellery & jewellery, watch \\
\hline Other Products \& & $\begin{array}{l}\text { battery, binoculars, candles, cons printing service, film, } \\
\text { gervice }\end{array}$ \\
$\begin{array}{l}\text { gasoline, golf clubs, industrial prod - foods, industrial prod } \\
\text { - general, industrial prod - newsprint, industrial prod - tech, } \\
\text { lighter, lottery, lumber, online service, pens, pet food, pet } \\
\text { insurance, pet medicine, pet supplies, toys, Tupperware }\end{array}$ \\
\hline
\end{tabular}




\section{APPENDIX C: DEVELOPED NATIONS}

\begin{tabular}{|l|l|}
\hline & North America \\
\hline Bermuda & United States of America \\
\hline Canadal & \\
\hline
\end{tabular}

\begin{tabular}{|l|l|}
\hline \multicolumn{2}{|c|}{} \\
\hline Hong Kong (China) & Singapore \\
\hline Israel & South Korea \\
\hline Japan & Republic of China (Taiwan) \\
\hline Macau (China) & \\
\hline
\end{tabular}

\begin{tabular}{|l|l|}
\hline Andorra & Europe \\
\hline Austria & Liechtenstein \\
\hline Belgium & Luxembourg \\
\hline Cyprus & Monaco \\
\hline Denmark & Netherlands \\
\hline Faeroe Islands (Denmark) & Norway \\
\hline Finland & Portugal \\
\hline France & San Marino \\
\hline Germany & Spain \\
\hline Greece & Sweden \\
\hline Iceland & Switzerland \\
\hline Ireland & United Kingdom \\
\hline Italy & Vatican City \\
\hline
\end{tabular}

\begin{tabular}{|l|l|}
\hline & Oceania \\
\hline Australia & New Zealand \\
\hline Source: World Bank \& International Monetary Fund \\
\hline
\end{tabular}


APPENDIX D: FREQUENCY OF APPEALS BY PRODUCT CLASS

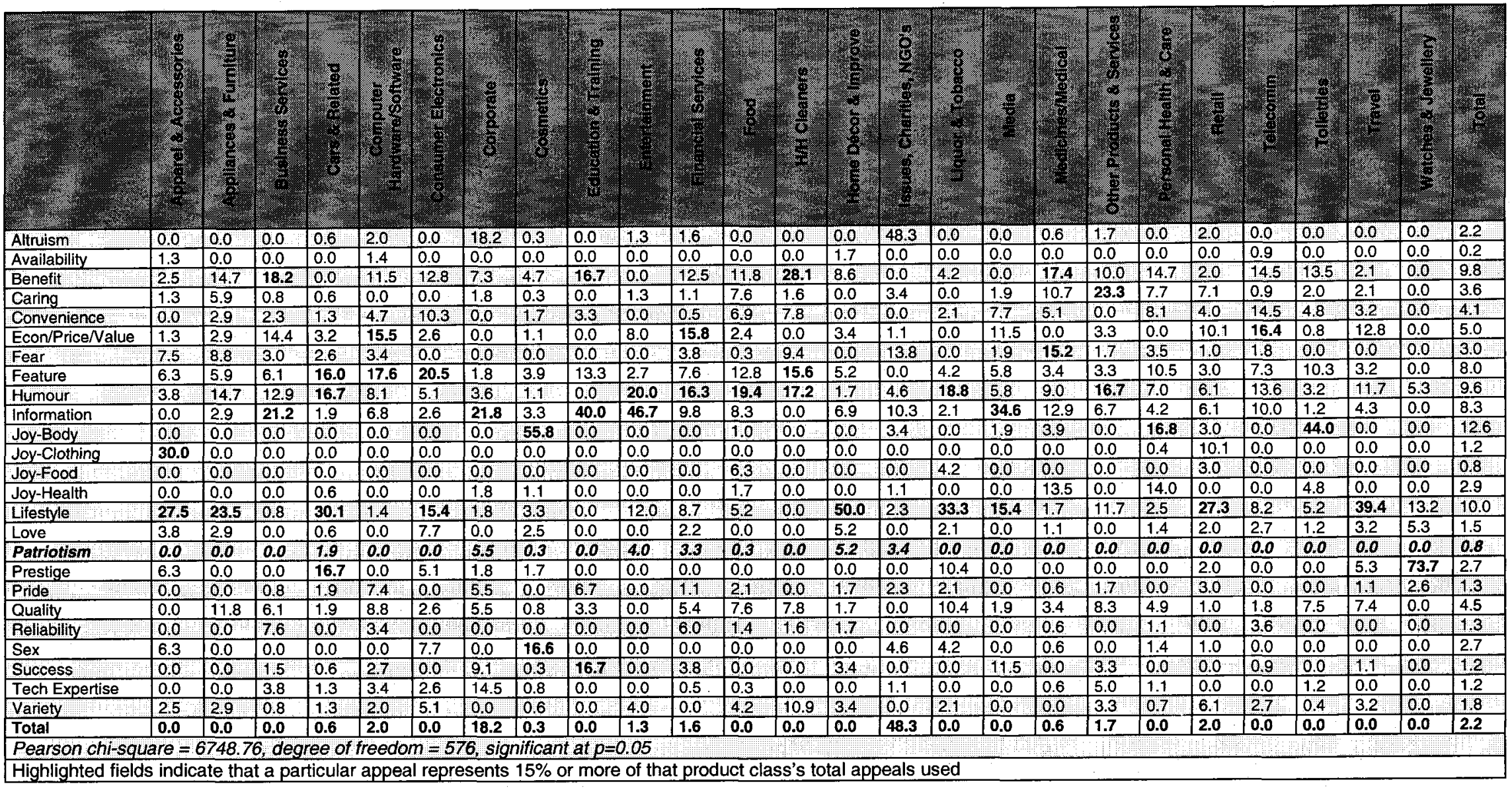




\section{APPENDIX D: APPEALS BY MAGAZINE TABLES}

\begin{tabular}{|c|c|c|c|c|c|}
\hline Appeal & Business & MeW S & Fastion & Weslyie & Tole \\
\hline Altruism & 20 & 20 & 17 & 8 & 65 \\
\hline Availability & 3 & 0 & 2 & 0 & 5 \\
\hline Benefit & 75 & 22 & 64 & 133 & 294 \\
\hline Caring & 7 & 2 & 18 & 80 & 107 \\
\hline Convenience & 28 & 9 & 48 & 37. & 122 \\
\hline Econ/Price/Value & 65 & 35 & 21 & 28 & 149 \\
\hline Fear & 17 & 9 & 16 & 48 & 90 \\
\hline Feature & 78 & 20 & 47 & 97 & 242 \\
\hline Humour & 73 & 42 & 73 & 100 & 288 \\
\hline Information & 96 & 44 & 56 & 55 & 251 \\
\hline Joy-Body & 0 & 2 & 275 & 101 & 378 \\
\hline Joy-Clothing & 0 & 0 & 30 & 5 & 35 \\
\hline Joy-Food & 0 & 1 & 9 & 13 & 23 \\
\hline Joy-Health & 2 & 2 & 31 & 53 & 88 \\
\hline Lifestyle & 76 & 53 & 78 & 95 & 302 \\
\hline Love & 2 & 3 & 19 & 20 & 44 \\
\hline Patriotism & 5 & 12 & 3 & 3 & 23 \\
\hline Prestige & 46 & 12 & 21 & 1 & 80 \\
\hline Pride & 14 & 7 & 4 & 14 & 39 \\
\hline Quality & 44 & 13 & 34 & 43 & 134 \\
\hline Reliability & 24 & 7 & 3 & 6 & 40 \\
\hline Sex & 3 & 1 & 64 & 12 & 80 \\
\hline Success & 30 & 4 & 1 & 2 & 37 \\
\hline Tech Expertise & 16 & 7 & 9 & 5 & 37 \\
\hline Variety & 8 & 3 & 20 & 24 & 55 \\
\hline Total & 732 & 330 & 963 & 983 & 3008 \\
\hline
\end{tabular}

\begin{tabular}{|c|c|c|c|c|c|c|c|c|c|c|c|c|c|}
\hline & \multicolumn{3}{|c|}{ Business } & \multicolumn{3}{|c|}{ News } & \multicolumn{3}{|c|}{ Fashion } & \multicolumn{3}{|c|}{ Mitestyse } & \\
\hline & N & Exp & ari & 11 & Exp & Cont & $\mathrm{N}$ & Expros & Chi & (11) & Exp. & 81 & \\
\hline Other & 727 & 726.4 & 0.0 & 318 & 327.5 & 0.3 & 960 & 955.6 & 0.0 & 980 & 975.5 & 0.0 & 2985 \\
\hline Patriotic & 5 & 5.6 & 0.1 & 12 & 2.5 & 35.6 & 3 & 7.4 & 2.6 & 3 & 7.5 & 2.7 & 23 \\
\hline Total & 732 & & & 330 & & & 963 & & & 983 & & & 3008 \\
\hline
\end{tabular}




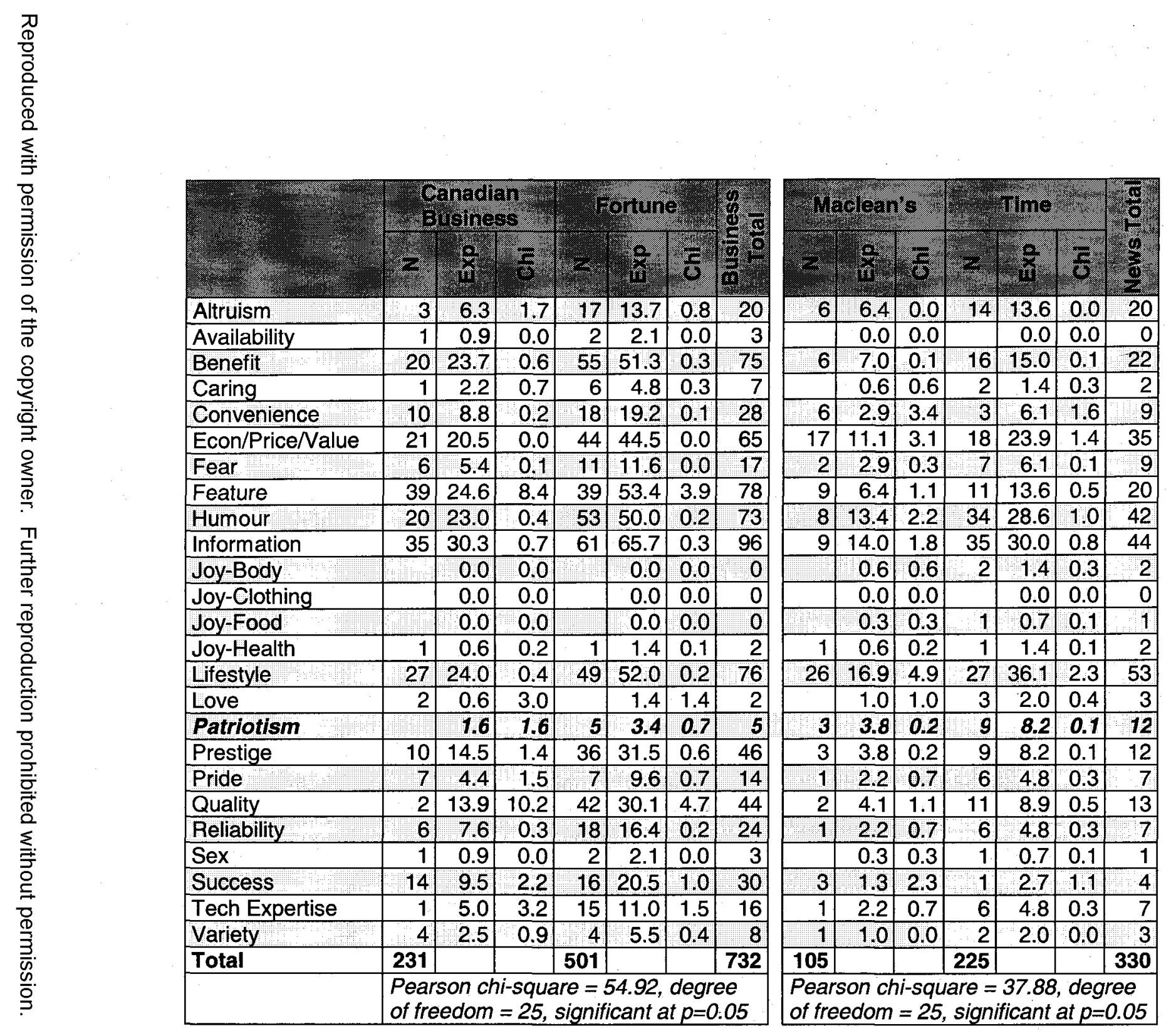




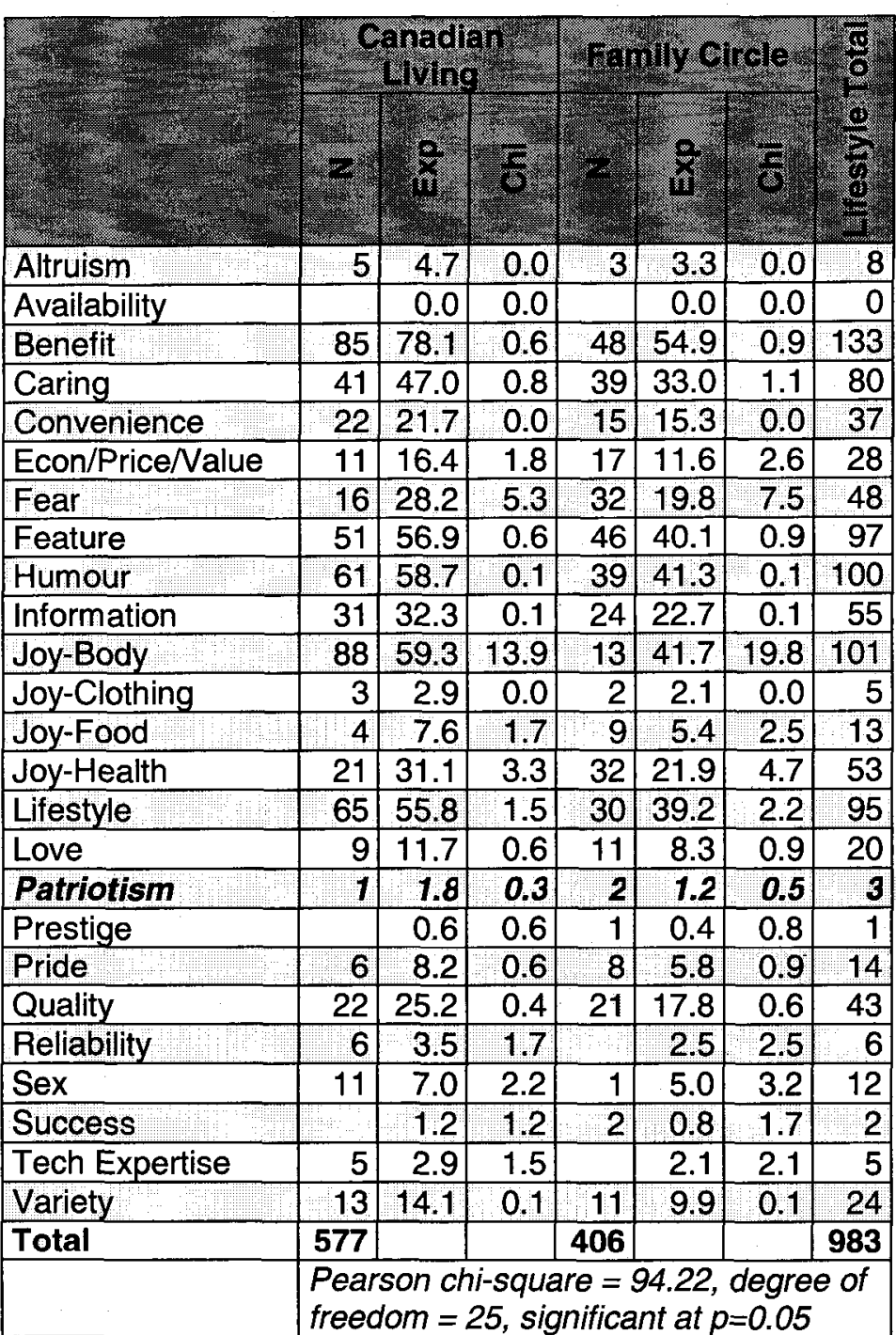

\begin{tabular}{|c|c|c|c|c|c|c|}
\hline 1 & $\frac{2}{x}$ & 요 & 8 & $\frac{8}{411}$ & $\frac{8}{8}$ & $\frac{\frac{9}{6}}{\frac{5}{6}}$ \\
\hline 15 & 7.8 & 6.7 & 2 & 9.2 & 5.6 & 17 \\
\hline & 0.9 & 0.9 & $\frac{5}{2}$ & 1.1 & 0.8 & \\
\hline 38 & 29.3 & 2.6 & 26 & 34.7 & 2.2 & 64 \\
\hline 16 & 8.2 & 7.3 & 2 & 9.8 & 6.2 & 18 \\
\hline 24 & 22.0 & 0.2 & 24 & 26.0 & 0.2 & 48 \\
\hline 9 & 9.6 & 0.0 & 12 & 11.4 & 0.0 & 21 \\
\hline 8 & 7.3 & 0.1 & 8 & 8.7 & $\overline{0.1}$ & 16 \\
\hline 31 & 21.5 & 4.2 & 16 & 25.5 & 3.5 & 47 \\
\hline 20 & 33.4 & 5.4 & 53 & 39.6 & 4.6 & 73 \\
\hline 19 & 25.6 & 1.7 & 37 & 30.4 & 1.5 & 56 \\
\hline 144 & 125.9 & 2.6 & 131 & 149.1 & 2.2 & 275 \\
\hline & 13.7 & 13.7 & 30 & 16.3 & 11.6 & 30 \\
\hline 6 & 4.1 & 0.9 & 3 & 4.9 & 0.7 & 9 \\
\hline 9 & 14.2 & 1.9 & 22 & 16.8 & 1.6 & 31 \\
\hline 27 & 35.7 & 2.1 & 51 & 42.3 & 1.8 & 78 \\
\hline 6 & 8.7 & 0.8 & 13 & 10.3 & 0.7 & 19 \\
\hline 1 & 1.4 & 0.1 & 2 & 1.6 & 0.1 & 3 \\
\hline 4 & 9.6 & 3.3 & 17 & 11.4 & 2.8 & 21 \\
\hline 3 & 1.8 & 0.7 & 1 & 2.2 & 0.6 & 4 \\
\hline 21 & 15.6 & 1.9 & 13 & 18.4 & 1.6 & 34 \\
\hline 3 & 1.4 & 1.9 & & 1.6 & 1.6 & 3 \\
\hline 25 & 29.3 & 0.6 & 39 & 34.7 & 0.5 & 64 \\
\hline & 0.5 & 0.5 & 1 & 0.5 & 0.4 & 1 \\
\hline 5 & 4.1 & 0.2 & 4 & 4.9 & 0.2 & 9 \\
\hline 7 & 9.2 & 0.5 & 13 & 10.8 & 0.4 & 20 \\
\hline 441 & & & 522 & & & 963 \\
\hline
\end{tabular}



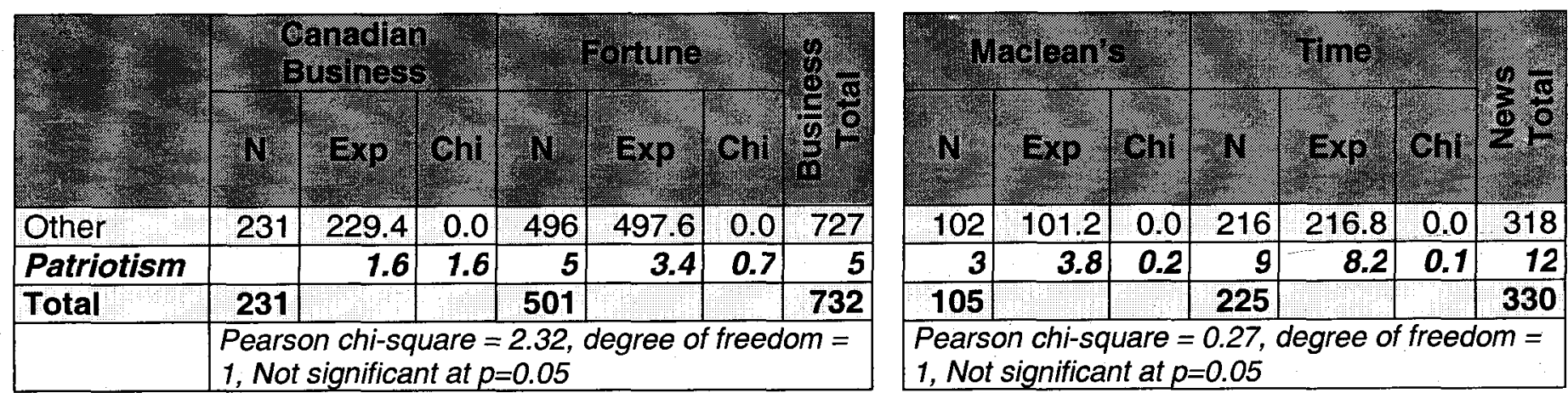

\begin{tabular}{|c|c|c|c|c|c|c|c|}
\hline 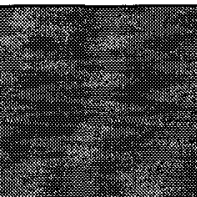 & $4=$ & diantw & ent & 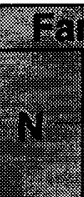 & $\frac{11 y \text { Gir }}{\text { Exp }}$ & Ph: & $\frac{9}{8} \frac{9}{9}$ \\
\hline Other & 520 & 520.4 & 0.0 & 440 & 439.6 & 0.0 & 960 \\
\hline Patriotism & 2 & 1.6 & 0.1 & 1 & 1.4 & 0.1 & 3 \\
\hline Total & 522 & & & 441 & & & 963 \\
\hline & \\
\hline
\end{tabular}

\begin{tabular}{|c|c|c|c|c|c|c|}
\hline & $\begin{array}{l}\text { Plow } \\
\text { Evos }\end{array}$ & $\frac{2}{8.51}$ & +5 & $\frac{\text { lamoy }}{2}$ & $\frac{3}{3}$ & $\frac{8}{8}$ \\
\hline 404 & 404.8 & 0.0 & 576 & 575.2 & 0.0 & 980 \\
\hline 2 & 1.2 & 0.5 & 1 & 1.8 & 0.3 & 3 \\
\hline 406 & & & 577 & & & 983 \\
\hline
\end{tabular}




\section{APPENDIX F: FREQUENCY OF EXECUTION STYLE BY PRODUCT CLASS}

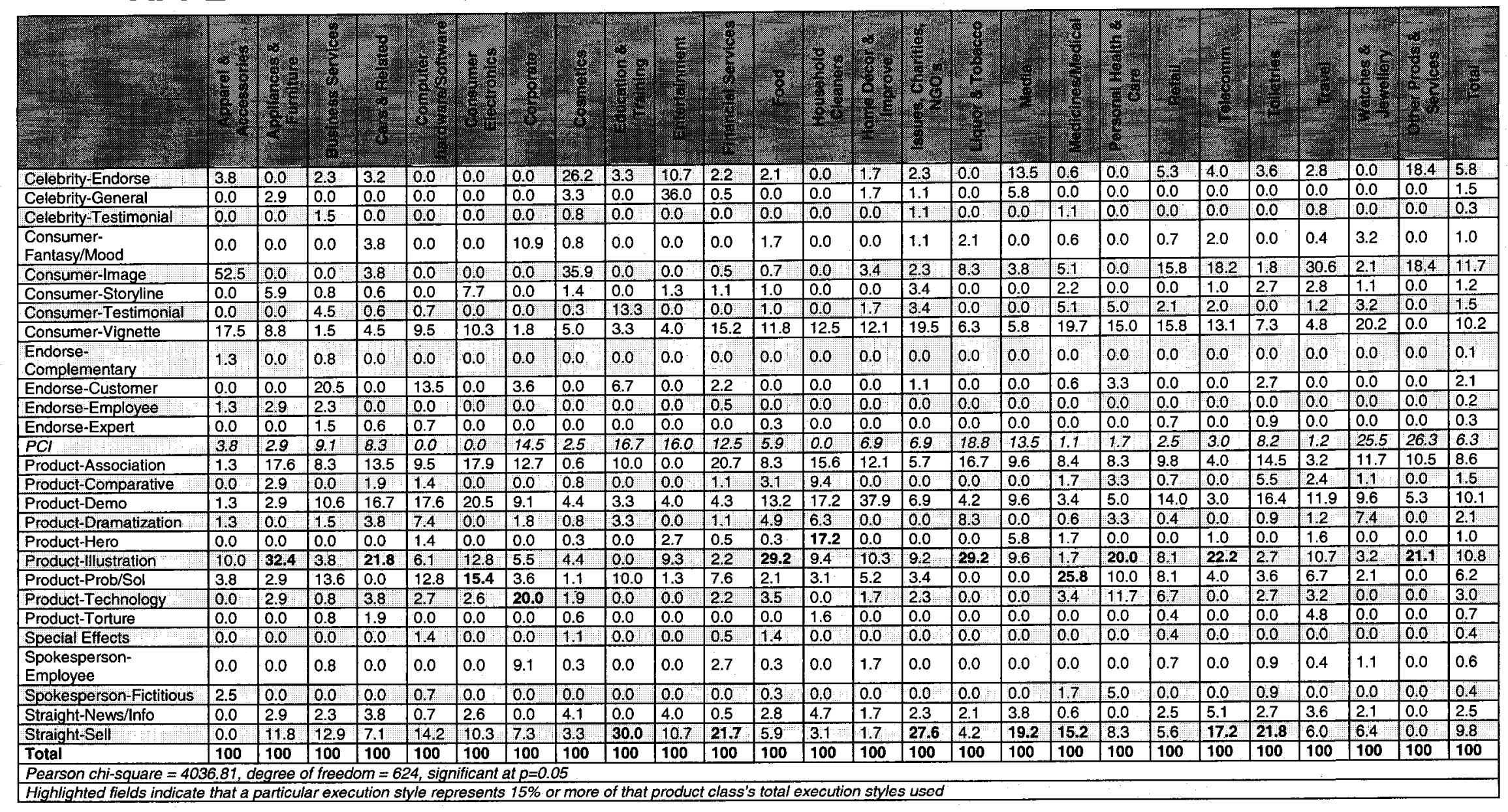




\section{APPENDIX E: EXECUTION STYLE BY MAGAZINE TABLES}

\begin{tabular}{|c|c|c|c|c|c|}
\hline Execution Sty & Busmess & Neves & $1=95 \mathrm{ron}$ & 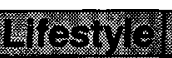 & Total \\
\hline Celebrity-Endorse & 17 & 13 & 101 & 42 & 173 \\
\hline Celebrity-General & 4 & 6 & 27 & 9 & 46 \\
\hline Celebrity-Testimonial & 2 & 1 & 3 & 4 & 10 \\
\hline Consumer-Fantasy/Mood & 11 & 5 & 10 & 5 & 31 \\
\hline Consumer-Image & 16 & 6 & 234 & 95 & 351 \\
\hline Consumer-Storyline & 10 & 6 & 11 & 10 & 37 \\
\hline Consumer-Testimonial & 14 & 5 & 13 & 14 & 46 \\
\hline Consumer-Vignette & 56 & 30 & 78 & 144 & 308 \\
\hline Endorse-Complementary & 1 & 0 & 1 & 0 & 2 \\
\hline Endorse-Customer & 45 & 15 & 1 & 1 & 62 \\
\hline Endorse-Employee & 5 & 0 & 0 & 1 & 6 \\
\hline Endorse-Expert & 4 & 1 & 2 & 1 & 8 \\
\hline $\mathrm{PCl}$ & 70 & 40 & 32 & 46 & 188 \\
\hline Product-Association & 102 & 26 & 30 & 102 & 260 \\
\hline Product-Comparative & 10 & 5 & 10 & 21 & 46 \\
\hline Product-Demo & 91 & 26 & 76 & 111 & 304 \\
\hline Product-Dramatization & 20 & 11 & 16 & 17 & 64 \\
\hline Product-Hero & 4 & 2 & 10 & 13 & 29 \\
\hline Product-Illustration & 48 & 31 & 102 & 145 & 326 \\
\hline Product-Prob/Sol & 49 & 14 & 46 & 78 & 187 \\
\hline Product-Technology & 24 & 10 & 28 & 29 & 91 \\
\hline Product-Torture & 3 & 1 & 9 & 7 & 20 \\
\hline Special Effects & 3 & 2 & 3 & 4 & 12 \\
\hline Spokesperson-Employee & 9 & 1 & 3 & 6 & 19 \\
\hline Spokesperson-Fictitious & 1 & 0 & 2 & 8 & 11 \\
\hline Straight-News/Info & 11 & 10 & 31 & 23 & 75 \\
\hline Straight-Sell & 102 & 63 & 84 & 47 & 296 \\
\hline Total & 732 & 330 & 963 & 983 & 3008 \\
\hline
\end{tabular}

\begin{tabular}{|c|c|c|c|c|c|c|c|c|c|c|c|c|c|}
\hline & \multirow{2}{*}{\multicolumn{3}{|c|}{ Business: }} & \multicolumn{3}{|c|}{ News: } & \multicolumn{3}{|c|}{ Fashion } & \multicolumn{3}{|c|}{ Lifestyl } & \multirow{2}{*}{ Toto } \\
\hline & & & ChI & N. & $\operatorname{Exp}$ & ChI & N & Exp & Chi & 11 & Exp & Ohi & \\
\hline Other & 662 & 686.3 & 0.9 & 290 & 309.4 & 1.2 & 931 & 902.8 & 0.9 & 937 & 921.6 & 0.3 & 2820 \\
\hline $\mathrm{PCl}$ & 70 & 45.8 & 12.5 & 40 & 20.6 & 18.2 & 32 & \begin{tabular}{|l|}
60.2 \\
\end{tabular} & 13.2 & 46 & 61.4 & 3.9 & 188 \\
\hline Total & 732 & & & 330 & & & 963 & & & 983 & & & 3008 \\
\hline
\end{tabular}




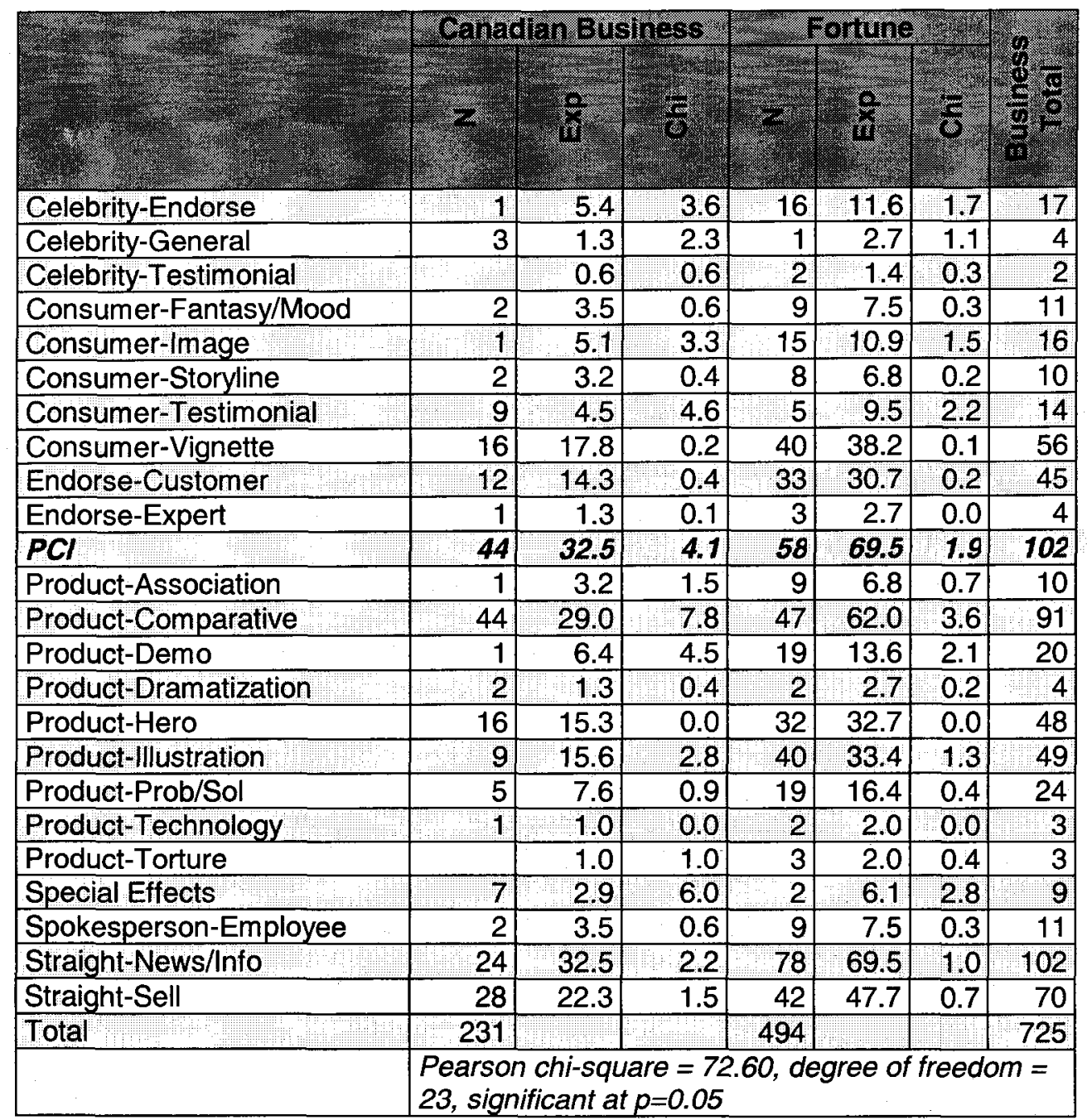

\begin{tabular}{|c|c|c|c|c|c|c|}
\hline$\sqrt{3}$ & dean & $\frac{5}{5}$ & $\frac{3}{3}$ & 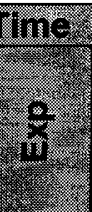 & $\frac{5}{6}$ & 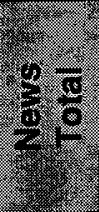 \\
\hline 4 & 4.1 & 0.0 & 9 & 8.9 & 0.0 & 13 \\
\hline 3 & 1.9 & 0.6 & 3 & 4.1 & 0.3 & 6 \\
\hline & 0.3 & 0.3 & 1 & 0.7 & 0.1 & 1 \\
\hline 1 & 1.6 & 0.2 & 4 & 3.4 & 0.1 & 5 \\
\hline 3 & 1.9 & 0.6 & 3 & 4.1 & 0.3 & 6 \\
\hline & 1.9 & 1.9 & 6 & 4.1 & 0.9 & 6 \\
\hline 1 & 1.6 & 0.2 & 4 & 3.4 & 0.1 & 5 \\
\hline 7 & 9.5 & 0.7 & 23 & 20.5 & 0.3 & 30 \\
\hline 4 & 4.8 & 0.1 & 11 & 10.2 & 0.1 & 15 \\
\hline & 0.3 & 0.3 & 1 & 0.7 & 0.1 & 1 \\
\hline 11 & 8.3 & 0.9 & 15 & 17.7 & 0.4 & 26 \\
\hline & 1.6 & 1.6 & 5 & 3.4 & 0.7 & 5 \\
\hline 7 & 8.3 & 0.2 & 19 & 17.7 & 0.1 & 26 \\
\hline 7 & 3.5 & 3.5 & 4 & 7.5 & 1.6 & 11 \\
\hline 2 & 0.6 & 2.9 & & 1.4 & 1.4 & 2 \\
\hline 11 & 9.9 & 0.1 & 20 & 21.1 & 0.1 & 31 \\
\hline 1 & 4.5 & 2.7 & 13 & 9.5 & 1.3 & 14 \\
\hline 3 & 3.2 & 0.0 & 7 & 6.8 & 0.0 & 10 \\
\hline & 0.3 & 0.3 & 1 & 0.7 & 0.1 & 1 \\
\hline & 0.6 & 0.6 & 2 & 1.4 & 0.3 & 2 \\
\hline & 0.3 & 0.3 & 1 & 0.7 & 0.1 & 1 \\
\hline 5 & 3.2 & 1.0 & 5 & 6.8 & 0.5 & 10 \\
\hline 18 & 20.0 & 0.2 & 45 & 43.0 & 0.1 & 63 \\
\hline 17 & 12.7 & 1.4 & 23 & 27.3 & 0.7 & 40 \\
\hline 105 & & & 225 & & & 330 \\
\hline
\end{tabular}



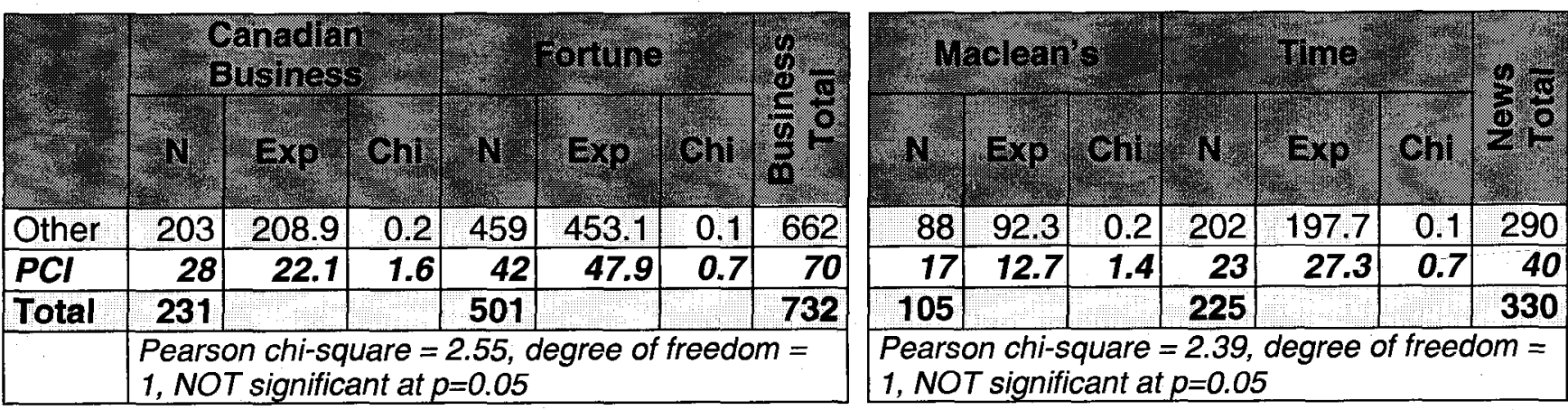

\begin{tabular}{|c|c|c|c|c|c|c|c|}
\hline 8. & 13 & F 89 & Chl & 1 & 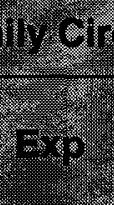 & Sht & $\frac{0}{8} \frac{1}{8}$ \\
\hline Other & 548 & 550.0 & 0.0 & 389 & 387.0 & 0.0 & 937 \\
\hline $\mathrm{PCl}$ & 29 & 27.0 & 0.1 & 17 & 19.0 & 0.2 & 46 \\
\hline Total & 571 & & & 403 & & & 974 \\
\hline & \\
\hline
\end{tabular}

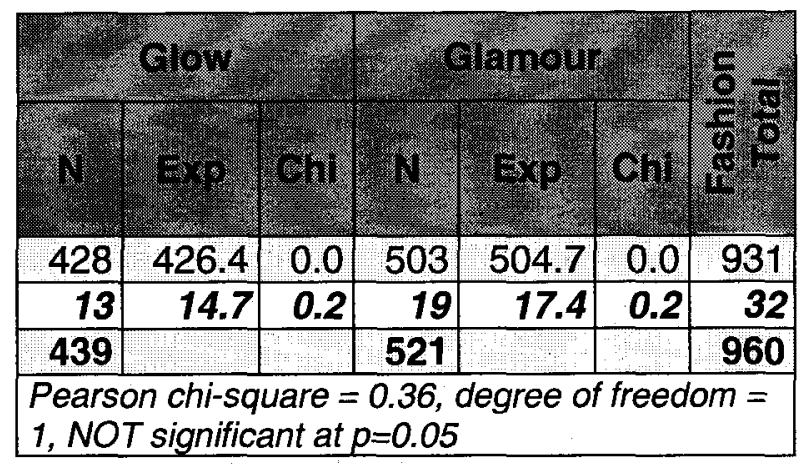


APPENDIX H: EXECUTION STYLE VERSUS APPEAL

\begin{tabular}{|c|c|c|c|c|c|c|c|c|c|c|c|c|c|c|c|c|c|c|c|c|c|c|c|c|c|c|}
\hline & re & $\frac{8}{8}$ & $\frac{9}{6}$ & & $\frac{\frac{9}{5}}{\frac{3}{8}}$ & $\frac{8}{8}$ & 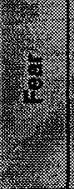 & $\frac{9}{2}$ & $\sqrt{9}$ & $\frac{9}{9}$ & 8 & 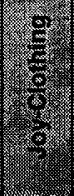 & $\frac{8}{9}$ & $\frac{5}{8}$ & & & 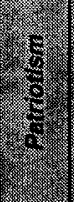 & $\frac{5}{8}$ & $\frac{\frac{3}{4}}{3}$ & & $\frac{13}{3}$ & & $\frac{8}{8}$ & $\frac{7}{80}$ & & $\frac{10}{8}$ \\
\hline Celebrity-Endorse & 1.5 & 0.0 & 1.0 & 0.9 & 0.0 & 1.3 & 0.0 & 1.2 & 0.3 & 6.8 & 24.9 & 2.9 & 8.7 & 13.6 & 6.0 & 0.0 & 0.0 & 3.8 & 2.6 & 0.7 & 0.0 & 12.5 & 5.4 & 0.0 & 1.8 & 5.8 \\
\hline Celebrity-General & 0.0 & 0.0 & 0.3 & 0.0 & 0.8 & 0.0 & 0.0 & 0.4 & 3.1 & 6.4 & 0.0 & 0.0 & 0.0 & 0.0 & 2.0 & 13.6 & 0.0 & 0.0 & 0.0 & 0.0 & 0.0 & 7.5 & 0.0 & 0.0 & 0.0 & 1.5 \\
\hline Celebrity-Testimonial & 1.5 & 0.0 & 0.7 & 0.0 & 0.0 & 0.0 & 0.0 & 0.0 & 0.0 & 0.8 & 1.3 & 0.0 & 0.0 & 0.0 & 0.0 & 0.0 & 0.0 & 0.0 & 0.0 & 0,0 & 0.0 & 0.0 & 0.0 & 0.0 & 0.0 & 3. \\
\hline Consumer-Fantasy/Mood & 4.6 & 0.0 & 0.0 & 0.0 & 1.6 & 0.0 & 0.0 & 0.0 & 1.7 & 0.4 & 0.5 & 0.0 & \begin{tabular}{|l|}
13.0 \\
\end{tabular} & 1.1 & 2.0 & 0.0 & 0.0 & 1.3 & 0.0 & 0.7 & 0.0 & 2.5 & 10.8 & 0.0 & 0.0 & 0 \\
\hline Consume & 0.0 & 20.0 & 3.7 & 2.8 & 5.7 & 4.0 & 0.0 & 4.5 & 0.3 & 0.8 & 49.2 & 65.7 & 4.3 & 9,1 & 12.6 & 2.3 & 0.0 & \begin{tabular}{|l|}
7.5 .5 \\
\end{tabular} & 5.1 & 2.2 & 0.0 & 38.8 & 0.0 & 2.7 & 1.8 & 11.7 \\
\hline Consumer-Storyline & 4.6 & 0.0 & 3.7 & 0.0 & 0.0 & 0.7 & 1.1 & 0.0 & 0.7 & 1.2 & 1.3 & 0.0 & 0.0 & 1.1 & 2.6 & 0.0 & 0.0 & 0.0 & 2.6 & 0.0 & 0.0 & 0.0 & 0.0 & 2.7 & 0.0 & 1.2 \\
\hline Consumer-T & 4.6 & 0.0 & 2.4 & 2.8 & 0.0 & 0.7 & 0.0 & 0.0 & 0.0 & 3.2 & 0.8 & 0.0 & 0.0 & 8.0 & 0.7 & 0.0 & 0.0 & 0.0 & 5.1 & 4.5 & 0.0 & 1.3 & 8.1 & 0.0 & 0.0 & 1.5 \\
\hline Consumer-Vignette & 7.7 & 0.0 & 3.7 & 46.7 & 5.7 & 8.7 & 17.8 & 3.3 & 11.5 & 6.0 & 0.3 & 8.6 & 13.0 & 17.0 & 16.9 & 52.3 & 4.3 & 6.3 & 23.1 & 11.2 & 5.0 & 15.0 & 8.1 & 2.7 & 10.9 & 10.2 \\
\hline Endorse-Complem & 0.0 & 0.0 & 0.0 & 0.0 & 0.0 & 0.0 & 0.0 & 0.0 & 0.0 & 0.4 & 0.0 & 0.0 & 0.0 & 0.0 & 0.3 & 0.0 & 0.0 & 0.0 & 0.0 & 0.0 & 0.0 & 0.0 & 0.0 & 0.0 & 00 & 0.1 \\
\hline Endorse-Customer & 1.5 & 0.0 & 2.0 & 0.0 & 0.8 & 9.4 & 1.1 & 0.8 & 0.3 & 4.4 & 0.0 & 0.0 & 0.0 & 1.1 & 1.0 & 0.0 & 0.0 & 0.0 & 2.6 & 1.5 & 30.0 & 0.0 & 5.4 & 10.8 & 0 & \\
\hline Endorse-Employee & 0.0 & 0.0 & 0.0 & 0.0 & 0.0 & 2.0 & 0.0 & 0.0 & 0.0 & 0.4 & 0.0 & 0.0 & 0.0 & 0.0 & 0.3 & 0.0 & 0.0 & 1.3 & 0.0 & 0.0 & 0.0 & & 0.0 & 0.0 & 0.0 & 2 \\
\hline -Expert & 0.0 & 0.0 & 0.7 & 0.0 & 0.0 & 0.7 & 0.0 & 0.4 & 0.3 & \begin{tabular}{|l|l}
0.4 \\
\end{tabular} & 0.3 & 0.0 & 0.0 & 1.1 & 0.0 & 0.0 & 0.0 & 0.0 & 0.0 & 0.0 & 0.0 & 0.0 & 0.0 & 0.0 & 0.0 & 0.3 \\
\hline$P C I$ & 6.2 & 0.0 & 2.7 & 2.8 & 1.6 & 3.4 & 4.4 & 2.9 & 5.2 & 12.0 & 0.8 & 0.0 & 8.7 & 0.0 & 13.9 & 6.8 & 91.3 & 15.0 & 7.7 & 8.2 & 10.0 & 6.3 & 2.7 & 0.0 & 5.5 & 6.3 \\
\hline Product-As & 10.8 & 0.0 & 13.3 & 5.6 & 12.3 & 10.1 & 8.9 & 8.3 & 13.9 & 4.0 & 2.1 & 0.0 & 4.3 & 10.2 & 10.3 & 0.0 & 0.0 & 18.8 & 7.7 & 6.7 & 7.5 & 3.8 & 27.0 & 5.4 & 10.9 & 0 \\
\hline Product-Comparative & 0.0 & 0.0 & 2.7 & 1.9 & 2.5 & 1.3 & 2.2 & 2.1 & 0.3 & 0.8 & 0.5 & 0.0 & 0.0 & 2.3 & 0.7 & 0.0 & 0.0 & 0.0 & 0.0 & 9.7 & 5.0 & 0.0 & 0.0 & 0.0 & 0.0 & 5. \\
\hline Product-Demo & 4.6 & 80.0 & 11.9 & 7.5 & 19.7 & 4.7 & 8.9 & 24.4 & \begin{tabular}{|l|l|}
15.6 \\
\end{tabular} & 4.4 & 6.3 & 2.9 & 13.0 & 4.5 & 10.9 & $\$ 1.4$ & 0.0 & 2.5 & 2.6 & 9.0 & 2.5 & 3.8 & 5.4 & 8.1 & 10.9 & 10.1 \\
\hline natization & 3.1 & 0.0 & 3.1 & 0.0 & 6.6 & 1.3 & 4.4 & 0.8 & 5.6 & 0.8 & 0.0 & 0.0 & 0.0 & 0.0 & 4.0 & 0.0 & 0.0 & 2.5 & 5.1 & 2.2 & 0.0 & 0.0 & 0.0 & 0.0 & 0.0 & 2.1 \\
\hline Product-Hero & 0.0 & 0.0 & 3.1 & 0.9 & 0.8 & 0.7 & 1.1 & 2.5 & 1.0 & 0.0 & 1.1 & 0.0 & 0.0 & 0.0 & 0.0 & 0.0 & 0.0 & 1.3 & 0.0 & 0.0 & 0.0 & 0.0 & 5.4 & 0.0 & 0.0 & 1.0 \\
\hline Product-lllustration & 7.7 & 0.0 & 9.2 & 5.6 & 19.7 & 10.7 & 6.7 & 20.2 & 18.8 & 6.0 & 2.4 & 11.4 & 17.4 & 5.7 & 8.6 & 2.3 & 0.0 & 25.0 & 7.7 & 15.7 & 7.5 & 5.0 & 27 & 10.8 & 34.5 & 10.8 \\
\hline Product-Prob/Sol & 0.0 & 0.0 & 15.3 & 4.7 & 6.6 & 6.0 & 22.2 & 5.8 & 8.0 & 4.4 & 1.6 & 5.7 & \begin{tabular}{|l|l}
0.0 \\
\end{tabular} & 6.8 & 3.0 & 4.5 & 0.0 & 0.0 & 7.7 & 7.5 & 7.5 & 2.5 & 0.0 & 10.8 & 9.1 & 6.2 \\
\hline Produ & 4.6 & 0.0 & 4.4 & 3.7 & 0.0 & 0.7 & 4.4 & 4.1 & 0.7 & 8.0 & 1.3 & 0.0 & 0.0 & 6.8 & 0.3 & 0.0 & 0. & 0.0 & 2.6 & 3.7 & 2.5 & 0.0 & 0.0 & 37.8 & 1.8 & 3.0 \\
\hline Product-Torture & 0.0 & 0.0 & 1.7 & 0.0 & 0.0 & 0.0 & 0.0 & 2.1 & 0.7 & 0.0 & 0.8 & 0.0 & 0.0 & 0.0 & 0.7 & 0.0 & 0.0 & 0.0 & 0.0 & 2.2 & 0.0 & 0.0 & 0.0 & 0.0 & 0.0 & 0.7 \\
\hline Special Effects & 1.5 & 0.0 & 0.3 & 0.0 & 0.0 & 0.0 & 0.0 & 0.4 & 0.0 & 0.0 & 1.1 & 0.0 & \begin{tabular}{|l|}
17.4 \\
\end{tabular} & 0.0 & 0.0 & 0.0 & 0.0 & 0.0 & 0.0 & 0.7 & 0.0 & 0.0 & 0.0 & 0.0 & 0.0 & 0.4 \\
\hline Spokesper & 1.5 & 0.0 & 0.7 & 0.9 & 0.0 & 0.0 & 0.0 & 0.4 & 0.7 & 0.4 & 0.8 & 0.0 & 0.0 & 0.0 & & 0.0 & 0.0 & 0.0 & 10.3 & 0.0 & 2.5 & 0.0 & 5.4 & 2.7 & 0.0 & 0.6 \\
\hline Spokesperson-Fictit & 0.0 & 0.0 & 0.0 & 4.7 & 0.0 & 0.7 & 2.2 & 0.4 & 0.3 & 0.0 & 0.0 & 0.0 & 0.0 & 1.1 & 0.0 & 0.0 & 0.0 & 0.0 & 0.0 & 0.0 & 0.0 & 0.0 & 0.0 & 0.0 & 0.0 & 0.4 \\
\hline Straight-News/Into & 3.1 & 0.0 & 1.7 & 1.9 & 7.4 & 0.7 & 0.0 & 7.0 & 1.4 & 5.6 & 1.3 & 2.9 & 0.0 & 2.3 & 1.3 & 0.0 & 0.0 & 1.3 & 0.0 & 2.2 & 0.0 & 0.0 & 0.0 & 0.0 & 9.1 & 2.5 \\
\hline Straight-Sell & 30.8 & 0.0 & 11.6 & 6.5 & 8.2 & 32.2 & 14.4 & 7.9 & 9.4 & 22.7 & 1.3 & 0.0 & 0.0 & 8.0 & 2.0 & 6.8 & 4.3 & 3.8 & 7.7 & 11.2 & 20.0 & 1.3 & 13.5 & 5.4 & 3.6 & 9.8 \\
\hline Total & 1 & 100 & 100 & 10 & 100 & 10 & 100 & 100 & 100 & 100. & 10 & 100 & 100 & 100 & 100 & 100 & 10 & 100 & 100 & 100 & 100 & 100 & 100 & 100 & 100 & 100 \\
\hline
\end{tabular}




\section{APPENDIX I: NORMALIZED PCI INTENSITY BY PRODUCT CLASS}

\begin{tabular}{|c|c|c|c|c|c|c|c|c|c|c|c|c|c|c|c|c|c|c|c|c|c|c|c|}
\hline Sy productclass & $\frac{10}{10}$ & 18 & $\frac{2}{2}$ & $\frac{c}{3}$ & $\frac{\operatorname{sene}}{154}$ & & & & & 80. & 00 & 0 & & 67 & & & $\frac{S A}{92}$ & & $\frac{9}{6}$ & $\frac{19}{12}$ & 8 & & $\frac{5}{210}$ \\
\hline Apparel \& Accessories & 8 & 6 & & & & & & & & & & 30 & 34 & 2 & & & & & & & & & \\
\hline Appliances \& Furniture & 1 & 18 & 6 & & & & & & & & & 2 & 7 & & & & & & & & & & \\
\hline Business Service & 2 & 15 & 15 & & 1 & & & & & & & 15 & 55 & 20 & & 4 & 3 & 1 & & 1 & & & \\
\hline Cars \& Related & 8 & 48 & 4 & & & & & & & & & 15 & 70 & 11 & & & & & & & & & \\
\hline Computer Hard/Software & & 28 & 13 & 1 & 1 & & & & & & & 6 & 73 & 23 & & 4 & & & & & & & \\
\hline Consumer Electronics & & 14 & 6 & 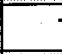 & 1 & & & & & & & 5 & 12 & + & & & & & & & & & \\
\hline Corporate & 1 & 7 & 2 & & & & & & & & & 8 & 26 & 1 & & 1 & 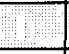 & & & & & & \\
\hline Cosmetics & 21 & 183 & 7 & & & & & & & & & 20 & 118 & 10 & & 2 & 1 & & & & & & \\
\hline Education \& Training & 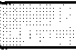 & 14 & 2 & 2 & 2 & 1 & & 1 & & & & & 6 & & & 2 & 3 & 1 & & & & & \\
\hline Entertainment & & 24 & 4 & 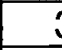 & 3 & 1 & & & 1 & & & 10 & 20 & 3 & & & 3 & & & & & & \\
\hline Financial Service & & 27 & 11 & $s$ & 1 & 2 & 1 & & & & & 7 & 99 & 2 & & 2 & 1 & & & & & & \\
\hline Food & 29 & 98 & 10 & 2 & 1 & & & & & & & 34 & 105 & $t$ & & & 1 & & & & & & \\
\hline Household Cleaners & 8 & 30 & & & & & & & & & & 6 & 20 & & & & $\square$ & & & & & & \\
\hline Home Décor \& Improve & 13 & 11 & & & & & & & & & & 6 & 22 & 3 & & 2 & & & 1 & & & & \\
\hline Issues, Charities, NGO's & 8 & 24 & 10 & 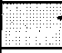 & 1 & 1 & 1 & & 1 & & & 1 & 37 & 2 & & 1 & & & & & & & \\
\hline Liquor \& Tobacco & & 6 & & & & & & & & & & 3 & 31 & 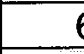 & & 2 & & & & & & & \\
\hline Media & & 22 & 7 & & & & & & & & & 1 & 20 & - & & & 1 & & & & & & \\
\hline Medicines/Medical & 14 & 31 & & & & & & & & & & 55 & 77 & 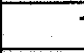 & & & & & & & & & \\
\hline Other Products \& Service & 2 & 23 & & & & & & & & & & 3 & 29 & 3 & & & & & & & & & \\
\hline Personal Health \& Care & 23 & 154 & 10 & 2 & 2 & & & & & & & 16 & 76 & 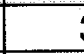 & & & & 1 & & & & & \\
\hline Retail & 8 & 36 & 14 & & & & 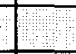 & & & & & 2 & 34 & 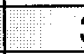 & & 2 & & & & & & & \\
\hline Telecomm & 1 & 17 & 17 & 2 & 7 & & & & & & & 5 & 48 & 1 & & 2 & 1 & & & 1 & & & \\
\hline Toiletries & 11 & 128 & 6 & 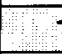 & 1 & 1 & & & & & & 35 & 67 & & & 1 & 1 & & & & & & \\
\hline Travel & 1 & 9 & 18 & 2 & 1 & 3 & 1 & & 1 & & 2 & 4 & 37 & 1 & & 1 & & 2 & & 1 & & & \\
\hline Watches \& Jewellery & & 5 & & & & & & & & & 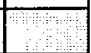 & 4 & 26 & & & 3 & & & & - & & & \\
\hline Total & 159 & 978 & 162 & 3 & $\overline{4}$ & 9 & 3 & 1 & 3 & 0 & 2 & 293 & 1149 & 16 & 20 & 29 & 12 & 5 & 1 & 3 & 0 & 0 & $\mathbf{0}$ \\
\hline
\end{tabular}




\section{APPENDIX J: NORMALIZED PCI INTENSITY BY EXECUTION STYLE}

\begin{tabular}{|c|c|c|c|c|c|c|c|c|c|c|c|c|c|c|c|c|c|c|c|c|c|c|}
\hline 1. & 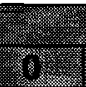 & & $\frac{1.28}{2+2}$ & & & b & 3 & & & 9 & 10 & & $\frac{112}{4}$ & 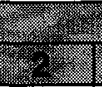 & & 12 & & $\frac{20}{3+12}$ & & & $\sqrt{12}$ & $\frac{28}{12}$ \\
\hline Celebrity-Endorse & 4 & 76 & 2 & & & & & & & & & 7 & 77 & 6 & 1 & & & & & & & \\
\hline Celebrity-General & 4 & 19 & 1 & & & & & & & & & 7 & 15 & & & & & & & & & \\
\hline Celebrity-Testimonial & & 4 & 4 & & & & & & ? & & & & 6 & & & & & & & & & \\
\hline Consumer-Fantasy/Mood & 3 & 8 & 1 & & & & & & & & & 6 & 12 & 1 & & & & & & & & \\
\hline Consumer-Image & 30 & 166 & 5 & 1 & & & & & & & & 40 & 105 & 3 & 1 & & & & & & & \\
\hline Consumer-Storyline & & 14 & 1 & & & 1 & & & & & & 5 & 13 & 3 & & & & & & & & \\
\hline Consumer-Testimonial & & 15 & 7 & & & & & & & is: & & 8 & 11 & 5 & & & & & & & & \\
\hline Consumer-Vignette & 28 & 76 & 8 & 1 & & & & & & & 1 & 25 & 153 & 12 & 2 & 2 & & & & & & \\
\hline Endorse-Complementary & & & $\rightarrow$ & $=$ & 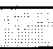 & & & & & & & : & 1 & 1 & 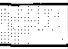 & & & & & & & \\
\hline Endorse-Customer & & 10 & 6 & & & & & & & & & & 32 & 12 & 1 & & 1 & & & & & \\
\hline Endorse-Employee & & 1 & & 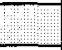 & & & & & $\because$ & . & & 1 & 3 & 1 & & & & & & 4 & & \\
\hline Endorse-Expert & & 1 & & & & & & & & & & 1 & 4 & 1 & 1 & & & & & & & \\
\hline $\mathrm{PCI}$ & ? & 27 & 33 & 12 & 3 & 6 & 3 & & 2 & & 1 & 1 & 57 & 25 & 8 & 5 & 3 & 1 & 1 & & & \\
\hline Product-Association & 11 & 102 & 14 & & & 1 & & & 1 & & & 25 & 96 & 8 & 2 & & & & & & & \\
\hline Product-Comparative & 7 & 8 & 1 & & & & & & 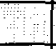 & & 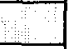 & 9 & 14 & 7 & 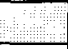 & & & & & & & \\
\hline Product-Demonstration & 12 & 90 & 26 & 2 & & & & & & & & 31 & 126 & 16 & & 1 & & & & & & \\
\hline Product-Dramatization, & 3 & 9 & 5 & & & & & & 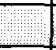 & 7 & & 13 & 31 & 3 & & & & & & 0 & & \\
\hline Product-Hero & & 17 & & & & & & & & & & 4 & 7 & 1 & & & & & & & & \\
\hline Product-Illustration & 25 & 122 & 11 & & & & & & & 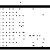 & & 31 & 120 & 13 & 3 & 1 & & & & & & \\
\hline Product-Problem/Solution & 7 & 52 & 4 & 1 & 1 & & & & & & & 36 & 81 & 5 & & & & & & & & \\
\hline Product-Technology & 5 & 47 & 5 & & & & & & $\infty$ & & & 2 & 27 & 4 & 1 & & & & & 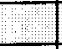 & 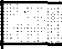 & \\
\hline Product-Torture & & 10 & 1 & & & & & & & & & & 9 & & & & & & & & & \\
\hline Special Effects & 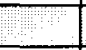 & 4 & 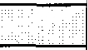 & 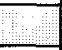 & & & & & 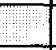 & . & 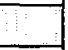 & 2 & 5 & 1 & & & & & 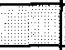 & & & \\
\hline Spokesperson-Employee & 2 & 7 & 2 & & & & & & & & & 3 & 3 & 1 & 1 & & & & & & & \\
\hline Spokesperson-Fictitious & 2 & 4 & & 1 & & & & & & 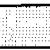 & & 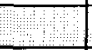 & 4 & 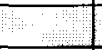 & 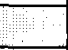 & 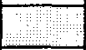 & & 1 & & & & \\
\hline Straight-News/Info & 7. & 27 & 1 & 1 & & & & & & & & 9 & 24 & 3 & 2 & 1 & & & & & & \\
\hline Straight-Sell & 9 & 62 & 28 & 14 & & 1 & 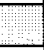 & 1 & & 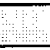 & 0 & 27 & 113 & 30 & 6 & 2 & 1 & 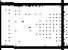 & 2 & & & 3 \\
\hline Total & 159 & 978 & 162 & 33 & 4 & 9 & 3 & 1 & 3 & 0 & 2 & 293 & 1149 & 162 & 29 & 12 & 5 & 1 & 3 & 0 & 0 & 0 \\
\hline
\end{tabular}




\section{APPENDIX K: NORMALIZED PCI INTENSITY BY APPEAL}

\begin{tabular}{|c|c|c|c|c|c|c|c|c|c|c|c|}
\hline 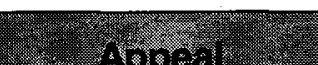 & & & & & & & & & & & \\
\hline 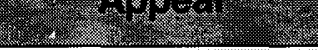 & 0. & 18 & 21 & 3. & 4 & 5 & 6. & 2 & 88 & 8 & 20 \\
\hline Altruism & 2 & 20 & 4 & 1 & & 1 & & & 1 & & \\
\hline Availability & & 1 & & & & & & & & & \\
\hline Benefit & 13 & 117 & 17 & 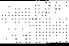 & 1 & 1 & & & & & \\
\hline Caring & 9 & 45 & 4 & & & & & & & & \\
\hline Convenience & 5 & 43 & 11 & 3 & & 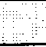 & & & & & \\
\hline Econ/Price/Value & 5 & 29 & 15 & 4 & & 3 & & & & & 2 \\
\hline Fear & 8 & 20 & 2 & 2 & & F" & & & & & \\
\hline Feature & 16 & 95 & 17 & 1 & 1 & & & & & & \\
\hline Humour & 11 & 82 & 14 & 2 & & & & te & & & \\
\hline Information & 5 & 53 & 25 & 4 & 1 & 2 & 2 & 1 & 1 & & \\
\hline Joy-Body & 15 & 207 & 8 & 1 & & 1 & & & & & \\
\hline Joy-Clothing & & 3 & & & & & & & & & \\
\hline Joy-Food & & 7 & 3 & & & & & & & & \\
\hline Joy-Health & 3 & 28 & 1 & & & & & & & & \\
\hline Lifestyle & 30 & 80 & 22 & 9 & 1 & 1 & 1 & & 1 & & \\
\hline Love & 3 & 14 & & & & & & & & & \\
\hline Patriotism & & 1 & 4 & & & 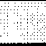 & & & & & \\
\hline Prestige & 3 & 13 & 1 & & & & & & & & \\
\hline Pride & 2 & 13 & 2 & & & & & & & & \\
\hline Quality & 6 & 37 & 4 & & & & & & & & \\
\hline Reliability & 3 & 7 & 3 & 3 & & & & & & & \\
\hline Sex & 13 & 24 & & & & & & & & & \\
\hline Success & & 13 & 3 & 1 & & & & & & & \\
\hline Tech Expertise & 1 & 10 & 1 & & & & & & & & \\
\hline Variety & 6 & 16 & 1 & 2 & & 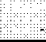 & & 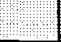 & & & \\
\hline Total & 159 & 978 & 162 & 33 & 4 & 9 & 3 & 1 & 3 & 0 & 2 \\
\hline
\end{tabular}

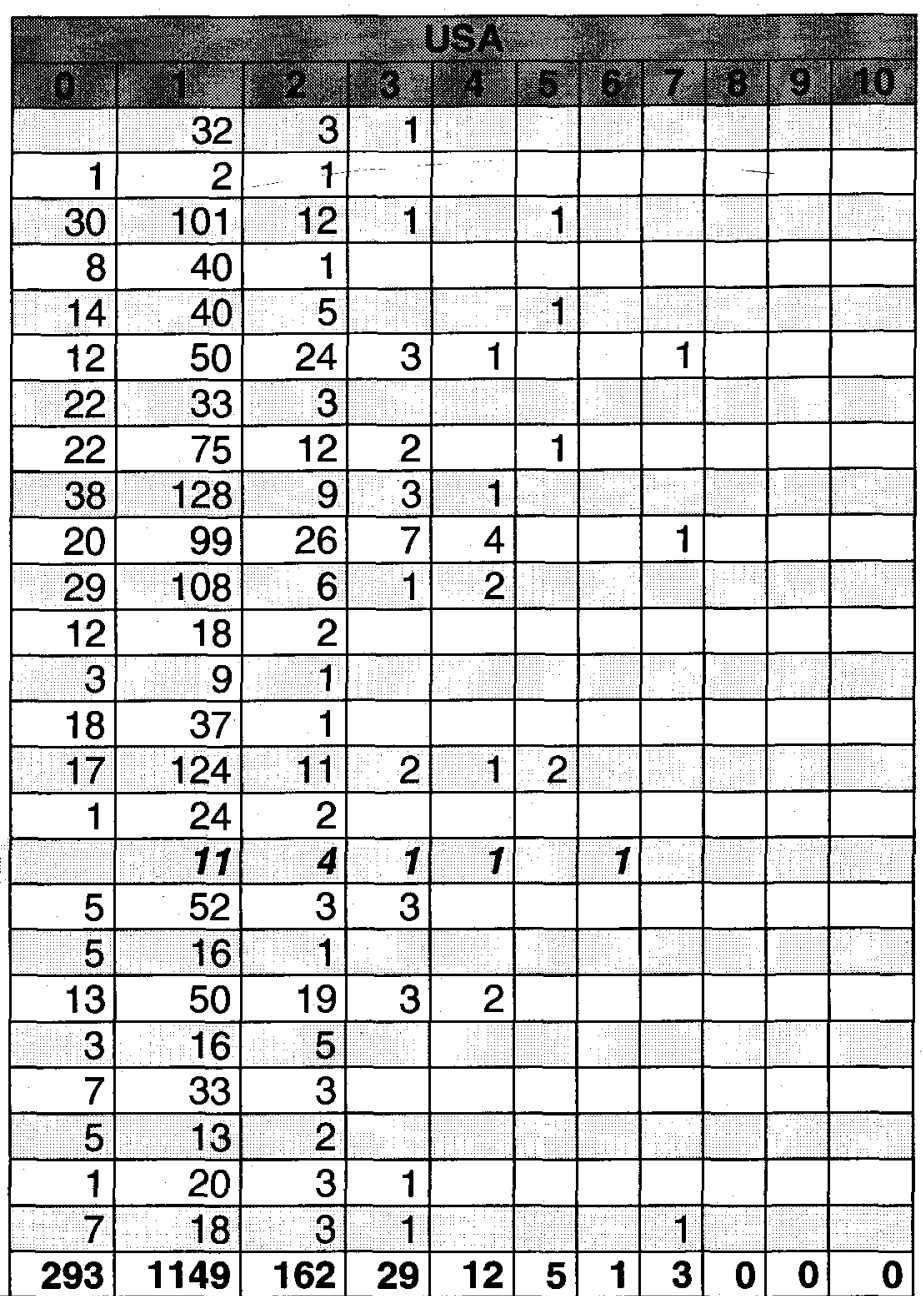


APPENDIX L: NORMALIZED PCI INTENSITY BY ADVERTISER'S HOME COUNTRY

\begin{tabular}{|c|c|c|c|c|c|c|c|c|c|c|c|}
\hline Belgium & & & & 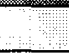 & & & & & 3 & 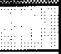 & \\
\hline Bermuda & & 2 & & & & & & & & & \\
\hline Canada & 38 & 184 & 73 & 24 & 1 & 5 & 2 & 1 & 1 & & \\
\hline Switzerland & 1 & 40 & 9 & 3 & & & & & & & \\
\hline Dubai & & & & & & & & & & & \\
\hline Germany & 14 & 28 & 5 & 1 & & & & & & & \\
\hline Demark & & & & & & & & & & & \\
\hline Spain & & & & & & & & & & & \\
\hline France & 7 & 99 & 8 & & & & 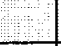 & & & & \\
\hline United Kingdom & 21 & 23 & 4 & & & & & & & & \\
\hline Israel & & & & & & & & & & & 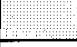 \\
\hline Ireland & & & & & & & & & & & \\
\hline Italy & & 1 & & & & & & & & & \\
\hline Japan & 9 & 46 & 13 & 2 & & & & & & & \\
\hline Mexico & + & & 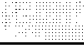 & 1 & & & & 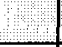 & & & \\
\hline Netherlands & & & & & & & & & & & \\
\hline Australia & & 1 & & & - & & & & - & & \\
\hline China & & & 1 & & 1 & 1 & & & & & \\
\hline South Africa & & & + & & & 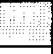 & & & 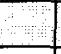 & & \\
\hline Singapore & & & & & & & & & 1 & & \\
\hline Finland & & 7 & & & & & & & - & & \\
\hline South Korea & & & & & & & & & & & \\
\hline Sweden & & 3 & 1 & 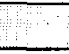 & 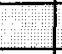 & & & & 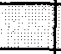 & & 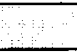 \\
\hline Thailand & & & & & & & & & & & \\
\hline USA & 69 & 544 & 48 & 2 & 2 & 3 & 1 & 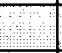 & 1 & & 2 \\
\hline Total & 159 & 978 & 162 & 33 & 4 & 9 & 3 & 1 & 3 & 0 & 2 \\
\hline
\end{tabular}

\begin{tabular}{|c|c|c|c|c|c|c|c|c|c|c|}
\hline \multicolumn{11}{|c|}{ 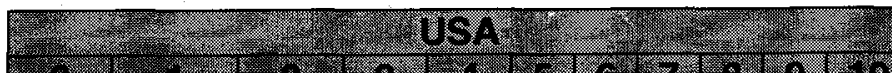 } \\
\hline 10 & 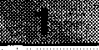 & 22 & 3 & 4 & 85 & 6 & 28 & 8 & 9 & $=10$ \\
\hline & & 1 & & & & & & & & \\
\hline & 1 & & & & & & & & & \\
\hline 9 & 4 & 3 & & & 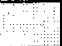 & & & & & \\
\hline 2 & 23 & 2 & 2 & 1 & & & & & & \\
\hline & & 1 & 9 & 18 & & & & & & \\
\hline 4 & 40 & $g$ & & & & & & & & \\
\hline & 2 & $\theta_{1}$ & 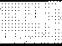 & 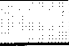 & 1 & & & & & \\
\hline 1 & & & & & & & & & & \\
\hline 13 & 71 & 6 & 3 & & & & 1 & & 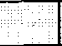 & \\
\hline 44 & 28 & 3 & & & & & & & & \\
\hline & 1 & 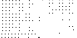 & & & & & H & & & \\
\hline & 1 & & & & & & & & & \\
\hline & 9 & 1 & 1 & & & & & & & \\
\hline 10 & 82 & 15 & 2 & & & & & & & \\
\hline & & & & & . & & & & 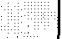 & \\
\hline 1 & 10 & 1 & & & & & & & & \\
\hline & & & & & & & & & 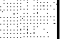 & 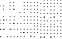 \\
\hline & 1 & & & & & & & & & \\
\hline & 3 & & & & & & & & 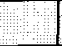 & \\
\hline & & 2 & 1 & 1 & 1 & & & & & \\
\hline 4 & 13 & 1 & & & & & & & & \\
\hline & 2 & & & & & & & & & \\
\hline & 1 & 4 & & & & & & & & \\
\hline & 2 & & & & & & & & & \\
\hline 205 & 855 & 113 & 20 & 10 & 4 & 1 & 2 & & & \\
\hline 293 & 1149 & 162 & 29 & 12 & 5 & 1 & 3 & 0 & 0 & 0 \\
\hline
\end{tabular}




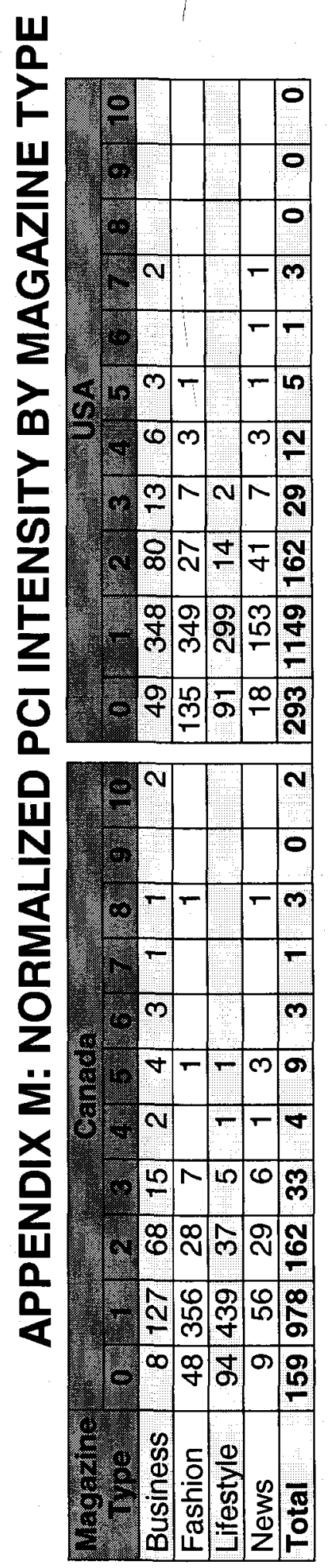




\section{APPENDIX F: L'ORÉAL PARIS ADVERTISEMENT}

\section{Canadian Living (Canada)}
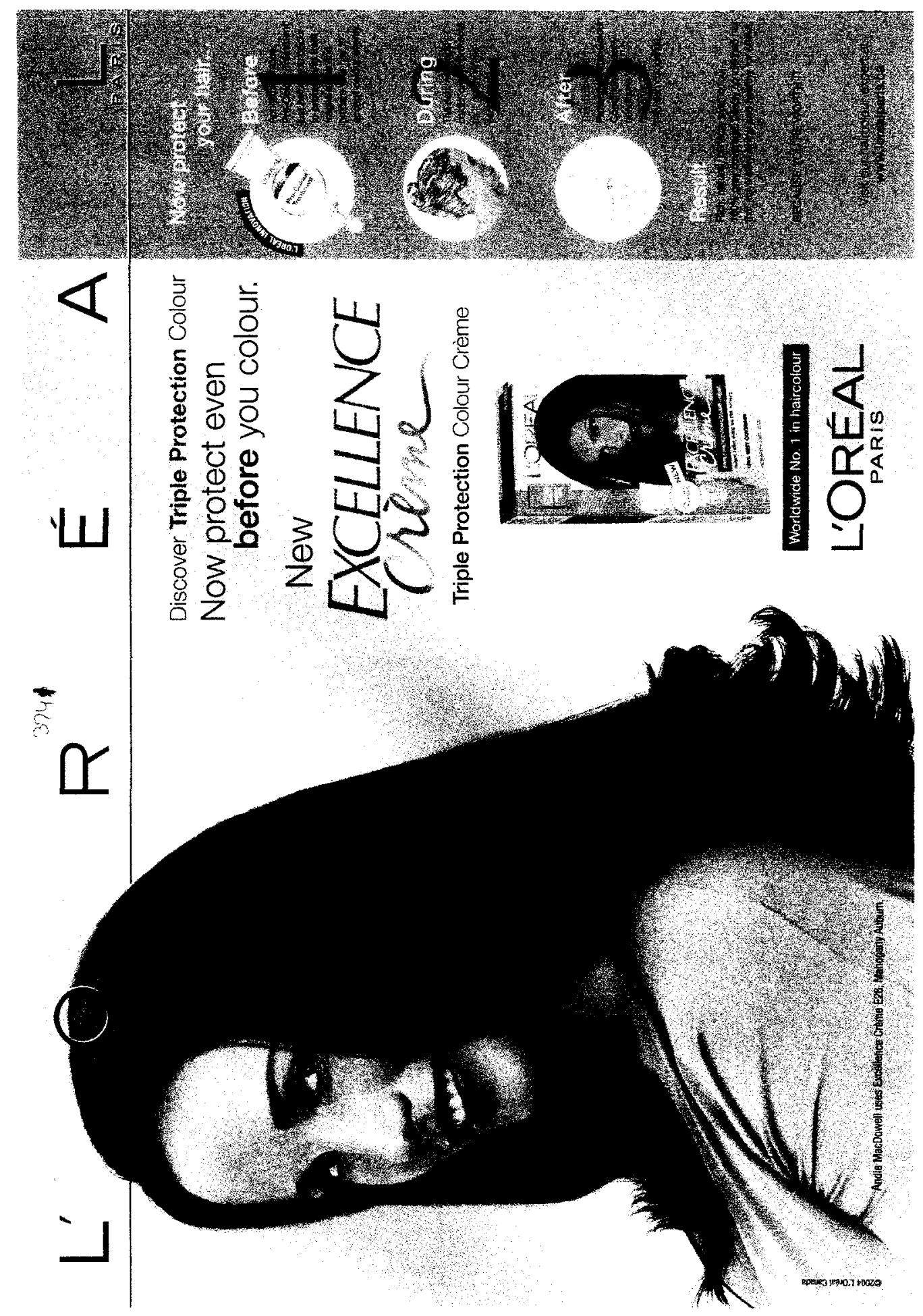
Family Circle (USA)

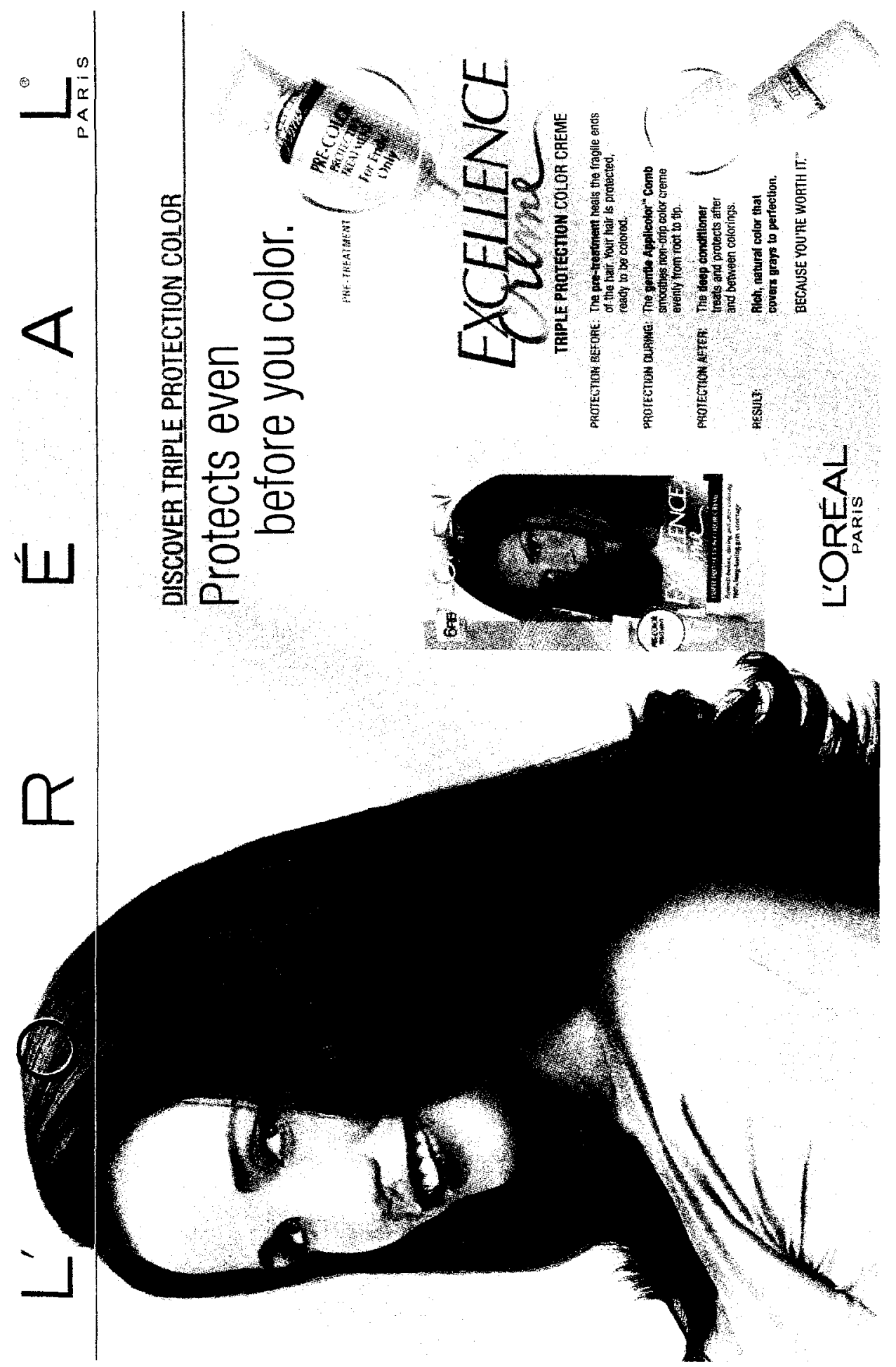




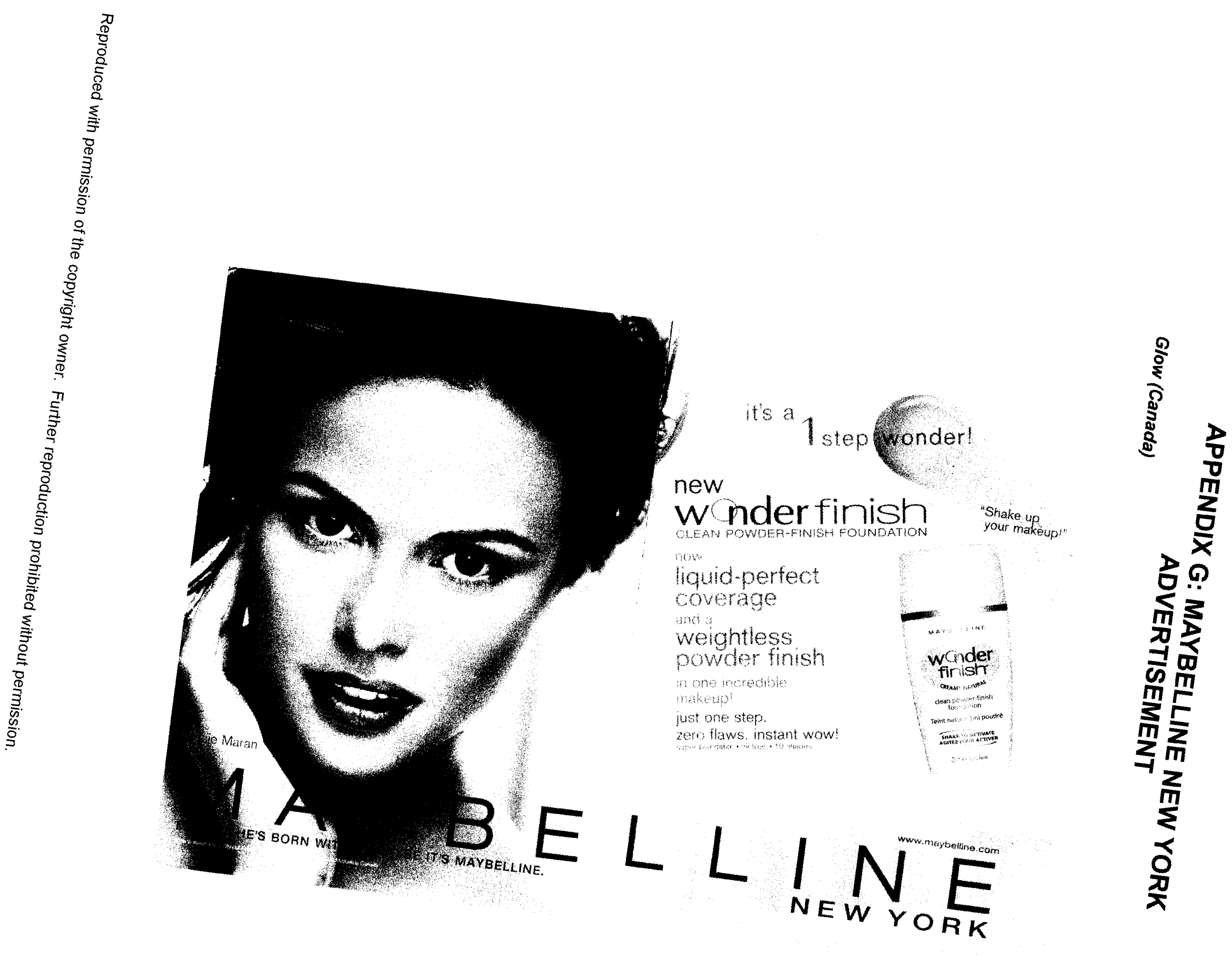


Glamour (USA)

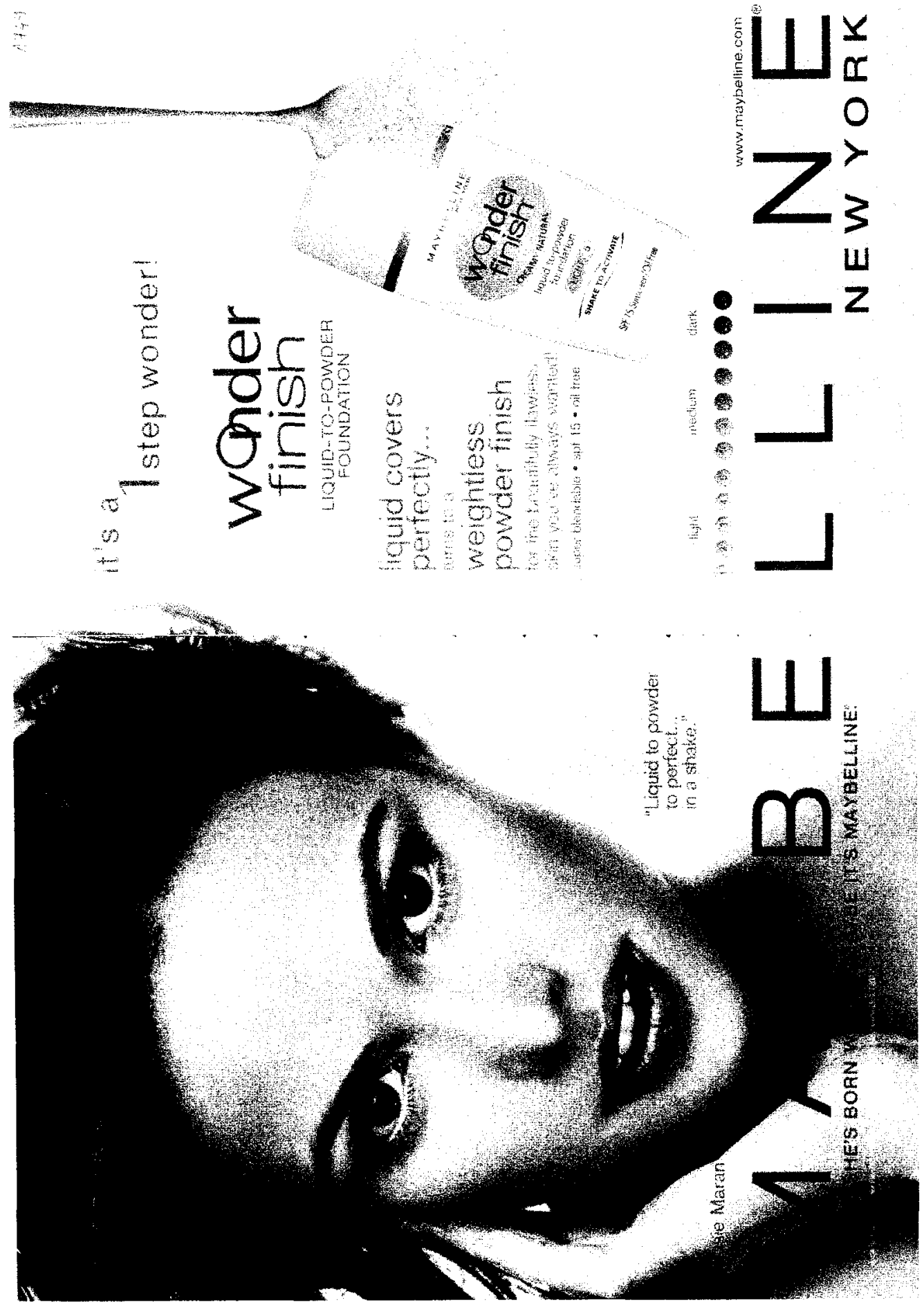

